Nevada

Environmental

Restoration

Project

Closure Report for Corrective

Action Unit 544: Cellars, Mud Pits,

and Oil Spills

Nevada National Security Site,

Nevada

Controlled Copy No.:

Revision No.: 0

May 2011

Approved for public release; further dissemination unlimited.

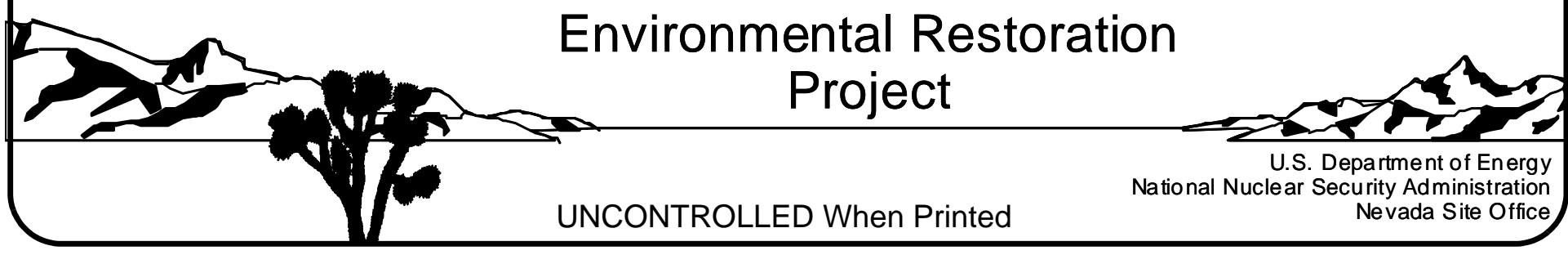


Available for sale to the public from:

U.S. Department of Commerce

National Technical Information Service

5301 Shawnee Road

Alexandria, VA 22312

Telephone: 800.553.6847

Fax: 703.605.6900

E-mail: orders@ntis.gov

Online Ordering: $\underline{h t t p: / / w w w . n t i s . g o v / h e l p / o r d e r m e t h o d s . a s p x ~}$

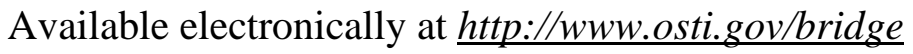

Available for a processing fee to U.S. Department of Energy and its contractors, in paper, from:

U.S. Department of Energy

Office of Scientific and Technical Information

P.O. Box 62

Oak Ridge, TN 37831-0062

Phone: 865.576.8401

Fax: 865.576.5728

Email: reports@adonis.osti.gov

Reference herein to any specific commercial product, process, or service by trade name, trademark, manufacturer, or otherwise, does not necessarily constitute or imply its endorsement, recommendation, or favoring by the United States Government or any agency thereof or its contractors or subcontractors. 


\title{
CLOSURE REPORT FOR CORRECTIVE ACTION UNIT 544: CELLARS, MUD PITS, AND OIL SPILLS NEVADA NATIONAL SECURITY SITE, NEVADA
}

\author{
U.S. Department of Energy \\ National Nuclear Security Administration \\ Nevada Site Office \\ Las Vegas, Nevada
}

Controlled Copy No.:

Revision No.: 0

May 2011

Approved for public release; further dissemination unlimited.

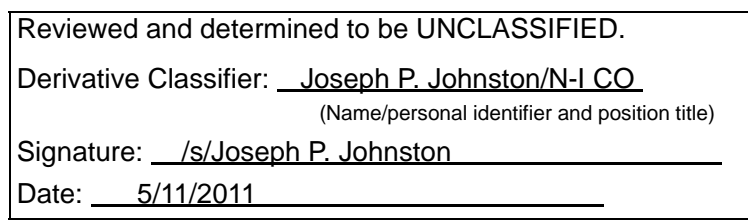




\section{CLOSURE REPORT FOR CORRECTIVE ACTION UNIT 544: CELLARS, MUD PITS, AND OIL SPILLS NEVADA NATIONAL SECURITY SITE, NEVADA}

Approved by: /s/Kevin J. Cabble

Date: 5/12/2011

Kevin J. Cabble

Federal Sub-Project Director

Industrial Sites Sub-Project

Approved by: /s/Robert F. Boehlecke

Date: $5 / 12 / 2011$

Robert F. Boehlecke

Federal Project Director

Environmental Restoration Project 


\section{Table of Contents}

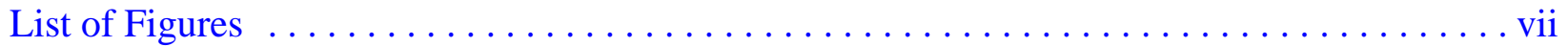

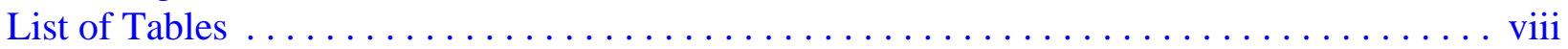

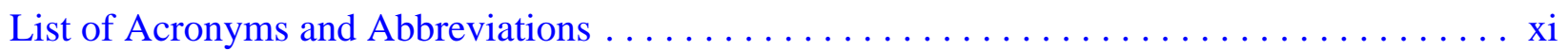

Executive Summary . . . . . . . . . . . . . . . . . . . . . . . . . ES-1

$1.0 \quad$ Introduction. . . . . . . . . . . . . . . . . . . . . . . . . . . 1

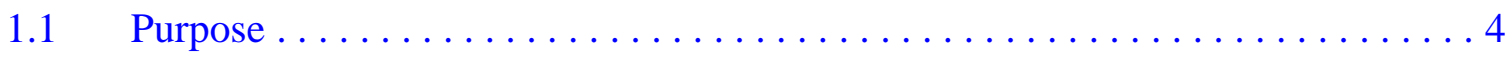

1.1.1 Mud Pit CASs Recommended for No Further Action Based

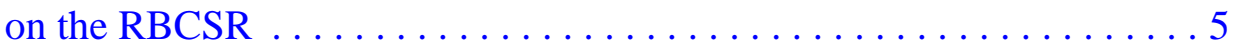

1.1.1.1 Los Alamos National Laboratory

Pretest Mud Pits .................. 6

1.1.1.2 Lawrence Livermore National Laboratory

Pretest Mud Pits . ................. 7

1.1.1.3 Lawrence Livermore National Laboratory

Post-test Mud Pits . ................ 7

1.1.2 CASs Not Meeting RBCSR Criteria . . . . . . . . . . . . . . . 7

1.1.2.1 CAS 02-37-08, Cellar \& Mud Pit . . . . . . . . . . . . 7

1.1.2.2 CAS 02-37-09, Cellar \& Mud Pit ............. 8

1.1.2.3 CAS 09-09-46, U-9itsx20 PS \#1A Mud Pit . . . . . . . . 8

1.1.2.4 CAS 19-25-01, Oil Spill . ................ 8

1.1.2.5 CAS 19-99-06, Waste Spill $\ldots \ldots \ldots \ldots \ldots \ldots \ldots \ldots$

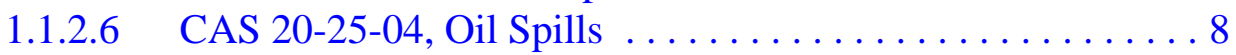

1.1.2.7 CAS 20-25-05, Oil Spills ................ 9

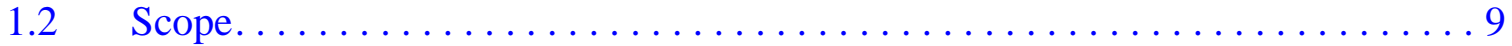

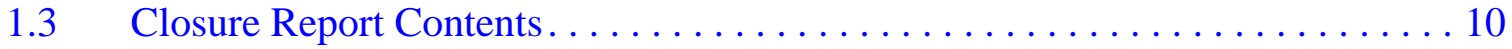

1.3.1 Applicable Programmatic Plans and Documents . . . . . . . . . . . 10

1.3.2 Data Quality Objectives . . . . . . . . . . . . . . . . 11

1.3.3 Data Quality Assessment Summary .................... 12

$2.0 \quad$ Closure Activities . . . . . . . . . . . . . . . . . 13

2.1 Description of Corrective Action Investigation Activities . . . . . . . . . . . 13

2.1.1 CAS 02-37-08, Cellar \& Mud Pit Closure Activities. . . . . . . . . . . . 15

2.1.2 CAS 02-37-09, Cellar \& Mud Pit Closure Activities. . . . . . . . . . . . 15

2.1.3 CAS 09-09-46, U-9itsx20 PS \#1A Mud Pit Closure Activities . . . . . . . 16

2.1.4 CAS 19-25-01, Oil Spill Closure Activities. . . . . . . . . . . . . . . 16

2.1.5 CAS 19-99-06, Waste Spill Closure Activities . . . . . . . . . . . . 17

2.1.6 CAS 20-25-04, Oil Spills Closure Activities . . . . . . . . . . . . . 17

2.1.7 CAS 20-25-05, Oil Spills Closure Activities . . . . . . . . . . . . . 17

2.2 Deviations from SAFER Plan as Approved $\ldots \ldots \ldots \ldots \ldots \ldots \ldots \ldots \ldots$

2.3 Corrective Action Schedule as Completed .................... 18

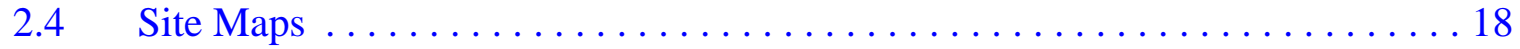




\section{Table of Contents (Continued)}

$3.0 \quad$ Waste Disposition. ....................................... 19

$3.1 \quad$ Waste Streams. . . . . . . . . . . . . . . . . . . . . . . . . . . . 19

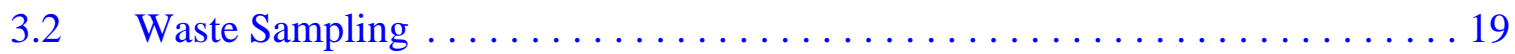

$3.3 \quad$ Waste Disposal . . . . . . . . . . . . . . . . . . . . . . . . . . . 19

$4.0 \quad$ Closure Verification Results............................... 20

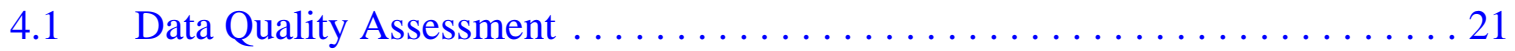

4.1.1 Review DQOs and Sampling Design.................. 22

4.1.1.1 Decision I .......................... 22

4.1.1.1.1 DQO Provisions To Limit

False Negative Decision Error ........... 22

4.1.1.1.2 DQO Provisions To Limit

False Positive Decision Error ........... 29

4.1.1.2 Sampling Design ........................ 29

4.1.2 Conduct a Preliminary Data Review .................. 30

4.1.3 Select the Test and Identify Key Assumptions............... 30

4.1.4 Verify the Assumptions .......................... 32

4.1.5 Draw Conclusions from the Data..................... 32

4.1.5.1 Decision Rules for Decision I . . . . . . . . . . . . . . 33

$4.2 \quad$ Use Restrictions . . . . . . . . . . . . . . . . . . . . . . . . . . 33

$5.0 \quad$ Conclusions and Recommendations .......................... 34

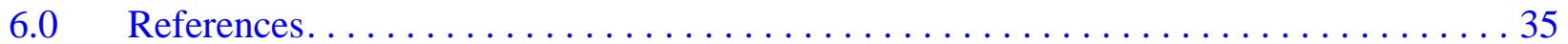

\section{Appendix A - Data Quality Objectives as Developed in the SAFER Plan}

\section{Appendix B - Confirmation Sampling Test Results}

B.1.0 Introduction. . . . . . . . . . . . . .

B.1.1 CAU 544 CASs.................................

B.1.1.1 Mud Pit CASs Recommended for No Further Action

Based on the RBCSR .........................

B.1.1.1.1 Los Alamos National Laboratory Pretest Mud Pits ...... B-4

B.1.1.1.2 Lawrence Livermore National Laboratory

Pretest Mud Pits ......................... B-4

B.1.1.1.3 Lawrence Livermore National Laboratory

Post-test Mud Pits ....................... B-4

B.1.1.2 CASs Recommended for Sampling .................. B-5

B.1.1.2.1 CAS 02-37-08, Cellar \& Mud Pit ............... B-5

B.1.1.2.2 CAS 02-37-09, Cellar \& Mud Pit .............. B-5 


\section{Table of Contents (Continued)}

B.1.1.2.3 CAS 09-09-46, U-9itsx20 PS \#1A Mud Pit . . . . . . . . . B-5

B.1.1.2.4 CAS 19-25-01, Oil Spill . .................. B-5

B.1.1.2.5 CAS 19-99-06, Waste Spill ............... B-5

B.1.1.2.6 CAS 20-25-04, Oil Spills ............... B-6

B.1.1.2.7 Corrective Action Site 20-25-05, Oil Spills . . . . . . . B-6

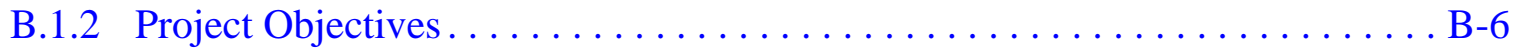

B.1.3 Contents . . . . . . . . . . . . . . . . . . . . . . .

B.2.0 Investigation Overview $\ldots \ldots \ldots \ldots \ldots \ldots \ldots \ldots \ldots \ldots \ldots \ldots \ldots \ldots$

B.2.1 Sample Locations . . . . . . . . . . . . . . . . . . . . .

B.2.2 Investigation Activities . . . . . . . . . . . . . . . . . . . .

B.2.2.1 Field Screening. . . . . . . . . . . . . . . . . . . . B-10

B.2.2.2 Surface and Subsurface Soil Sampling. . . . . . . . . . . . . B-11

B.2.2.3 Waste Characterization Sampling . . . . . . . . . . . . . . . . B-12

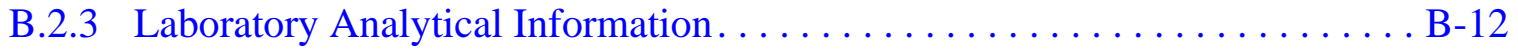

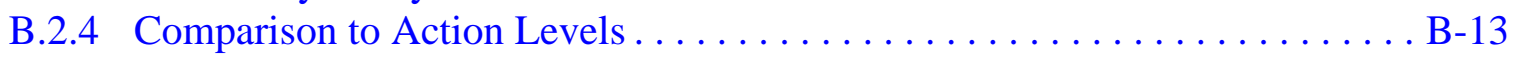

B.3.0 CAS 02-37-08, Cellar \& Mud Pit, Investigation Results . . . . . . . . . . . . . . . B-14

B.3.1 SAFER Activities . . . . . . . . . . . . . . . . . . . . . .

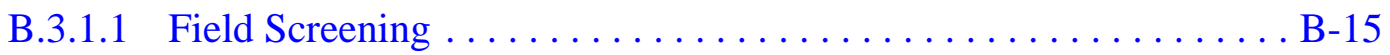

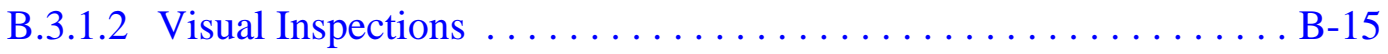

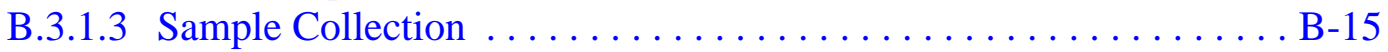

B.3.1.4 Deviations................................ . . . .

B.3.2 Investigation Results. . . . . . . . . . . . . . . . . . . . .

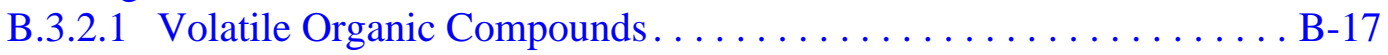

B.3.2.2 Semivolatile Organic Compounds . . . . . . . . . . . . . . . B-18

B.3.2.3 RCRA Metals . . . . . . . . . . . . . . . . . . B-18

B.3.2.4 Polychlorinated Biphenyls . . . . . . . . . . . . . . . B-19

B.3.2.5 Gamma-Emitting Radionuclides . . . . . . . . . . . . . . . B-19

B.3.2.6 Plutonium and Uranium Isotopes, and Strontium-90 . . . . . . . . B-19

B.3.3 Nature and Extent of Contamination . . . . . . . . . . . . . . B-19

B.3.4 Revised Conceptual Site Model . . . . . . . . . . . . . . . B-20

B.4.0 CAS 02-37-09, Cellar \& Mud Pit, Investigation Results . . . . . . . . . . . . . . . B-21

B.4.1 SAFER Activities . . . . . . . . . . . . . . . . . . . .

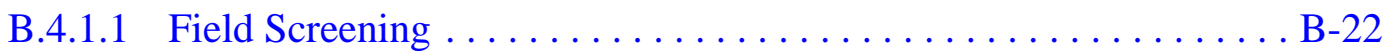

B.4.1.2 Visual Inspections . . . . . . . . . . . . . . . . . . . . B-22

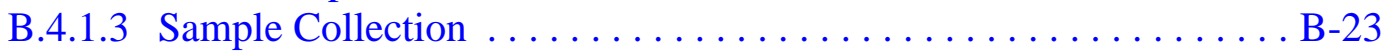

B.4.1.4 Deviations. . . . . . . . . . . . . . . . . . . . . . . . . . B-23

B.4.2 Investigation Results. . . . . . . . . . . . . . . . . . . B-23

B.4.2.1 Volatile Organic Compounds.................... B-25 


\section{Table of Contents (Continued)}

B.4.2.2 Semivolatile Organic Compounds ................... B-25

B.4.2.3 RCRA Metals . .......................... B-26

B.4.2.4 Polychlorinated Biphenyls ...................... B-26

B.4.2.5 Gamma-Emitting Radionuclides ................. B-27

B.4.2.6 Plutonium and Uranium Isotopes, and Strontium-90 . . . . . . . B-27

B.4.3 Nature and Extent of Contamination . . . . . . . . . . . . . . . . B-28

B.4.4 Revised Conceptual Site Model . . . . . . . . . . . . . . . . . . . . B-28

B.5.0 CAS 09-09-46, U-9itsx20 PS \#1A Mud Pit, Investigation Results . . . . . . . . . . B-29

B.5.1 SAFER Activities . . . . . . . . . . . . . . . . . . . . . . . . B-29

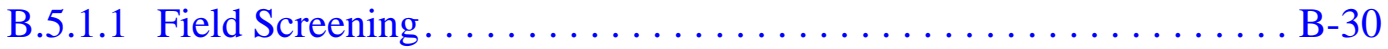

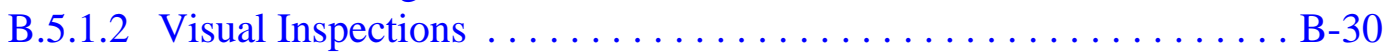

B.5.1.3 Sample Collection ......................... B-30

B.5.1.4 Deviations.............................. B-30

B.5.2 Investigation Results. . . . . . . . . . . . . . . . . . . . . .

B.5.2.1 Gamma-Emitting Radionuclides ................ B-32

B.5.2.2 Plutonium and Uranium Isotopes, and Strontium-90 . . . . . . . B-33

B.5.3 Nature and Extent of Contamination . . . . . . . . . . . . . . . . B-33

B.5.4 Revised Conceptual Site Model . . . . . . . . . . . . . . . . . . B-33

B.6.0 CAS 19-25-01, Oil Spill, Investigation Results . . . . . . . . . . . . . . B-34

B.6.1 SAFER Activities . . . . . . . . . . . . . . . . . . . . . . . .

B.6.1.1 Field Screening. ............................

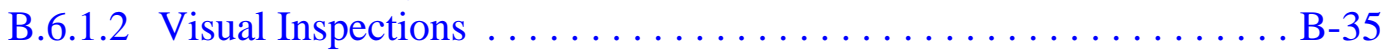

B.6.1.3 Sample Collection $\ldots \ldots \ldots \ldots \ldots \ldots \ldots \ldots \ldots \ldots \ldots \ldots \ldots \ldots \ldots$

B.6.1.4 Deviations.............................. B-36

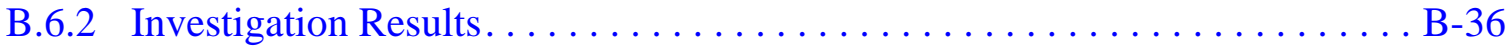

B.6.2.1 Volatile Organic Compounds.................... B-38

B.6.2.2 Semivolatile Organic Compounds .................. B-38

B.6.2.3 RCRA Metals and Hexavalent Chromium.................. B-39

B.6.2.4 Polychlorinated Biphenyls ...................... B-40

B.6.2.5 Gamma-Emitting Radionuclides ................. B-40

B.6.3 Nature and Extent of Contamination $\ldots \ldots \ldots \ldots \ldots \ldots \ldots \ldots \ldots \ldots \ldots \ldots$

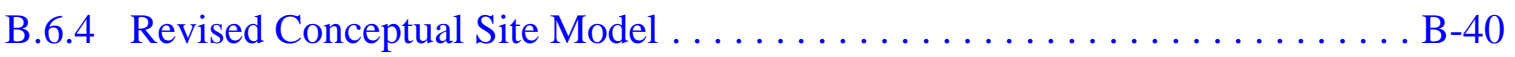

B.7.0 CAS 19-99-06, Waste Spill, Investigation Results. . . . . . . . . . . . . . . B-41

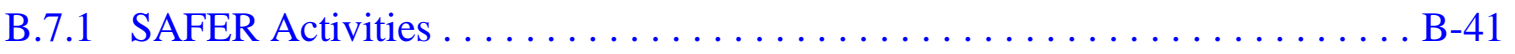

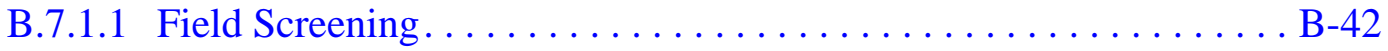

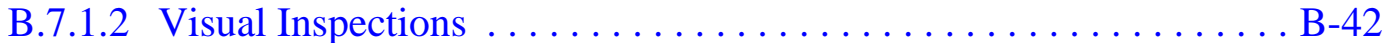

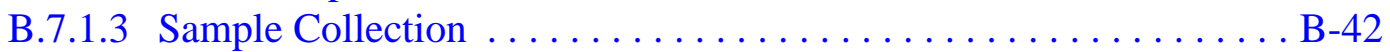

B.7.1.4 Deviations............................. B-44 


\section{Table of Contents (Continued)}

B.7.2 Investigation Results. ............................. B-44

B.7.2.1 Volatile Organic Compounds..................... B-44

B.7.2.2 Semivolatile Organic Compounds ................. B-44

B.7.2.3 RCRA Metals and Hexavalent Chromium. . . . . . . . . . . . . . B-45

B.7.2.4 Polychlorinated Biphenyls ...................... B-45

B.7.2.5 Gamma-Emitting Radionuclides $\ldots \ldots \ldots \ldots \ldots \ldots \ldots \ldots \ldots$ B-45

B.7.3 Nature and Extent of Contamination . . . . . . . . . . . . . . . . . B-46

B.7.4 Revised Conceptual Site Model . . . . . . . . . . . . . . . . . . B-46

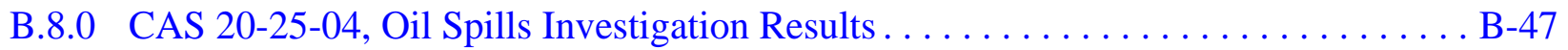

B.9.0 CAS 20-25-05, Oil Spills, Investigation Results ................. B-49

B.9.1 SAFER Activities . . . . . . . . . . . . . . . . . . . . . . . .

B.9.1.1 Field Screening............................ B-50

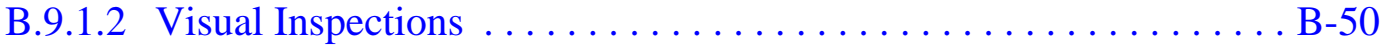

B.9.1.3 Sample Collection ......................... B-50

B.9.1.4 Deviations............................... B-50

B.9.2 Investigation Results. ............................. B-50

B.9.2.1 Volatile Organic Compounds..................... B-52

B.9.2.2 Semivolatile Organic Compounds .................. B-52

B.9.2.3 RCRA Metals and Hexavalent Chromium. . . . . . . . . . . . B-52

B.9.2.4 Polychlorinated Biphenyls . ..................... B-52

B.9.2.5 Gamma-Emitting Radionuclides ................... B-53

B.9.3 Nature and Extent of Contamination $\ldots \ldots \ldots \ldots \ldots \ldots \ldots \ldots \ldots \ldots \ldots \ldots \ldots \ldots$

B.9.4 Revised Conceptual Site Model .......................... B-54

B.10.0 LANL and LLNL Pretest and Post-test Mud Pits................... B-55

B.11.0 Waste Management.................................. B-56

B.11.1 Investigation-Derived Waste $\ldots \ldots \ldots \ldots \ldots \ldots \ldots \ldots \ldots \ldots \ldots \ldots \ldots \ldots \ldots$

B.11.2 Waste Streams. . . . . . . . . . . . . . . . . . . . . . . . . .

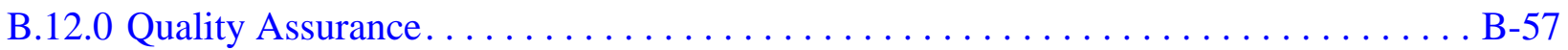

B.12.1 Data Validation............................... B-57

B.12.1.1 Tier I Evaluation. . . . . . . . . . . . . . . . . . . . . . . . . B-57

B.12.1.2 Tier II Evaluation . . . . . . . . . . . . . . . . . . . B-58

B.12.1.3 Tier III Evaluation $\ldots \ldots \ldots \ldots \ldots \ldots \ldots \ldots \ldots \ldots \ldots \ldots \ldots \ldots \ldots$

B.12.2 Field QC Samples ..........................

B.12.2.1 Laboratory QC Samples ....................... B-62

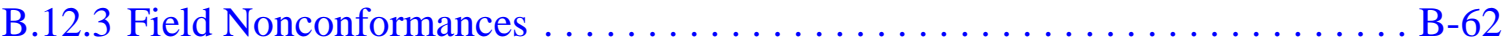

B.12.4 Laboratory Nonconformances $\ldots \ldots \ldots \ldots \ldots \ldots \ldots \ldots \ldots \ldots . . \ldots \ldots$ B-62 


\section{Table of Contents (Continued)}

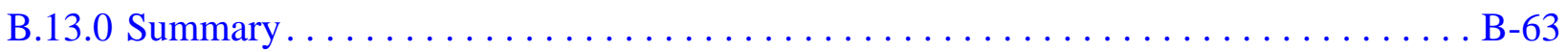

B.14.0 References.................................... B-65

\section{Appendix C - Use Restrictions}

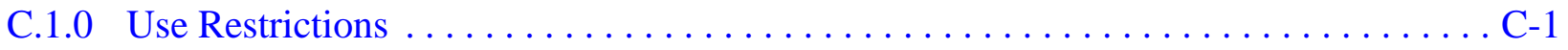

C.1.1 CAS 20-25-04 Use Restrictions . . . . . . . . . . . . . . . . . . C-1

\section{Attachment C-1 - Use Restriction}

\section{Appendix D - Risk Evaluation}

D.1.0 Risk Assessment.....................................

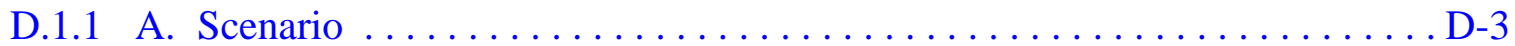

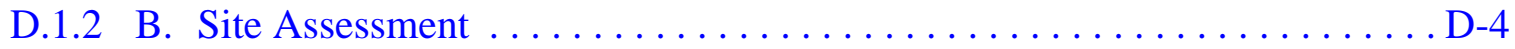

D.1.3 C. Site Classification and Initial Response Action ............... D-6

D.1.4 D. Development of Tier 1 Lookup Table of RBSLs . . . . . . . . . . . . . . D-6

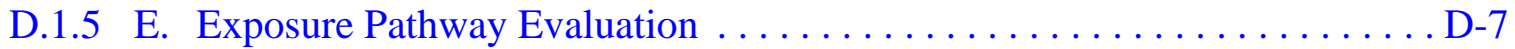

D.1.6 F. Comparison of Site Conditions with Tier 1 RBSLs . . . . . . . . . . . D-7

D.1.7 G. Evaluation of Tier 1 Results . . . . . . . . . . . . . . . . . . D

D.1.8 H. Tier 1 Remedial Action Evaluation $\ldots \ldots \ldots \ldots \ldots \ldots \ldots \ldots \ldots \ldots$ D-7

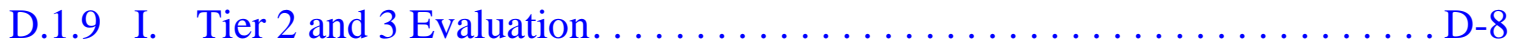

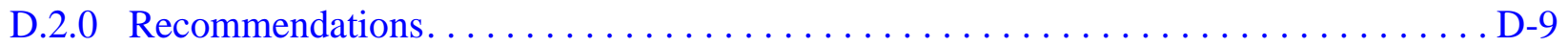

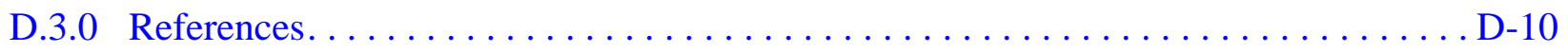




\section{List of Figures}

Number

Title

Page

1-1 Nevada National Security Site. ............................. 2

1-2 CAU 544 CAS Location Map ................................ 3

B.3-1 Sample Locations at CAS 02-37-08, Cellar \& Mud Pit $\ldots \ldots \ldots \ldots \ldots \ldots$ B-16

B.4-1 Sample Locations at CAS 02-37-09, Cellar \& Mud Pit .............. B-24

B.5-1 Sample Locations at CAS 09-09-46, U-9itsx20 PS \#1A Mud Pit. .......... B-31

B.6-1 Sample Locations at CAS 19-25-01, Oil Spill ................... B-37

B.7-1 Sample Locations at CAS 19-99-06, Waste Spill . . . . . . . . . . . . . B-43

B.8-1 Location of CAS 20-25-04, Oil Spills...................... B-48

B.9-1 Sample Locations and Analytical Results Exceeding FALs at CAS 20-25-05, Oil Spills ............................. B-51

D.1-1 Risk-Based Corrective Action Decision Process $\ldots \ldots \ldots \ldots \ldots \ldots \ldots . \ldots . \ldots \ldots$ 


\section{List of Tables}

Number

Title

Page

1-1 Mud Pit Categories and CASs Based on the RBCSR................. 5

1-2 Mud Pit CASs Recommended for No Further Action Based

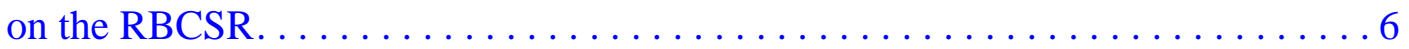

2-1 Corrective Action Investigation Activities Conducted at Each

CAS To Meet SAFER Plan Requirements for CAU $544 \ldots \ldots \ldots \ldots \ldots \ldots 13$

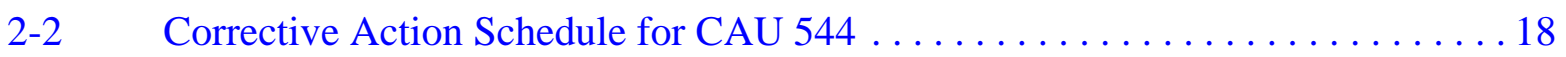

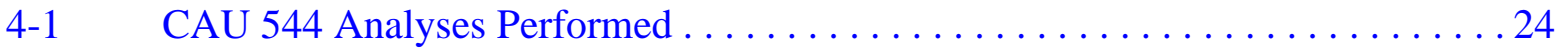

4-2 Analytes Failing Sensitivity Criteria............................ 25

4-3 Precision Measurements .................................. 26

4-4 Accuracy Measurements.............................. 27

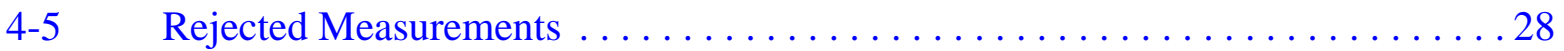

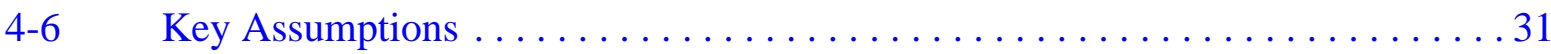

B.1-1 CAU 544 CASs Recommended for No Further Action Based

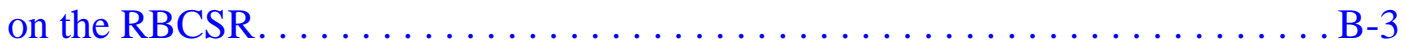

B.2-1 Corrective Action Investigation Activities Conducted at Each CAS To Meet SAFER Plan Requirements for CAU $544 \ldots \ldots \ldots \ldots \ldots \ldots$. B-8

B.2-2 Laboratory Analyses and Methods, CAU 544 Investigation Samples . . . . . . . B-12

B.3-1 Samples Collected at CAS 02-37-08, Cellar \& Mud Pit ............... B-14

B.3-2 Sample Results for VOCs Detected above MDCs at CAS 02-37-08, Cellar \& Mud Pit. .................................. -17

B.3-3 Sample Results for SVOCs Detected above MDCs at CAS 02-37-08, Cellar \& Mud Pit. ................................. 


\section{List of Tables (Continued)}

Number

Title

Page

B.3-4 Sample Results for Metals Detected above MDCs at CAS 02-37-08,

Cellar \& Mud Pit. . . . . . . . . . . . . . . . . . . . . . . . . . B-18

B.3-5 Sample Results for Gamma-Emitting Radionuclides Detected above MDCs at CAS 02-37-08, Cellar \& Mud Pit . . . . . . . . . . . . . . . . . . . . B-19

B.3-6 Sample Results for Isotopes Detected above MDCs at CAS 02-37-08, Cellar \& and Mud Pit . . . . . . . . . . . . . . . . . . . . B-20

B.4-1 Samples Collected at CAS 02-37-09, Cellar \& Mud Pit . . . . . . . . . . . B-21

B.4-2 Sample Results for Metals Detected above MDCs at CAS 02-37-09, Cellar \& Mud Pit. . . . . . . . . . . . . . . . . . . . . . . . . . . . B-26

B.4-3 Sample Results for PCBs Detected above MDCs at CAS 02-37-09, Cellar \& Mud Pit.

B.4-4 Sample Results for Gamma-Emitting Radionuclides Detected above MDCs at CAS 02-37-09, Cellar \& Mud Pit

B.4-5 Sample Results for Isotopes Detected above MDCs at CAS 02-37-09, Cellar \& Mud Pit. . . . . . . . . . . . . . . . . . . . . . B-28

B.5-1 Samples Collected at CAS 09-09-46, U-9itsx20 PS \#1A Mud Pit. . . . . . . . . B-29

B.5-2 Samples Results for Gamma-Emitting Radionuclides Detected above MDCs at CAS 09-09-46, U-9itsx20 PS \#1A Mud Pit .

B.5-3 Sample Results for Isotopes Detected above MDCs at CAS 09-09-46, U-9itsx20 PS \#1A Mud Pit.

B.6-1 Samples Collected at CAS 19-25-01, Oil Spill. . . . . . . . . . . . . . . B-34

B.6-2 Sample Results of VOCs Detected above MDCs at CAS 19-25-01, Oil Spill

B.6-3 Sample Results for SVOCs Detected above MDCs at CAS 19-25-01, Oil Spill. 


\section{List of Tables (Continued)}

Number

Title

Page

B.6-4 Sample Results for Metals Detected above MDCs at

CAS 19-25-01, Oil Spill . . . . . . . . . . . . . . . . . . . . . B-39

B.6-5 Sample Results for Gamma-Emitting Radionuclides Detected above MDCs at CAS 19-25-01, Oil Spill . . . . . . . . . . . . . . . . B-40

B.7-1 Samples Collected at CAS 19-99-06, Waste Spill . . . . . . . . . . . . . . . . B-41

B.7-2 Sample Results for Metals Detected above MDCs at

CAS 19-99-06, Waste Spill. . . . . . . . . . . . . . . . . . . . . . . B-45

B.7-3 Sample Results for PCBs Detected above MDCs at

CAS 19-99-06, Waste Spill. . . . . . . . . . . . . . . . . . . B-46

B.7-4 Sample Results for Gamma-Emitting Radionuclides Detected above

MDCs at CAS 19-99-06, Waste Spill . . . . . . . . . . . . . . . . . . . . B-46

B.9-1 Samples Collected at CAS 20-25-05, Oil Spills . . . . . . . . . . . . . . . . B-49

B.9-2 Sample Results for Metals Detected above MDCs at

CAS 20-25-05, Oil Spills . . . . . . . . . . . . . . . . . . B-53

B.9-3 Sample Results for PCBs Detected above MDCs at

CAS 20-25-05, Oil Spills . . . . . . . . . . . . . . . . . . . . B-53

B.9-4 Sample Results for Gamma-Emitting Radionuclides Detected above

MDCs at CAS 20-25-05, Oil Spills . . . . . . . . . . . . . . . . B-54

D.1-1 Maximum Reported Value for Tier 1 Comparison . ................ D-4 


\section{List of Acronyms and Abbreviations}

Ac

Am

ASTM

bgs

CA

CAA

CAI

CAS

CAU

CLP

COC

COPC

CR

Cs

CSM

DOE

DQA

DQI

DQO

DRO

EML

EPA

FADL

FAL

FD

FFACO
Actinium

Americium

ASTM International

Below ground surface

Contamination Area

Corrective action alternative

Corrective action investigation

Corrective action site

Corrective action unit

Contract Laboratory Program

Contaminant of concern

Contaminant of potential concern

Closure report

Cesium

Conceptual site model

U.S. Department of Energy

Data quality assessment

Data quality indicator

Data quality objective

Diesel-range organics

Environmental Measurements Laboratory

U.S. Environmental Protection Agency

Field activity daily log

Final action level

Field duplicate

Federal Facility Agreement and Consent Order 


\section{List of Acronyms and Abbreviations (Continued)}

FSL Field-screening level

FSR Field-screening result

$\mathrm{ft} \quad$ Foot

GPS Global Positioning System

HASL Health and Safety Laboratory

HWAA Hazardous waste accumulation area

ID Identification

IDW Investigation-derived waste

in. Inch

LANL Los Alamos National Laboratory

LCS Laboratory control sample

LLNL Lawrence Livermore National Laboratory

MDC Minimum detectable concentration

$\mathrm{mg} / \mathrm{kg} \quad$ Milligrams per kilogram

mi Mile

MS Matrix spike

MSD Matrix spike duplicate

N/A Not applicable

NAC Nevada Administrative Code

NAD North American Datum

NCRP National Council on Radiation Protection and Measurements

NDEP Nevada Division of Environmental Protection

NFA No further action

N-I Navarro-Intera, LLC

NIOSH National Institute for Occupational Safety and Health

NIST National Institute of Standards and Technology 


\section{List of Acronyms and Abbreviations (Continued)}

\begin{tabular}{|c|c|}
\hline NNSA/NSO & $\begin{array}{l}\text { U.S. Department of Energy, National Nuclear Security Administration } \\
\text { Nevada Site Office }\end{array}$ \\
\hline NNSS & Nevada National Security Site \\
\hline PAL & Preliminary action level \\
\hline PB & Preparation blank \\
\hline PCB & Polychlorinated biphenyl \\
\hline $\mathrm{pCi} / \mathrm{g}$ & Picocuries per gram \\
\hline PPE & Personal protective equipment \\
\hline $\mathrm{Pu}$ & Plutonium \\
\hline QA & Quality assurance \\
\hline QAPP & Quality Assurance Project Plan \\
\hline QC & Quality control \\
\hline RBCA & Risk-based corrective action \\
\hline RBCSR & Risk-Based Closure Strategy Report \\
\hline RBSL & Risk-based screening level \\
\hline RCRA & Resource Conservation and Recovery Act \\
\hline RPD & Relative percent difference \\
\hline RSL & Regional Screening Level \\
\hline SAFER & Streamlined Approach for Environmental Restoration \\
\hline SCL & Sample collection log \\
\hline SDG & Sample delivery group \\
\hline $\mathrm{Sr}$ & Strontium \\
\hline SSTL & Site-specific target level \\
\hline SVOC & Semivolatile organic compound \\
\hline Th & Thorium \\
\hline $\mathrm{TPH}$ & Total petroleum hydrocarbons \\
\hline $\mathrm{U}$ & Uranium \\
\hline
\end{tabular}




\section{List of Acronyms and Abbreviations (Continued)}

$\begin{array}{ll}\text { UCL } & \text { Upper confidence limit } \\ \text { UR } & \text { Use restriction } \\ \text { URMA } & \text { Underground radioactive material area } \\ \text { UTM } & \text { Universal Transverse Mercator } \\ \text { VOC } & \text { Volatile organic compound } \\ \text { VSP } & \text { Visual Sample Plan } \\ \text { \%R } & \text { Percent recovery }\end{array}$




\section{Executive Summary}

This Closure Report (CR) presents information supporting the closure of Corrective Action Unit (CAU) 544: Cellars, Mud Pits, and Oil Spills, Nevada National Security Site, Nevada. This CR complies with the requirements of the Federal Facility Agreement and Consent Order that was agreed to by the State of Nevada; U.S. Department of Energy (DOE), Environmental Management; U.S. Department of Defense; and DOE, Legacy Management. The corrective action sites (CASs) within CAU 544 are located within Areas 2, 7, 9, 10, 12, 19, and 20 of the Nevada National Security Site. Corrective Action Unit 544 comprises the following CASs:

- 02-37-08, Cellar \& Mud Pit

- 02-37-09, Cellar \& Mud Pit

- 07-09-01, Mud Pit

- 09-09-46, U-9itsx20 PS \#1A Mud Pit

- 10-09-01, Mud Pit

- 12-09-03, Mud Pit

- 19-09-01, Mud Pits (2)

- 19-09-03, Mud Pit

- 19-09-04, Mud Pit

- 19-25-01, Oil Spill

- 19-99-06, Waste Spill

- 20-09-01, Mud Pits (2)

- 20-09-02, Mud Pit

- 20-09-03, Mud Pit

- 20-09-04, Mud Pits (2)

- 20-09-06, Mud Pit

- 20-09-07, Mud Pit

- 20-09-10, Mud Pit

- 20-25-04, Oil Spills

- 20-25-05, Oil Spills

The purpose of this CR is to provide documentation supporting the completed corrective actions and data confirming that the closure objectives for CASs within CAU 544 were met. To achieve this, the following actions were performed:

- Review the current site conditions, including the concentration and extent of contamination.

- Implement any corrective actions necessary to protect human health and the environment.

- Properly dispose of corrective action and investigation wastes. 
- Document Notice of Completion and closure of CAU 544 issued by the Nevada Division of Environmental Protection.

From December 7, 2010, through April 4, 2011, closure activities were performed as set forth in the Streamlined Approach for Environmental Restoration (SAFER) Plan for Corrective Action Unit 544: Cellars, Mud Pits, and Oil Spills, Nevada Test Site, Nevada. The purposes of the activities as defined during the data quality objectives process were as follows:

- Determine whether contaminants of concern (COCs) are present.

- If COCs are present, determine their nature and extent, implement appropriate corrective actions, and properly dispose of wastes.

Analytes detected during the closure activities were evaluated against final action levels (FALs) to determine COCs for CAU 544. Initial assessment of the data generated from closure activities indicated that the FALs were exceeded at CAS 19-25-01 for benzo(a)pyrene in three samples due to sensitivity issues. These samples were diluted during sample preparation, resulting in elevated detection limits that were greater than their corresponding FALs. A second round of sampling was conducted at this CAS, and valid results meeting the data quality indicator for sensitivity were obtained for benzo(a)pyrene in 14 other samples. Because benzo(a)pyrene was not detected in these additional samples, there is no reason to suspect that this contaminant is present in soil at CAS 19-25-01. A use restriction (UR) will be implemented at CAS 20-25-04 because sampling could not be conducted due to safety concerns regarding the potential crater area. Therefore, it is assumed that COCs are present in the soil at this CAS. No further action is necessary at the CASs where no contaminants of potential concern were found above preliminary action levels and at the mud pit CASs that meet the criteria of the Mud Pit Risk-Based Strategy Closure Report.

The DOE, National Nuclear Security Administration Nevada Site Office, provides the following recommendations:

- No further corrective action is required at the following CASs:

- 02-37-08

- 02-37-09

- 07-09-01

- 09-09-46

- 10-09-01 
- 12-09-03

- 19-09-01

- 19-09-03

- 19-09-04

- 19-25-01

- 19-99-06

- 20-09-01

- 20-09-02

- 20-09-03

- 20-09-04

- 20-09-06

- 20-09-07

- 20-09-10

- 20-25-05

- A UR is required at CAS 20-25-04.

- A Notice of Completion to the DOE, National Nuclear Security Administration Nevada Site Office, is requested from the Nevada Division of Environmental Protection for closure of CAU 544.

- Corrective Action Unit 544 should be moved from Appendix III to Appendix IV of the Federal Facility Agreement and Consent Order. 


\subsection{Introduction}

This Closure Report (CR) presents information supporting closure of Corrective Action Unit (CAU) 544: Cellars, Mud Pits, and Oil Spills, Nevada National Security Site (NNSS), Nevada. This complies with the requirements of the Federal Facility Agreement and Consent Order (FFACO) that was agreed to by the State of Nevada; U.S. Department of Energy (DOE), Environmental Management; U.S. Department of Defense; and DOE, Legacy Management (FFACO, 1996; as amended March 2010). Corrective Action Unit 544 contains 20 corrective action sites (CASs) located in Areas 2, 7, 9, 10, 12, 19, and 20 of the NNSS. The NNSS is located approximately 65 miles (mi) northwest of Las Vegas, Nevada (Figure 1-1).

The following 20 CASs compose CAU 544 and are shown on Figure 1-2:

- 02-37-08, Cellar \& Mud Pit

- 02-37-09, Cellar \& Mud Pit

- 07-09-01, Mud Pit

- 09-09-46, U-9itsx20 PS \#1A Mud Pit

- 10-09-01, Mud Pit

- 12-09-03, Mud Pit

- 19-09-01, Mud Pits (2)

- 19-09-03, Mud Pit

- 19-09-04, Mud Pit

- 19-25-01, Oil Spill

- 19-99-06, Waste Spill

- 20-09-01, Mud Pits (2)

- 20-09-02, Mud Pit

- 20-09-03, Mud Pit

- 20-09-04, Mud Pits (2)

- 20-09-06, Mud Pit

- 20-09-07, Mud Pit

- 20-09-10, Mud Pit

- 20-25-04, Oil Spills

- 20-25-05, Oil Spills 


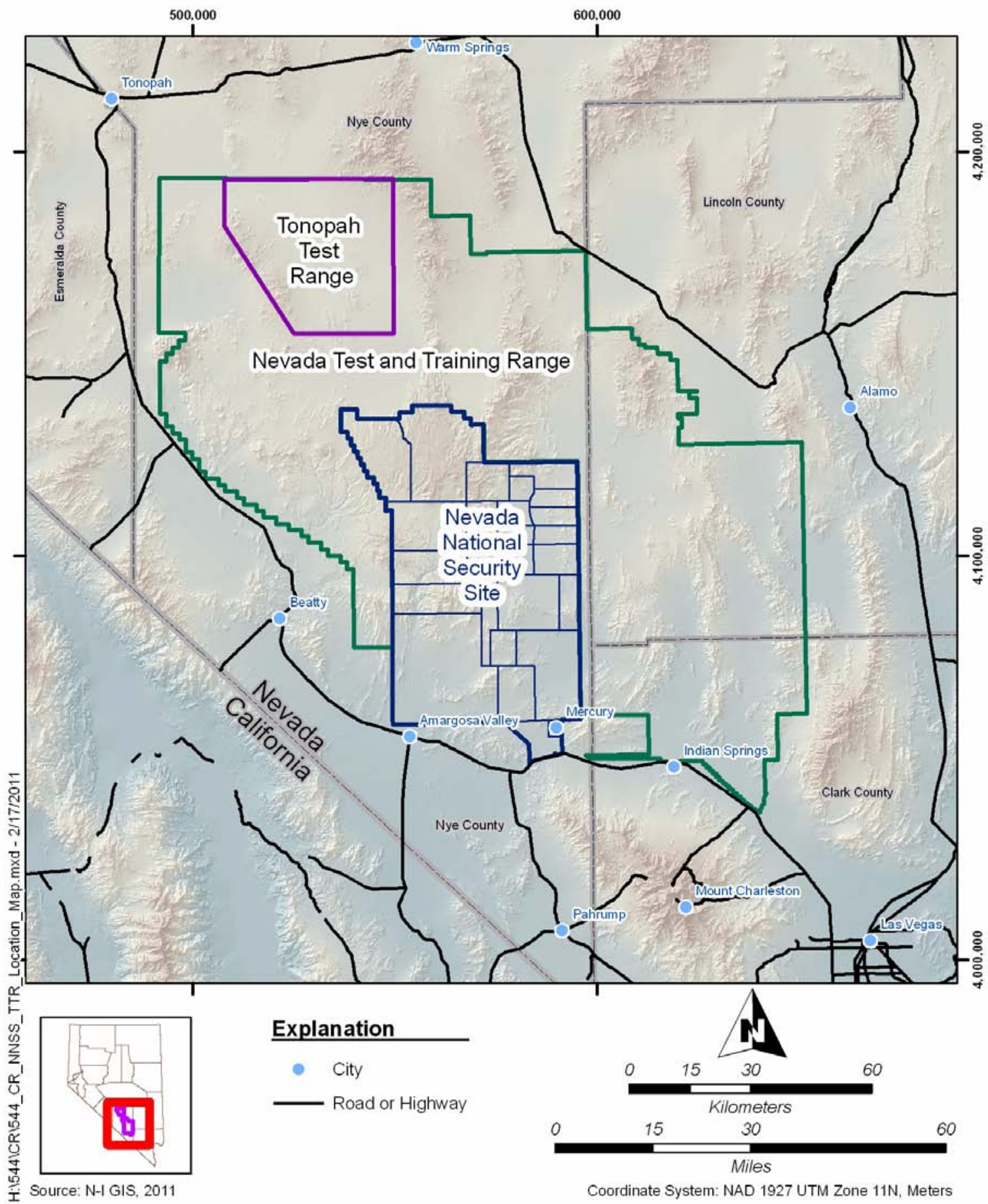

Figure 1-1 Nevada National Security Site 


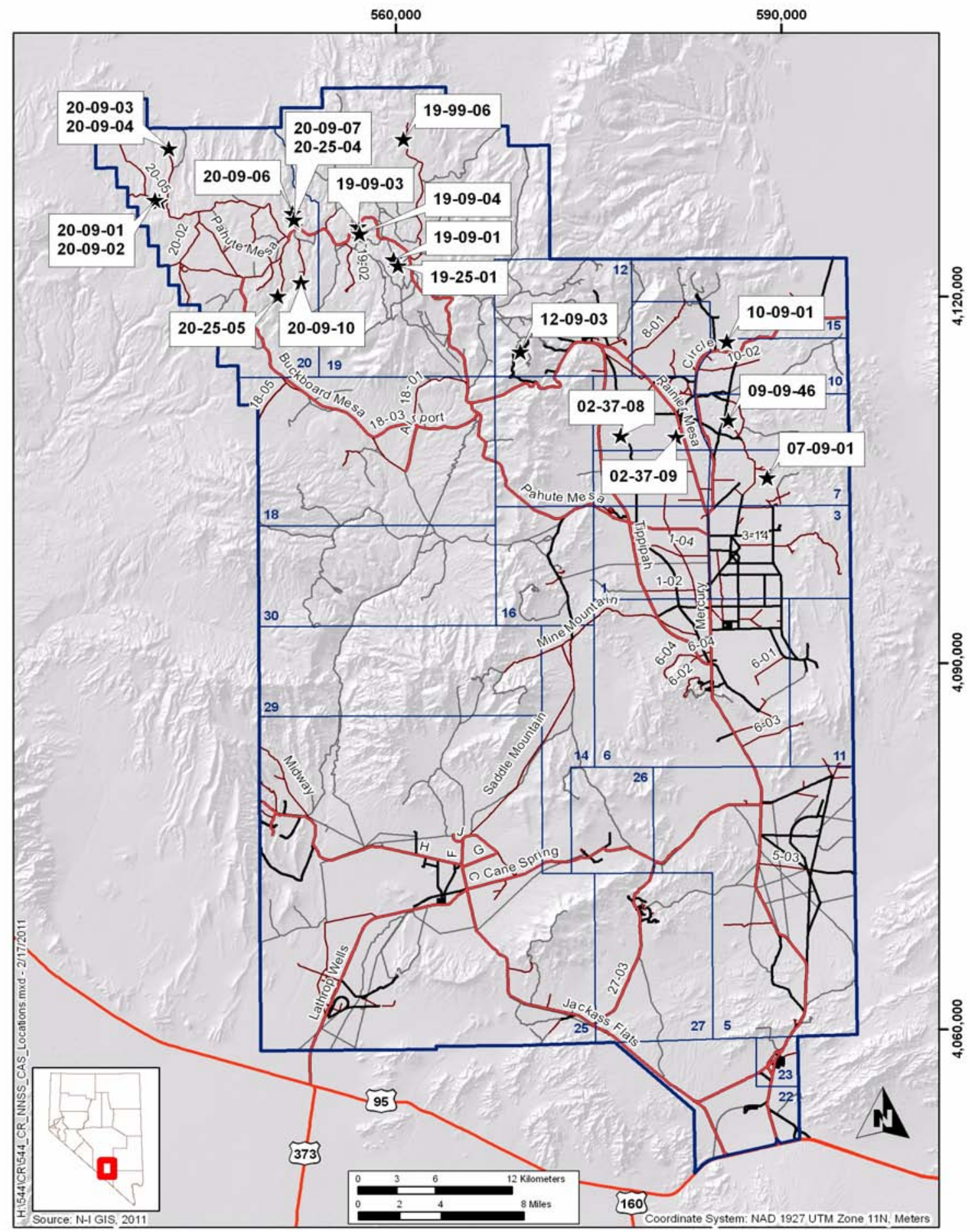

Figure 1-2

CAU 544 CAS Location Map 


\subsection{Purpose}

This CR provides documentation and justification for the closure of 19 CASs in CAU 544 without further corrective action, and how and why a use restriction (UR) has been applied to CAS 20-25-04. These justifications are based on process knowledge, the closure strategy presented in the Mud Pit Risk-Based Closure Strategy Report (RBCSR) (NNSA/NSO, 2004), and the results of the investigative activities conducted in accordance with the Streamlined Approach for Environmental Restoration (SAFER) Plan for Corrective Action Unit 544: Cellars, Mud Pits, and Oil Spills, Nevada Test Site, Nevada (NNSA/NSO, 2010). The SAFER Plan provides information relating to site history as well as the scope and planning of the investigation. Therefore, this information will not be repeated in this $\mathrm{CR}$.

The CAU consists of a total of 20 CASs—2 CASs in Area 2, 5 CASs in Area 19, 9 CASs in Area 20, and 1 CAS each in Areas 7, 9, 10, and 12. All CASs are located within craters or crater areas. The 20 CASs include 4 oil/waste spill CASs, 14 mud pit CASs, and 2 cellar and mud pit CASs.

During the planning phase of this effort, it was determined that many of the CASs met the criteria established during the mud pit effort (CAUs 530-535) for closure without sampling. The criteria included the following:

- CAS is either a single mud pit or system of mud pits.

- CAS is not located in a radiological or radioactive material posted area.

- There are no biasing factors evident at the mud pits based on visual inspections.

The mud pit CASs are in-ground structures used during drilling activities that supported the underground nuclear weapons testing program conducted at the NNSS. Drilling activities were conducted to place the device, obtain lithologic data on the geologic material in which the test was being conducted, emplace monitoring devices both before and after the test, or collect post-test data on the effects of the test. Drilling fluids were typically used during these drilling activities to cool and lubricate the drill bit, stabilize the wall of the drill hole to keep it from collapsing, and suspend the drill cuttings and bring them to the surface (NNSA/NSO, 2006). The drilling fluid used was primarily a bentonite, polymer, or detergent mixture, but was sometimes supplemented with diesel fuel to lubricate the drill bit or to increase the viscosity of the drilling mud and provide better lift for removing the drill cuttings (NNSA/NSO, 2006). Typically, mud containing suspended drill cuttings 
would be deposited in a return mud pit where the cuttings would settle out. The mud would then be transferred to the suction mud pit where it would be recirculated to the drill hole.

The CAU 544 mud pits were categorized according to the categories presented in the Mud Pit RBCSR (NNSA/NSO, 2004). Table 1-1 presents the categories, mud pit system descriptions, and the associated CAU 544 CASs.

Table 1-1

Mud Pit Categories and CASs Based on the RBCSR

\begin{tabular}{|c|c|c|c|}
\hline $\begin{array}{l}\text { Mud Pit } \\
\text { Category }\end{array}$ & Category Description & Type of Mud Pit System & CAU 544 CASs \\
\hline 1 & LANL pretest mud pits & $\begin{array}{l}\text { One earthen, large-return mud pit or } \\
\text { two earthen mud pits with a connecting trench }\end{array}$ & $\begin{array}{l}07-09-01 \\
19-09-01 \\
19-09-03 \\
19-09-04\end{array}$ \\
\hline 2 & LANL post-test mud pits & $\begin{array}{l}\text { Primarily one earthen, small-return mud pit or } \\
\text { a mud spill in the vicinity of the drilling activity }\end{array}$ & N/A \\
\hline 3 & LLNL pretest mud pits & Primarily one earthen, large-return mud pit & $\begin{array}{l}10-09-01 \\
20-09-02 \\
20-09-03 \\
20-09-04 \\
20-09-06 \\
20-09-07 \\
20-09-10\end{array}$ \\
\hline 4 & LLNL post-test mud pits & $\begin{array}{l}\text { Primarily one earthen, small-return mud pit or } \\
\text { a mud spill in the vicinity of the drilling activity }\end{array}$ & $\begin{array}{l}02-37-08 \\
02-37-09 \\
09-09-46 \\
12-09-03 \\
20-09-01\end{array}$ \\
\hline
\end{tabular}

LANL $=$ Los Alamos National Laboratory

LLNL = Lawrence Livermore National Laboratory

N/A = Not applicable

\subsubsection{Mud Pit CASs Recommended for No Further Action Based on the RBCSR}

The following sections discuss the categorization of the mud pits recommended for no further action (NFA). Based on the criteria presented in the RBCSR (NNSA/NSO, 2004) and CAUs 530-535 closure document (NNSA/NSO, 2006), 13 mud pit CASs and 1 mud pit CAS component have been recommended for NFA. The evaluation of these mud pit CASs followed the criteria and processes discussed in the RBCSR, and as such, each of these CASs was identified by the laboratory that 
conducted the test and whether it was a pretest boring or post-test boring. The CASs, laboratories that conducted the tests, and the categories are presented in Table 1-1. The mud pit CASs recommended for NFA based on the RBCSR (NNSA/NSO, 2004) and CAUs 530-535 closure document (NNSA/NSO, 2006) are listed in Tables 1-2 and B.1-1.

Table 1-2

Mud Pit CASs Recommended for No Further Action Based on the RBCSR

\begin{tabular}{|c|c|c|c|}
\hline CAS & Location & Type of Mud Pit & Mud Pit Category \\
\hline 02-37-08, Cellar \& Mud Pit & $\mathrm{U}-2 \mathrm{cn}$ & LLNL post-test & 4 \\
\hline 07-09-01, Mud Pit & U-7bi & LANL pretest & 1 \\
\hline 10-09-01, Mud Pit & U-10cb & LLNL pretest & 3 \\
\hline 12-09-03, Mud Pit & U-12e.14 PS \#1A & LLNL post-test & 4 \\
\hline 19-09-01, Mud Pits (2) & U-19ab & LANL pretest & 1 \\
\hline 19-09-03, Mud Pit & U-19ar & LANL pretest & 1 \\
\hline 19-09-04, Mud Pit & U-19ad & LANL pretest & 1 \\
\hline 20-09-01, Mud Pits (2) & $\begin{array}{c}\text { RSM } 20 \mathrm{~J} 35 \\
\text { U-20m PS }\end{array}$ & LLNL post-test & 4 \\
\hline 20-09-02, Mud Pit & $\begin{array}{c}\text { RSM } 20 \mathrm{~J} 36 \\
\text { U-20m PS }\end{array}$ & LLNL pretest & 3 \\
\hline 20-09-03, Mud Pit & $U-20 p$ & LLNL pretest & 3 \\
\hline 20-09-04, Mud Pits (2) & $U-20 p$ & LLNL pretest & 3 \\
\hline 20-09-06, Mud Pit & $U-20 z$ & LLNL pretest & 3 \\
\hline 20-09-07, Mud Pit & U-20aw & LLNL pretest & 3 \\
\hline 20-09-10, Mud Pit & U-20bg & LLNL pretest & 3 \\
\hline
\end{tabular}

${ }^{a}$ Mud Pit RBCSR (NNSA/NSO, 2004).

\subsubsection{Los Alamos National Laboratory Pretest Mud Pits}

Four mud pit CASs of CAU 544 were constructed as part of LANL pretest drilling activities. One CAS is located in Area 7, and the other three are located in Area 19. The LANL pretest mud pit generally consisted of one earthen, large-return mud pit or two earthen mud pits (a return pit and 
a suction pit) with a connecting trench or piping. The mud pits were typically covered with native soils after use (NNSA/NSO, 2006).

\subsubsection{Lawrence Livermore National Laboratory Pretest Mud Pits}

Seven mud pit CASs were constructed as part of LLNL pretest drilling activities. One CAS is located in Area 10, and the remaining six are located in Area 20. The LLNL mud pit generally consisted of one earthen, large-return mud pit that was not covered with native soils after use. A metal tank was commonly used as the suction pit for these systems, but it was removed after drilling was completed, leaving only the return mud pit (NNSA/NSO, 2006).

\subsubsection{Lawrence Livermore National Laboratory Post-test Mud Pits}

Five mud pit CASs in CAU 544 were constructed as part of the LLNL post-test drilling activities. Two of the CASs are located in Area 2, and one CAS each is located in Areas 9, 12, and 20. Of these five LLNL post-test mud pit CASs, only two (CASs 02-37-09 and 09-09-46) have been sampled as part of the CAU 544 corrective action investigation (CAI); the other three mud pit CASs have been recommended for NFA based on the RBCSR criteria (NNSA/NSO, 2004). The LLNL post-test mud pit generally consisted of one earthen, small-return mud pit. After use, these return mud pits were commonly allowed to dry out, surveyed for radiation, and covered with native soils (NNSA/NSO, 2006).

Additional information regarding the history of each site, planning, and the scope of the investigation is presented in the CAU 544 SAFER Plan (NNSA/NSO, 2010).

\subsubsection{CASs Not Meeting RBCSR Criteria}

The CAU 544 CASs that did not meet the RBCSR criteria (NNSA/NSO, 2004) were included in the sampling effort and are discussed in the following sections.

\subsubsection{CAS 02-37-08, Cellar \& Mud Pit}

Corrective Action Site 02-37-08 is located in Area 2 of the NNSS and consists of potential environmental releases associated with a backfilled cellar located in the vicinity of the U-2cn crater. The cellar is located within a fenced area posted with "Underground Radioactive Material Area" 
(URMA) signs. However, the mud pit component of this CAS meets the criteria specified in the RBCSR (NNSA/NSO, 2004) and is recommended for closure without sampling.

\subsubsection{CAS 02-37-09, Cellar \& Mud Pit}

Corrective Action Site 02-37-09 is located in Area 2 of the NNSS and consists of potential environmental releases associated with the backfilled cellar and backfilled mud pit. The cellar and mud pit are located in the vicinity of the U-2dc4a (Tyg-D) crater. Both the cellar and mud pit are located within a fenced URMA.

\subsubsection{CAS 09-09-46, U-9itsx20 PS \#1A Mud Pit}

Corrective Action Site 09-09-46 is located in Area 9 of the NNSS and consists of potential releases associated with the mud pit. The mud pit is located on the eastern edge and within the fenced U-9itsx20 crater area and has not been backfilled. The mud pit and crater area are posted as a Contamination Area (CA).

\subsubsection{CAS 19-25-01, Oil Spill}

Corrective Action Site 19-25-01 is located approximately 1,800 feet (ft) southwest of the U-19ab crater in Area 19. The CAS consists of a suspected release of hydrocarbons to the soil associated with an oil spill.

\subsubsection{CAS 19-99-06, Waste Spill}

Corrective Action Site 19-99-06 is located east of the U-19j emplacement hole in Area 19. The environmental concern at this CAS consists of potential environmental releases associated with several large spills of cement suspected to have occurred during the installation of the casing in the adjacent emplacement hole.

\subsubsection{CAS 20-25-04, Oil Spills}

Corrective Action Site 20-25-04 is located in Area 20 of the NNSS and consists of potential releases of hydrocarbons to the soil near U-20aw. The reported oil spills cover several square feet of soil and are located within a potential crater area. Because the crater has been reported to be potentially less 
stable than other craters (Pawloski, 2003), sampling was not conducted at this CAS for safety concerns.

\subsubsection{CAS 20-25-05, Oil Spills}

Corrective Action Site 20-25-05 is located in Area 20 of the NNSS and consists of potential releases of hydrocarbons to the soil from numerous reported oil spills. The CAS is located near U-20be, in the area formerly used as the trailer park for the nuclear test, and not within the crater area.

\subsection{Scope}

After all CASs had been reviewed and visited, the CASs listed in Table 1-2 were eliminated from further investigation based on the RBCSR (NNSA/NSO, 2004) and CAUs 530-535 closure document (NNSA/NSO, 2006). Sampling was conducted at two mud pit CASs (02-37-09 and 09-09-46) to support the NFA recommendation. The corrective action of NFA was completed by demonstrating through environmental sample analytical results using judgmental and probabilistic sampling that contaminants of concern (COCs) do not exist within the mud pits at CASs 02-37-09 and 09-09-46; within the cellars at CASs 02-37-08 and 02-37-09; or within the oil/waste spill CASs 19-25-01, 19-99-06, and 20-25-05. Corrective Action Site 20-25-04 could not be sampled because of its location within a potential crater area; therefore, a UR will be implemented at CAS 20-25-04 to prevent future access to the potential contamination. Activities conducted during the field investigation to accomplish this scope included the following:

- $\quad$ Removing surface debris and/or materials to facilitate sampling.

- Performing radiological field-screening surveys.

- Collecting environmental samples for laboratory analysis.

- $\quad$ Collecting quality control (QC) samples.

- Justifying why no further corrective action is necessary and the technical rationale for implemented closure activities.

- Documenting Notice of Completion and closure of CAU 544. 


\subsection{Closure Report Contents}

This CR is divided into the following sections and appendices:

- Section 1.0, "Introduction," summarizes the purpose, scope, and contents of this CR.

- Section 2.0, “Closure Activities,” summarizes the closure activities, deviations from the SAFER Plan, the actual schedule, and the site conditions following completion of corrective actions.

- Section 3.0, "Waste Disposition,” discusses the wastes generated and entered into an approved waste management system as a result of the corrective action.

- Section 4.0, “Closure Verification Results,” describes verification activities and results.

- Section 5.0, “Conclusions and Recommendations,” provides the conclusions and recommendations along with the rationale for their determination.

- Section 6.0, "References," provides a list of all referenced documents used in the preparation of this CR.

- Appendix A, Data Quality Objectives (DQOs) as Developed in the SAFER Plan, provides the DQOs as presented in Appendix B of the CAU 544 SAFER Plan.

- Appendix B, Confirmation Sampling Test Results, provides a description of the project objectives, field closure and sampling activities, and closure results.

- Appendix C, Use Restrictions, documents the URs.

- Appendix D, Risk Evaluation, presents the risk evaluation results.

- Appendix E, Nevada Division of Environmental Protection (NDEP) Comments, contains NDEP comments on the draft version of this document.

\subsubsection{Applicable Programmatic Plans and Documents}

To ensure all project objectives, health and safety requirements, and QC procedures were adhered to, all closure activities were performed in accordance with the CAU 544 SAFER Plan (NNSA/NSO, 2010), FFACO (1996, as amended March 2010), and Industrial Sites Quality Assurance Project Plan (QAPP) (NNSA/NV, 2002). 


\subsubsection{Data Quality Objectives}

This section contains a summary of the DQO process that is presented in Appendix A. The DQOs were developed to identify data needs, clearly define the intended use of the environmental data, and design a data collection program that will satisfy these purposes. For mud pit CASs that are not in radiologically posted areas, the SAFER Plan stated that no contaminants of potential concern (COPCs) are expected. The RBCSR (NNSA/NSO, 2004) stated that based on process knowledge and previous sampling, these mud pits contained no COCs. The SAFER effort for CAUs 530-535 (NNSA/NSO, 2006) confirmed that there are no COCs present in the mud pits not impacted by radiological releases. It further recommended that if additional mud pits are identified that meet the established criteria, they should be closed and moved to Appendix IV of the FFACO without further investigation.

The problem statement for CAU 544 is as follows: "Existing information on the nature and extent of contamination is incomplete to evaluate and confirm closure of all the CASs in CAU 544.” To address this problem, the resolution of two decision statements is required:

- Decision I: “Is any COC present in environmental media within the CAS?” For the judgmental sampling design, any contaminant associated with a release from the CAS that is remaining at concentrations exceeding its corresponding final action level (FAL) will be defined as a COC. For the probabilistic sampling design, any significant COPC associated with a release from the CAS that has a 95th percent upper confidence limit (UCL) of the average concentration exceeding its corresponding FAL will be defined as a COC.

- Decision II: "If a COC is present, is sufficient information available to meet the closure objectives?” Sufficient information is defined to include the following:

- Identifying the lateral and vertical extent of COC contamination in media, if present.

- The information needed to characterize investigation-derived waste (IDW) and remediation waste for disposal.

The presence of a COC would require a corrective action. A corrective action may also be necessary if there is a potential for wastes that are present at a site to release COCs into site environmental media. 


\subsubsection{Data Quality Assessment Summary}

The data quality assessment (DQA) presented in Section 4.1 includes an evaluation of the data quality indicators (DQIs) to determine the degree of acceptability and usability of the reported data in the decision-making process. The DQO process ensures that the right type, quality, and quantity of data will be available to support the resolution of those decisions at an appropriate level of confidence. Using both the DQO and DQA processes helps ensure that DQO decisions are sound and defensible.

The DQA process, as presented in Section 4.1, consists of the following steps:

- $\quad$ Step 1: Review DQOs and Sampling Design.

- Step 2: Conduct a Preliminary Data Review.

- $\quad$ Step 3: Select the Test.

- Step 4: Verify the Assumptions.

- Step 5: Draw Conclusions from the Data.

Based on the results of the DQA presented in Section 4.1, the information generated during the investigation supports the conceptual site model (CSM) assumptions, and the data collected meet the DQOs and support their intended use in the decision-making process. 
The following sections summarize the CAU 544 closure activities and any deviations from the original scope of work. Results of confirmation sampling for individual CAU 544 CASs are presented in Appendix B of this document.

\subsection{Description of Corrective Action Investigation Activities}

The CAI activities were conducted between December 7, 2010, and April 4, 2011, in accordance with the requirements set forth in the CAU 544 SAFER Plan (NNSA/NSO, 2010). Table 2-1 lists the CAI activities that were conducted at each of the CASs listed in Section 1.1.2.

Table 2-1

Corrective Action Investigation Activities Conducted at Each CAS To Meet SAFER Plan Requirements for CAU 544

\begin{tabular}{|c|c|c|c|c|c|c|c|c|}
\hline \multirow[b]{2}{*}{ CAl Activities } & \multicolumn{8}{|c|}{ CAS } \\
\hline & 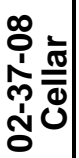 & 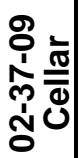 & 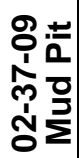 & 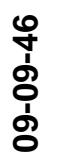 & 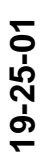 & $\begin{array}{l}\text { o } \\
\text { ò } \\
\text { ơ } \\
\text { o่ }\end{array}$ & 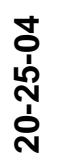 & 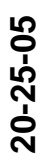 \\
\hline Visually inspected spill area boundaries. & -- & -- & -- & -- & $\mathrm{X}$ & $\mathrm{X}$ & -- & $\mathrm{X}$ \\
\hline Collected subsurface soil samples from biased locations at cellars. & $X$ & $X$ & -- & -- & -- & -- & -- & -- \\
\hline $\begin{array}{l}\text { Collected surface soil samples from biased locations at } \\
\text { oil/waste spills. }\end{array}$ & -- & -- & -- & -- & $\mathrm{X}$ & $\mathrm{X}$ & -- & $\mathrm{X}$ \\
\hline Collected soil samples from random locations at mud pits. & -- & -- & $X$ & $\mathrm{X}$ & -- & -- & -- & -- \\
\hline Recorded GPS coordinates of each location. & $X$ & $X$ & $\mathrm{X}$ & $X$ & $x$ & $\mathrm{X}$ & -- & $\mathrm{X}$ \\
\hline $\begin{array}{l}\text { Field screened samples for alpha and beta/gamma radiation using } \\
\text { a handheld survey instrument. }\end{array}$ & $X$ & $\mathrm{X}$ & $X$ & $\mathrm{X}$ & $\mathrm{X}$ & $\mathrm{X}$ & -- & $\mathrm{X}$ \\
\hline Submitted select samples for offsite laboratory analysis. & $X$ & $X$ & $\mathrm{X}$ & $X$ & $x$ & $\mathrm{X}$ & -- & $x$ \\
\hline
\end{tabular}

$X=$ Activity conducted

-- = Activity not applicable or conducted

GPS = Global Positioning System

Closure verification samples were collected from surface soils and subsurface soils, including residual drilling mud. Surface soil samples were collected using disposable sampling scoops. Subsurface soil samples were collected using hand augering and Geoprobe methods. All soil and 
drilling mud samples were field screened for alpha and beta/gamma radiation. The results were compared against screening levels to guide in the selection of CAS-specific verification sample locations. Resultant samples were shipped to offsite laboratories to be analyzed for appropriate chemical and radiological parameters.

A combination of judgmental and probabilistic sampling schemes was implemented to select sample locations and evaluate analytical results, as outlined in the SAFER Plan (NNSA/NSO, 2010). Judgmental sampling allows the methodical selection of sample locations that targets the populations of interest (defined in the DQOs) rather than non-selective random locations. Probabilistic sampling uses random sample locations in the absence of adequate biasing factors to define site-wide contamination characteristics.

For the judgmental sampling scheme, individual sample results (rather than average concentrations) are used to compare to FALs. Therefore, statistical methods to generate site characteristics (averages) are not necessary. If adequate prior information is available on the target site of interest, then the sampling may be designed to collect samples only from areas known to have the highest concentration levels on the target site. If the observed concentrations from these samples are below the action level, then a decision can be made that the site contains safe levels of the contaminant without the samples being truly representative of the entire area (EPA, 2006). The judgmental sampling design is used to determine the existence of contamination at specific locations and provide information (such as extent of contamination) about specific areas of the site. Confidence in judgmental sampling scheme decisions is established qualitatively by the validation of the CSM and justification that sampling locations are the most likely locations to contain a COC, if a COC exists.

For the probabilistic sampling scheme, the average contaminant concentrations at the site in question are used to compare to FALs. The averages from sample analytical results for each constituent are an estimation of the true average contaminant concentrations. Because the average contaminant concentration from samples is only an estimate of the true (unknown) average, it is uncertain how well the sample averages represent the actual averages. To reduce the probability of making a false negative decision error, the 95th percent UCLs of the respective sample contaminant concentration averages will be used to compare to FALs. Therefore, by definition, there will be a 95 percent probability that the true average concentration is less than the 95th percent UCL of the sample 
average. As stated in Section C.1.2.1 of the SAFER Plan (NNSA/NSO, 2010), UCLs will only be calculated for significant COPCs (i.e., a COPC detected in any sample within a CAS at a concentration greater than the preliminary action level [PAL]). If no COPCs are detected in any sample within a CAS at a concentration greater than the PAL, then it will be determined that COCs do not exist at the CAS. Confidence in probabilistic sampling scheme decisions is established by the validation of the CSM, justification that sampling locations are representative of site conditions, demonstration that the number of samples collected is sufficient, and demonstration that contaminant distribution assumptions are valid and appropriate to the statistical test being performed.

\subsubsection{CAS 02-37-08, Cellar \& Mud Pit Closure Activities}

Three Decision I biased soil samples (including one field duplicate [FD]) were collected from two locations within the cellar at CAS 02-37-08. The sample locations were selected based on the configuration of the post-test drill pipe. The subsurface samples were collected from depths of 8.0 to $10.0 \mathrm{ft}$ below ground surface (bgs) and 10.0 to $13.0 \mathrm{ft}$ bgs. These intervals represented the interface between backfill material and the cellar bottom. Refusal was met at $10.0 \mathrm{ft}$ bgs (the east side of the cellar) and $13.0 \mathrm{ft}$ bgs (the west side of the cellar). Geoprobe operations were terminated at refusal to avoid creating a migration pathway through the concrete bottom; therefore, no samples were collected from below the cellar.

The mud pit component of this CAS met the RBCSR criteria (NNSA/NSO, 2004) and was not sampled.

\subsubsection{CAS 02-37-09, Cellar \& Mud Pit Closure Activities}

Three Decision I biased soil samples (including one FD) were collected from two locations within the cellar at CAS 02-37-09. The subsurface samples were collected from depths of 9.0 to $11.0 \mathrm{ft}$ bgs and 12.0 to $16.0 \mathrm{ft}$ bgs. These intervals represented the interface between backfill material and the cellar bottom. Refusal was met at $11.0 \mathrm{ft}$ bgs (the south side of the cellar) and $16.0 \mathrm{ft}$ bgs (the north side of the cellar). Geoprobe operations were terminated at refusal to avoid creating a migration pathway through the concrete bottom; therefore, no samples were collected from below the cellar. 
Decision I randomly located soil samples were collected from 10 locations within the estimated boundary of the backfilled mud pit. One sample was collected from each of these locations. Some sample locations were moved towards the center of the mud pit because the original locations were believed to be located in the mud pit berms, outside the mud pit, or too close to the fence line to allow Geoprobe access. The samples were collected using both Geoprobe and hand augering methods. A thin, noncontinuous layer of light gray, dried material was noted in some of the samples at depths between 3.5 and $5.0 \mathrm{ft}$ bgs. Samples were collected at the interval where the dried material was discovered.

\subsubsection{CAS 09-09-46, U-9itsx20 PS \#1A Mud Pit Closure Activities}

A total of 11 Decision I surface soil samples (including 1 FD) were collected from 10 randomly selected locations within the boundary of the uncovered mud pit. The samples were collected using hand sampling techniques and consisted of light brown clayey silt.

\subsubsection{CAS 19-25-01, Oil Spill Closure Activities}

Five soil samples (including one FD) were collected from two biased locations at the oil spills. A thorough visual inspection identified the area where the oil stains were visible. The samples were biased to the darkest stained soil and were collected at depths of 0 to 3 inches (in.) bgs and 3 to 6 in. bgs. Surface soil samples also were collected from the outside edge of the stained soil area to bound any potential contamination.

Due to sensitivity issues with semivolatile organic compound (SVOC) results, the reporting limit was significantly higher than the PAL, which resulted in unusable data. A second round of sampling was conducted on April 4, 2011. Biased soil samples were collected from stained soil at depths of 0 to 3 in. bgs, 3 to 6 in. bgs, and 6 to 12 in. bgs. Soil samples were also collected from three locations at the outside edge of the oil spill. Samples were collected at depths of 0 to 3 in. bgs, 3 to 6 in. bgs, and 6 to 12 in. bgs to bound potential contamination on all sides of the oil spill. Valid results for the DQI of sensitivity were obtained for these samples; therefore, the data are usable. 


\subsubsection{CAS 19-99-06, Waste Spill Closure Activities}

Four soil samples (including one FD) were collected from two biased locations at the largest bentonite drilling mud and/or cement grout spill. One sample was collected from 4 to 6 in. bgs near the middle of bentonite drilling mud and/or cement grout, and one sample was collected from below the spill (6 to 12 in. bgs) near the middle of the spill at the native soil interface. A second surface soil sample was collected from the outside edge of the bentonite drilling mud and/or cement grout spill to bound any potential contamination.

\subsubsection{CAS 20-25-04, Oil Spills Closure Activities}

As discussed in Section 1.1.2.6, because the crater has been reported to be potentially less stable than other craters (Pawloski, 2003), sampling was not conducted at this CAS for safety concerns. Therefore, it is assumed that COCs are present in the soil at this CAS.

\subsubsection{CAS 20-25-05, Oil Spills Closure Activities}

Five surface soil samples (including one FD) were collected from two biased locations at the reported oil spills. The area was covered with pea gravel and vegetation, and the oil spill was not readily visible. Although a thorough visual inspection of the area was conducted, no stained soil suggesting the presence of an oil spill was identified. It was decided that weathering over the years had eliminated any visible evidence of the oil spill; therefore, the CAS marker was considered the location of the spill, and samples were collected according to the SAFER Plan (NNSA/NSO, 2010). The largest spill was reported to be approximately $10 \mathrm{ft}$ in size; samples were collected from the reported edge of the spill to bound any potential contamination.

\subsection{Deviations from SAFER Plan as Approved}

The only deviation to the SAFER Plan requirements (NNSA/NSO, 2010) at CAU 544 was that CAS 20-25-04 was not sampled due to its location within a potentially unstable crater area. The LLNL had conducted a stability study for the crater, but because the crater has been reported to be potentially less stable, sampling was not conducted at this CAS for safety concerns (Pawloski, 2003). 


\subsection{Corrective Action Schedule as Completed}

The corrective action activities for CAU 544 took place from December 7, 2010, through April 4, 2011. Table 2-2 presents a summary of these activities.

Table 2-2

Corrective Action Schedule for CAU 544

\begin{tabular}{||c|l||}
\hline Date & \multicolumn{1}{|c|}{ Activity } \\
\hline \hline December 7-16, 2010 & $\begin{array}{l}\text { Conducted soil sampling at CASs 02-37-08, 19-25-01, 19-99-06, and 20-25-05. } \\
\text { Began soil sampling at CAS 02-37-09 (cellar and mud pit). }\end{array}$ \\
\hline January 14, 2011 & Completed soil sampling at CAS 02-37-09 (cellar and mud pit). \\
\hline February 14, 2011 & Completed soil sampling at CAS 09-09-46. \\
\hline April 4, 2011 & Conducted a second round of soil sampling at CAS 19-25-01. \\
\hline
\end{tabular}

\subsection{Site Maps}

Site maps that show the components of the CASs (i.e., mud pit, cellar, or oil spill), sample locations, and geospatial coordinates of sample locations and other features of interest are presented for each CAS in Appendix B. 


\subsection{Waste Disposition}

Wastes generated during the SAFER field activities include disposable personnel protective equipment (PPE), disposable sampling equipment, housekeeping waste, and small amounts of decontamination rinsate. The types, amounts, and disposal of the wastes are detailed in the following subsections. Generated wastes such as PPE have been characterized based on the associated soil samples and knowledge of the waste-generating process. Site controls were in place to prevent the introduction of hazardous constituents to these waste streams.

\subsection{Waste Streams}

During the investigation, IDW generated was segregated into the following waste streams:

- Disposable PPE and sampling equipment

- Decontamination rinsate

Although decontamination rinsate was generated, the small volumes evaporated before the rinsate could be transferred for containment or sampled.

\subsection{Waste Sampling}

No waste sampling was conducted at CAU 544.

\subsection{Waste Disposal}

The IDW generated during the investigation consisted of PPE and disposable sampling equipment. Disposable PPE and sampling equipment waste was inspected for gross contamination and was determined to be nonhazardous and nonradiological based on observations, process knowledge, and radiological screening of associated samples. The waste was bagged, labeled, and placed in the rolloff bin at Building 23-153 for disposal at the NNSS industrial waste landfill. Although decontamination rinsate was generated, the small volumes evaporated before the rinsate could be transferred for containment or sampled. 


\subsection{Closure Verification Results}

Closure verification results consist of the analytical results from environmental samples that demonstrate that closure objectives were met. For NFA, verification results demonstrate that COCs do not exist within the CASs.

The CAU 544 SAFER Plan (NNSA/NSO, 2010) identified that the right type, quality, and quantity of data are needed to resolve the DQO decision statements. To verify that the dataset obtained as a result of this investigation supports the DQO decisions, a DQA was conducted. Section 4.1 provides a summary of the DQA, and Section 4.2 summarizes any URs for each CAS.

This section provides a summary of verification data from the closure activities as detailed in Appendix B. The CAU 544 sampling locations were accessible at all CASs, except for CAS 20-25-04. Sampling activities at planned locations were not restricted by buildings, storage areas, active operations, or aboveground and underground utilities. The analytical data support NFA as the closure option for all CAU 544 CASs. No soil samples had COPC concentrations that were detected or expected above the respective PALs. The following subsections provide a summary of the CAS-specific verification results as presented in Appendix B.

CAS 02-37-08, Cellar \& Mud Pit; CAS 02-37-09, Cellar \& Mud Pit; and CAS 09-09-46, U-9itsx20 PS \#1A Mud Pit

No COCs were identified at these cellar and mud pit CASs. The analytical data support NFA for these CASs.

CAS 19-25-01, Oil Spill; CAS 19-99-06, Waste Spill; and CAS 20-25-05, Oil Spills

No COCs were identified at these oil/waste spill CASs. The analytical data support NFA for these CASs.

\section{CAS 20-25-04, Oil Spills}

This CAS was not sampled during the field investigation due to its location within a potentially unstable crater area. Therefore, it is assumed that COCs are present in the soil at this CAS. 
Closure in place with a UR is the recommended corrective action. The UR will prevent unauthorized intrusive activities at this CAS. An annual post-closure inspection is associated with the UR to certify that postings are in place, intact, and readable. Signage will be placed to designate the restricted area. The UR is included in Appendix C.

\subsection{Data Quality Assessment}

The DQA process is the scientific evaluation of the actual investigation results to determine whether the DQO criteria established in the CAU 544 SAFER Plan (NNSA/NSO, 2010) were met and whether DQO decisions can be resolved at the desired level of confidence. The DQO process ensures that the right type, quality, and quantity of data will be available to support the resolution of those decisions at an appropriate level of confidence. Using both the DQO and DQA processes helps ensure that DQO decisions are sound and defensible.

The DQA involves five steps that begin with a review of the DQOs and end with an answer to the DQO decisions. The five steps are briefly summarized as follows:

Step 1: Review DQOs and Sampling Design—Review the DQO process to provide context for analyzing the data. State the primary statistical hypotheses; confirm the limits on decision errors for committing false negative (Type I) or false positive (Type II) decision errors; and review any special features, potential problems, or any deviations to the sampling design.

Step 2: Conduct a Preliminary Data Review_A preliminary data review should be performed by reviewing quality assurance (QA) reports and inspecting the data both numerically and graphically, validating and verifying the data to ensure that the measurement systems performed in accordance with the criteria specified, and using the validated dataset to determine whether the quality of the data is satisfactory.

Step 3: Select the Test—Select the test based on the population of interest, population parameter, and hypotheses. Identify the key underlying assumptions that could cause a change in one of the DQO decisions.

Step 4: Verify the Assumptions-Perform tests of assumptions. If data are missing or censored, determine the impact on DQO decision error. 
Step 5: Draw Conclusions from the Data-Perform the calculations required for the test.

\subsubsection{Review DQOs and Sampling Design}

This section contains a review of the DQO process presented in Appendix A. The DQO decisions are presented with the DQO provisions to limit false negative or false positive decision errors. Special features, potential problems, or any deviations to the sampling design also are presented.

\subsubsection{Decision I}

The Decision I statement as presented in the CAU 544 SAFER Plan is as follows: "Is any COC present in environmental media within the CAS?”

\section{Decision I Rules}

- If the population parameter of any COPC in a target population exceeds the FAL for that COPC, then that COPC is identified as a COC.

- If a COC is detected, then the Decision II statement must be resolved.

- If COCs are not identified, then the investigation is complete.

Population Parameter: For judgmental sampling results, the population parameter is the maximum observed sample result from each individual sample. For probabilistic sampling results, the population parameter is the 95th percent UCL of the sample population average concentration of each contaminant from each CAS.

\subsection{DQO Provisions To Limit False Negative Decision Error}

A false negative decision error (where consequences are more severe) was controlled by meeting the following criteria:

1. Have a high degree of confidence that locations selected will identify COCs if present anywhere within the CAS. For probabilistic sampling at the mud pits, determine the appropriate population distributions and ensure a sufficient sample size was collected.

2. Have a high degree of confidence that analyses conducted will be sufficient to detect any COCs present in the samples. 
3. Have a high degree of confidence that the dataset is of sufficient quality and completeness.

\section{Criterion 1}

The following methods (stipulated in the CAU 544 DQOs [NNSA/NSO, 2010]) were used in selecting sample locations:

1. Mud pit sample locations for CASs 02-37-09 and 09-09-46 were predetermined using the Visual Sample Plan (VSP) software (PNNL, 2007). The VSP software identified 10 locations within the mud pit perimeter using a triangular grid pattern and a randomly selected start location. Because no significant COPCs were detected, UCLs were not calculated, and it was determined that a sufficient number of samples were collected.

2. Cellar sample locations for CASs 02-37-09 and 09-09-46 were distributed equally on each side of the borehole casing or on the side of the cellar that was accessible for the appropriate sample collection method (i.e., Geoprobe and/or hand auger drilling at backfilled cellars).

3. Sample locations at backfilled cellars associated with lithology changes (i.e., identification of subsurface interfaces) were selected by visual observation.

4. Sample locations at the oil/waste spills were based on a typical CSM for a surface spill. Samples were collected from areas of suspected highest contaminant concentrations.

5. Sample locations associated with radiological field-screening results (FSRs) were selected by screening the area using a handheld NE Technology Electra.

6. Sample locations associated with professional judgement based on acceptable knowledge were selected by

- source and location of release,

- chemical nature and fate properties,

- physical transport pathways and properties, and

- hydrologic drivers.

\section{$\underline{\text { Criterion } 2}$}

All samples were analyzed using the analytical methods listed in Tables 3-4 and 3-5 of the SAFER Plan and for the chemical and radiological parameters listed in Section B.2.2.2 of the SAFER Plan (NNSA/NSO, 2010). Table 4-1 provides a reconciliation of samples analyzed to the planned analytical program. 
Table 4-1

\section{CAU 544 Analyses Performed}

\begin{tabular}{|c|c|c|c|c|c|c|c|c|c|}
\hline CAS & 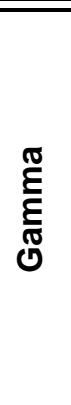 & 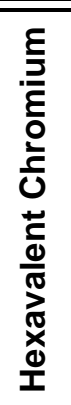 & 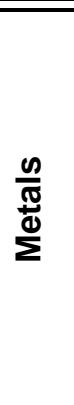 & 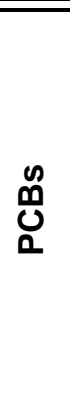 & 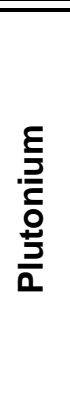 & 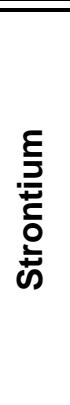 & 品 & $\begin{array}{l}\frac{\xi}{J} \\
\frac{\bar{J}}{\bar{L}} \\
\frac{\pi}{\nu}\end{array}$ & $\begin{array}{l}\text { O } \\
\text { @ }\end{array}$ \\
\hline $02-37-08$ & RS & RS & RS & RS & RS & RS & RS & RS & $\mathrm{RS}$ \\
\hline $\begin{array}{l}\text { 02-37-09 } \\
\text { Mud Pit }\end{array}$ & RS & -- & -- & -- & RS & RS & -- & RS & -- \\
\hline $\begin{array}{c}\text { 02-37-09 } \\
\text { Cellar }\end{array}$ & RS & RS & RS & RS & RS & RS & RS & RS & RS \\
\hline 09-09-46 & RS & -- & -- & -- & RS & RS & -- & RS & -- \\
\hline $19-25-01$ & RS & RS & RS & RS & -- & -- & RS & -- & RS \\
\hline $19-99-06$ & RS & RS & RS & RS & -- & -- & RS & -- & RS \\
\hline $20-25-05$ & RS & RS & RS & RS & -- & -- & RS & -- & RS \\
\hline
\end{tabular}

RS = Required and submitted

-- = Not required and not submitted

$\mathrm{PCB}=$ Polychlorinated biphenyl

VOC $=$ Volatile organic compound

Sample results were assessed against the acceptance criterion for the DQI of sensitivity as defined in the Industrial Sites QAPP (NNSA/NV, 2002). The sensitivity acceptance criterion defined in the SAFER Plan is that analytical detection limits will be less than the corresponding action level. This criterion was not achieved for the analytical results listed in Table 4-2. The SVOCs benzo(a)pyrene, dibenzo(a,h)anthracene, hexachlorobenzene, and n-nitrosodi-n-propylamine did not meet the criteria for sensitivity in three samples from CAS 19-25-01 (544C001, 544C002, and 544C003). These samples were diluted during sample preparation, resulting in elevated detection limits that were greater than their corresponding FAL concentrations. However, valid results meeting the DQI for sensitivity were obtained for these 4 constituents in 14 other samples from this CAS. Because these constituents were not detected in these additional samples, there is no reason to suspect that these contaminants are present at CAS 19-25-01, and there is sufficient information to make the DQO decision. Therefore, the dataset was determined to meet the criteria for completeness. Results that did not meet the sensitivity acceptance criterion were not used in making DQO decisions and were 
therefore considered as rejected data. The impact on DQO decisions is addressed in the assessment of completeness.

Table 4-2

Analytes Failing Sensitivity Criteria

\begin{tabular}{|c|c|c|c|c|}
\hline Sample & Constituent & CAS & $\begin{array}{c}\text { MDC } \\
(\mathrm{mg} / \mathrm{kg})\end{array}$ & $\begin{array}{c}\text { FAL } \\
(\mathrm{mg} / \mathrm{kg})\end{array}$ \\
\hline \multirow{4}{*}{$544 C 001$} & Benzo(a)pyrene & \multirow{12}{*}{$19-25-01$} & 0.254 & 0.21 \\
\hline & Dibenzo(a,h)anthracene & & 0.254 & 0.21 \\
\hline & Hexachlorobenzene & & 1.69 & 1.1 \\
\hline & N-Nitrosodi-n-propylamine & & 1.69 & 0.25 \\
\hline \multirow{4}{*}{$544 \mathrm{C} 002$} & Benzo(a)pyrene & & 0.246 & 0.21 \\
\hline & Dibenzo(a,h)anthracene & & 0.246 & 0.21 \\
\hline & Hexachlorobenzene & & 1.64 & 1.1 \\
\hline & N-Nitrosodi-n-propylamine & & 1.64 & 0.25 \\
\hline \multirow{4}{*}{ 544C003 } & Benzo(a)pyrene & & 0.26 & 0.21 \\
\hline & Dibenzo(a,h)anthracene & & 0.26 & 0.21 \\
\hline & Hexachlorobenzene & & 1.73 & 1.1 \\
\hline & N-Nitrosodi-n-propylamine & & 1.73 & 0.25 \\
\hline
\end{tabular}

MDC = Minimum detectable concentration $\mathrm{mg} / \mathrm{kg}=$ Milligrams per kilogram

\section{Criterion 3}

To satisfy the third criterion, the entire dataset, as well as individual sample results, was assessed against the acceptance criteria for the DQIs of precision, accuracy, representativeness, completeness, and comparability, as defined in the Industrial Sites QAPP (NNSA/NV, 2002). The DQI acceptance criteria are presented in Table 6-1 of the SAFER Plan (NNSA/NSO, 2010). As discussed below, these criteria were met for each of the DQIs.

\section{$\underline{\text { Precision }}$}

The analytical criteria for precision are evaluated using the relative percent difference (RPD) or normalized difference. For the purpose of determining the data precision of chemical analyses, the RPD between duplicate analyses was calculated. For radionuclides, the RPD was not calculated 
unless both the sample and its duplicate had concentrations of the target radionuclide exceeding five times their MDC. Otherwise radionuclide duplicate results were evaluated using the normalized difference. Table 4-3 provides the chemical and radiological precision analysis results for all contaminants that were qualified for precision. The only chemical contaminant qualified for precision was barium. The only radionuclide qualified for precision was uranium (U)-235.

Table 4-3

Precision Measurements

\begin{tabular}{|c|c|c|c|c|}
\hline Contaminant & Analysis & $\begin{array}{c}\text { Number of } \\
\text { Measurements } \\
\text { Qualified }\end{array}$ & $\begin{array}{c}\text { Number of } \\
\text { Measurements } \\
\text { Performed }\end{array}$ & $\begin{array}{c}\text { Percent } \\
\text { within } \\
\text { Criteria }\end{array}$ \\
\hline \hline Barium & Metals & 3 & 20 & 85 \\
\hline U-235 & Uranium & 8 & 27 & 70 \\
\hline
\end{tabular}

As shown in Table 4-3, the precision rate for barium was above the SAFER Plan acceptance criterion of 80 percent. Therefore, the DQI for precision was met. The sample qualified for $\mathrm{U}-235$ precision was based on differences in laboratory duplicate sample results. High variability in the sampled matrix may indicate the potential that discrete particles of contamination are present within the sample. Therefore, mixing will not produce homogeneity. This does not mean that the precision of the measurement is poor but that activities are variable within the sample. This is commonly observed in isotopic $U$ results because a single particle of $U$ within a sample can result in detectable activities attributed to the entire sample. Therefore, when a duplicate sample is analyzed for isotopic $\mathrm{U}$, the results can be significantly different depending on how many discrete particles are contained in each sample. However, there is negligible potential for a false negative DQO decision error because the highest reported activities are still very small in comparison to the FAL. The highest reported U-235 activity (0.151 picocuries per gram [pCi/g]) is significantly below the FAL of $17.6 \mathrm{pCi} / \mathrm{g}$. Therefore, the U-235 result that was qualified for reasons of precision can be confidently used to support DQO decisions. Because the precision rates for all other contaminants meet the acceptance criteria for precision, the dataset is determined to be acceptable for the DQI of precision.

\section{Accuracy}

For the purpose of determining data accuracy of sample analyses, environmental soil samples were evaluated and incorporated into the accuracy calculation. The results qualified for accuracy were 
associated with matrix spike (MS) recoveries that were outside control limits and could potentially be reported at concentrations lower or higher than actual concentrations. Table 4-4 provides the chemical accuracy analysis results for all contaminants qualified for accuracy. Accuracy rates for selenium, lead, and barium did not meet the SAFER Plan criterion of 80 percent. There were no radiological data qualified for accuracy.

Table 4-4

Accuracy Measurements

\begin{tabular}{|c|c|c|c|}
\hline Contaminant & $\begin{array}{c}\text { Number of } \\
\text { Measurements } \\
\text { Qualified }\end{array}$ & $\begin{array}{c}\text { Number of } \\
\text { Measurements } \\
\text { Performed }\end{array}$ & $\begin{array}{c}\text { Percent } \\
\text { within } \\
\text { Criteria }\end{array}$ \\
\hline \hline Bis(2-ethylhexyl)phthalate & 2 & 32 & 93.8 \\
\hline Selenium & 8 & 20 & 60 \\
\hline Lead & 13 & 20 & 35 \\
\hline Barium & 18 & 20 & 10 \\
\hline
\end{tabular}

All of the barium, lead, and selenium results qualified for accuracy were associated with an MS recovery that exceeded the upper limits. This indicates that the results may have been reported at concentrations higher than actual. This inaccuracy could impact a DQO decision by causing a false positive decision error. However, this did not occur at CAU 544, because no barium, lead, or selenium results exceeded the FAL. As the accuracy rate for all other contaminants meet the acceptance criteria for accuracy, the dataset is determined to be acceptable for the DQI of accuracy.

\section{Representativeness}

The DQO process as identified in Appendix A was used to address sampling and analytical requirements for CAU 544. During this process, appropriate locations were selected that enabled the samples collected to be representative of the population parameters identified in the DQO (the most likely locations to contain contamination and locations that bound COCs). The sampling locations identified in the Criterion 1 discussion meet this criterion. Therefore, the analytical data acquired during the CAU 544 CAI are considered representative of the population parameters. 


\section{Completeness}

The CAU 544 SAFER Plan (NNSA/NSO, 2010) defines acceptable criteria for completeness to be 80 percent of CAS-specific non-target contaminants identified having valid results and 100 percent of target contaminants (including Decision II samples) having valid results. Also, the dataset must be sufficiently complete to be able to make the DQO decisions. Target chemical contaminants for the CAU 544 cellars and oil/waste spills are identified as VOCs and SVOCs. Target radiological contaminants for the CAU 544 mud pits are identified as gamma-emitters, strontium (Sr)-90, isotopic $\mathrm{U}$, and isotopic plutonium $(\mathrm{Pu})$.

Rejected data (either qualified as rejected or data that failed the criterion of sensitivity) were not used in the resolution of DQO decisions and are not counted toward meeting the completeness acceptance criterion. Table 4-5 provides the rejected data for the site. The VOC 1,4-dioxane failed the criterion for sensitivity in 17 samples. The SVOC benzo(a)pyrene is a hazardous constituent of total petroleum hydrocarbons (TPH) and did not meet the criteria of 100 percent of target contaminants having valid results (Table 4-2). All other data for target contaminants were within the acceptable criteria.

Table 4-5

Rejected Measurements

\begin{tabular}{|c|c|c|c|c|}
\hline Constituent & Analysis & $\begin{array}{c}\text { Number of } \\
\text { Measurements } \\
\text { Qualified }\end{array}$ & $\begin{array}{c}\text { Number of } \\
\text { Measurements } \\
\text { Performed }\end{array}$ & $\begin{array}{c}\text { Percent } \\
\text { within } \\
\text { Criteria }\end{array}$ \\
\hline \hline 1,4-Dioxane & VOCs & 17 & 20 & 15 \\
\hline
\end{tabular}

\section{Comparability}

Field sampling, as described in the CAU 544 SAFER Plan (NNSA/NSO, 2010), was performed and documented in accordance with approved procedures that are in conformance with standard industry practices. Analytical methods and procedures approved by DOE were used to analyze, report, and validate the data. These methods and procedures are in conformance with applicable methods used in industry and government practices. Therefore, project datasets are considered comparable to other datasets generated using standard industry procedures, thereby meeting DQO requirements. 


\subsubsection{DQO Provisions To Limit False Positive Decision Error}

The false positive decision error was controlled by assessing the potential for false positive analytical results. Quality assurance/QC samples such as field blanks, trip blanks, laboratory control samples (LCSs), and method blanks were used to determine whether a false positive analytical result may have occurred. This provision is evaluated during the validation process, and appropriate qualifications are applied to the data results when applicable.

Proper decontamination of sampling equipment and the use of certified clean sampling equipment and containers also minimized the potential for cross contamination that could lead to a false positive analytical result.

\subsubsection{Sampling Design}

The SAFER Plan made the following commitments for sampling:

1. Probabilistic sampling will be conducted at the mud pits at CASs 02-37-09 and 09-09-46, in which 10 samples per mud pit will be collected from the residual drilling mud, defined as 0 to 6 in. bgs for open mud pits, or 0 to 6 in. below the cover material/mud interface or at the expected depth of mud for backfilled mud pits. Samples collected at mud pits will be analyzed for radiological constituents. Additional biased samples may be collected in areas of obvious spills or staining at the mud pits. Samples collected at the mud pits would be analyzed only for radiological constituents.

Result: All random sample locations designated by the VSP software were collected as planned and analyzed for the appropriate COPCs. An interface with residual mud was occasionally identified at the backfilled mud pit at CAS 02-37-09. The layout of sample locations was regenerated at CAS 02-37-09, where several sample locations were on the berms or outside the suspected boundary of the mud pit. No additional biased samples were collected at the mud pits.

2. Judgmental sampling will be conducted at the cellars at CASs 02-37-08 and 02-37-09. Two samples will be collected at the first 6 in. of soil directly beneath cover material using a Geoprobe and/or hand auger at backfilled cellars. Deeper subsurface samples would be collected, where possible, to provide potential Decision II information on vertical migration of contaminants. Actual sample locations within the cellar would be dependent on the presence and orientation of borehole casing. Samples collected at cellars would be analyzed for chemical and radiological constituents.

Result: Judgmental samples were collected as planned and analyzed for the appropriate COPCs. An interface with the cellar bottom was consistently identified at two backfilled 
cellars, and both cellars contained a concrete bottom. Samples were collected at each cellar from approximately $2 \mathrm{ft}$ above the concrete cellar floor.

3. Judgmental sampling will be conducted at the oil/waste spills at CASs 19-25-01, 19-99-06, and 20-25-05. If the spill is located, two samples will be collected at two locations. Two surface samples, defined as 0 to 6 in. bgs, will be collected: one at the location of the heaviest stained soil and one at the outside edge of the stained soil. Two subsurface soil samples, defined as 6 to 12 in. bgs, will be collected from these same locations. If the spill is not located, then two surface and two subsurface samples will be collected at the CAS marker and at the suspected outside edge of the spill.

Result: Based on visual inspections of the spills at CASs 19-25-01 and 19-99-06, judgmental samples were collected from depths different from those stated in the SAFER Plan. At CAS 19-25-01, samples were collected from 0 to 3 in. bgs, 3 to 6 in. bgs, and 6 to 12 in. bgs based on stained soil. At CAS 19-99-06, samples were collected at a depth from 4 to 6 in. bgs due to the bentonite drilling mud and/or cement grout spill extending below the surface of the soil. The samples were analyzed for the appropriate COPCs. Two oil spills (CASs 19-25-01 and 20-25-05) and one bentonite drilling mud and/or cement grout spill (CAS 19-99-06) were located, while the third oil spill (CAS 20-25-04) was not located.

\subsubsection{Conduct a Preliminary Data Review}

A preliminary data review was conducted by reviewing QA reports and inspecting the data. The contract analytical laboratories generate a QA nonconformance report when data quality does not meet contractual requirements. All data received from the analytical laboratories met contractual requirements, and a QA nonconformance report was not generated. Data were validated and verified to ensure that the measurement systems performed in accordance with the criteria specified. The validated dataset quality was found to be satisfactory.

\subsubsection{Select the Test and Identify Key Assumptions}

The tests for resolving DQO Decision I were the comparison of the maximum analyte result from each CAS to the corresponding FAL for the judgmental sampling design and the comparison of the 95 percent UCL of the average concentration of each significant COPC to the FAL for the probabilistic sampling design. The test for making DQO Decision II was the comparison of all COC analyte results from each bounding sample to the corresponding FALs.

The key assumptions that could impact a DQO decision are listed in Table 4-6. 


\section{Table 4-6}

\section{Key Assumptions}

\section{(Page 1 of 2)}

\begin{tabular}{|c|c|}
\hline Exposure Scenario & $\begin{array}{l}\text { Occasional use. The potential for contamination exposure is limited to industrial and } \\
\text { construction workers, and military personnel conducting training. These human } \\
\text { receptors may be exposed to COPCs through oral ingestion, inhalation, or dermal } \\
\text { contact (absorption) of soil and/or debris due to inadvertent disturbance of these } \\
\text { materials, or irradiation by radioactive materials. } \\
\text { The investigation results did not reveal any potential exposures than those identified } \\
\text { in the CSM. }\end{array}$ \\
\hline Affected Media & $\begin{array}{l}\text { Mud Pit: Residual mud contained in the boundaries of the radiologically posted mud } \\
\text { pits. Underlying soils are not expected to have been affected due to properties of } \\
\text { drilling mud. } \\
\text { Cellar: Surface soil and shallow subsurface soil at the base of the cellar. } \\
\text { Oil/Waste Spill: Surface soil and shallow subsurface soil underlying the spill. } \\
\text { Groundwater contamination is not a concern. Contaminants migrating to regional } \\
\text { aquifers are not considered. } \\
\text { The investigation reports did not reveal any affected media other than those identified } \\
\text { in the CSM. }\end{array}$ \\
\hline $\begin{array}{l}\text { Location of } \\
\text { Contamination/Release Points }\end{array}$ & $\begin{array}{l}\text { Mud Pit: Residual drilling mud contained within the boundaries of the radiologically } \\
\text { posted mud pit walls/berms. If a backfilled mud pit, the mud would be located directly } \\
\text { beneath the cover material (typically } 4.0-5.0 \mathrm{ft} \text { bgs). } \\
\text { Cellar: Surface soil and shallow subsurface soil at the base of the cellar (typically } \\
\text { 10.0-12.0 } \mathrm{ft} \text { bgs) contained within the boundaries of the corrugated metal casing } \\
\text { (typically } 10 \mathrm{ft} \text { in diameter). } \\
\text { Oil/Waste Spill: Surface and shallow subsurface soils. } \\
\text { The investigation results did not reveal any locations of contamination or release } \\
\text { points other than those identified in the SAFER Plan. }\end{array}$ \\
\hline Transport Mechanisms & $\begin{array}{l}\text { Infiltration and percolation of precipitation through affected media serves as the major } \\
\text { driving force for contamination to migrate vertically. Due to the low precipitation and } \\
\text { high evaporation rates of the arid environment, percolation of infiltrated precipitation is } \\
\text { limited and is not considered a significant mechanism regarding the transport of } \\
\text { contaminants to groundwater. } \\
\text { Lateral transportation of some contaminants may occur as a result of surface water } \\
\text { runoff or overflow of surface water accumulated in the mud pits and cellars. } \\
\text { Evaporation of volatile components may release contaminants to the air. } \\
\text { Wind blowing over open mud pits, cellars, and spills may resuspend contaminated } \\
\text { surface soil particles. } \\
\text { The investigation results did not reveal any transport mechanisms other than those } \\
\text { identified in the CSM. }\end{array}$ \\
\hline Preferential Pathways & None. The investigation results did not reveal any preferential pathways. \\
\hline
\end{tabular}




\section{Table 4-6}

\section{Key Assumptions}

(Page 2 of 2)

\begin{tabular}{|c|c|}
\hline $\begin{array}{l}\text { Lateral and Vertical } \\
\text { Extent of Contamination }\end{array}$ & $\begin{array}{l}\text { Mud Pit: The lateral extent of contamination in a mud pit is expected to be limited to } \\
\text { the walls/berms unless there is a noticeable breach that would allow for overland } \\
\text { transport. The vertical extent of potential contamination at a mud pit is expected to be } \\
\text { bound within the residual mud and would not be expected to migrate vertically } \\
\text { downward into the underlying soil. } \\
\text { Cellar: The lateral extent of contamination in cellars is expected to be limited by the } \\
\text { metal casing that surrounds the cellar cavity. The vertical extent of potential } \\
\text { contamination in the affected media of a cellar is not expected to infiltrate more than } \\
\text { a few inches below the base of cellar, if at all. } \\
\text { Oil/Waste Spill: The lateral extent of contamination of the oil/waste spills is expected } \\
\text { to be contiguous to the release points. The vertical extent of potential contamination } \\
\text { in the affected media at the oil/waste spills is dependent upon the soil type } \\
\text { immediately below the spill. Lateral and vertical extent of Coc contamination is } \\
\text { assumed to be within the spatial boundaries. } \\
\text { The investigation results did not reveal any lateral and vertical extent of contamination } \\
\text { other than those identified in the CSM. }\end{array}$ \\
\hline Groundwater Impacts & $\begin{array}{l}\text { Groundwater contamination is not expected because depth to groundwater varies } \\
\text { between } 725 \text { to } 3,100 \mathrm{ft} \text { bgs and averages approximately } 800 \mathrm{ft} \text { bgs (USGS and } \\
\text { DOE, 2009). } \\
\text { The investigation results did not reveal any indicators that groundwater could be } \\
\text { potentially impacted. }\end{array}$ \\
\hline Future Land Use & $\begin{array}{l}\text { Nonresidential. } \\
\text { The investigation results did not reveal any future land uses other than nonresidential. }\end{array}$ \\
\hline Other DQO Assumptions & None. \\
\hline
\end{tabular}

\subsubsection{Verify the Assumptions}

The results of the investigation support the key assumptions identified in the CAU 544 DQOs and Table 4-6. All data collected during the CAI supported the CSM and do not necessitate revisions to the CSM.

\subsubsection{Draw Conclusions from the Data}

This section resolves the two DQO decisions for each of the CAU 544 CASs. 


\subsubsection{Decision Rules for Decision I}

Decision Rule: If the concentration of any COPC in a target population exceeds the FAL for that COPC during the initial investigation, then that COPC is identified as a COC and Decision II sampling will be conducted.

Result: Because no COCs were identified at CASs 02-37-08, 02-37-09, 09-09-46, 19-25-01, 19-99-06, and 20-25-05, NFA is recommended as the corrective action alternative (CAA), and the Decision II statement does not need to be resolved for these CASs.

Based on the criteria presented in the RBCSR (NNSA/NSO, 2004) and CAUs 530-535 closure document (NNSA/NSO, 2006), 13 mud pit CASs and 1 mud pit CAS component have been recommended for closure without sampling. The evaluation of these mud pit CASs followed the criteria and processes discussed in the RBCSR.

\subsection{Use Restrictions}

Because sampling could not be conducted at CAS 20-25-04, it is assumed that COCs are present at this CAS. A UR will be implemented at CAS 20-25-04. The future use of any land related to CAS 20-25-04 is restricted from any activity that may alter or modify the containment controls as approved by the NDEP, unless appropriate concurrence is obtained in advance. Specific information and map locations relating to the imposed UR for CAS 20-25-04 are presented in Appendix C.

Risk evaluations completed for CAU 544 are presented in Appendix D. 


\subsection{Conclusions and Recommendations}

Based on the results of the closure activities, no further closure activities are necessary for CAU 544.

The DOE, National Nuclear Security Administration Nevada Site Office (NNSA/NSO) provides the following recommendations:

- No further corrective action is required at all CASs, except for CAS 20-25-04. Based on the findings and conclusions of the RBCSR and the CR for CAUs 530-535, and analytical results of the environmental samples collected during the investigation, no COCs have been released to the soil from these CASs in CAU 544. Therefore, corrective action is not required at these CASs.

- A UR will be implemented at CAS 20-25-04. Sampling could not be conducted due to safety concerns, so it is assumed that COCs are present in the soil at the CAS.

- A Notice of Completion is requested from NDEP for the closure of CAU 544.

- Corrective Action Unit 544 should be moved from Appendix III to Appendix IV of the FFACO, signifying closure. 


\subsection{References}

EPA, see U.S. Environmental Protection Agency.

FFACO, see Federal Facility Agreement and Consent Order.

Federal Facility Agreement and Consent Order. 1996 (as amended March 2010). Agreed to by the State of Nevada; U.S. Department of Energy, Environmental Management; U.S. Department of Defense; and U.S. Department of Energy, Legacy Management.

N-I GIS, see Navarro-Intera Geographic Information Systems.

NNSA/NSO, see U.S. Department of Energy, National Nuclear Security Administration Nevada Site Office.

NNSA/NV, see U.S. Department of Energy, National Nuclear Security Administration Nevada Operations Office.

Navarro-Intera Geographic Information Systems. 2011. ESRI ArcGIS Software.

PNNL, see Pacific Northwest National Laboratory.

Pacific Northwest National Laboratory. 2007. Visual Sample Plan, Version 5.0 User's Guide, PNNL-16939. Richland, WA.

Pawloski, G.A., Lawrence Livermore National Laboratory. 2003. Memorandum to B. Bangeter (NNSA/NSO) regarding status of surface crater collapse for selected LLNL tests on Pahute Mesa and Yucca Flat, 27 January. Livermore, CA.

USGS and DOE, see U.S. Geological Survey and U.S. Department of Energy.

U.S. Department of Energy, National Nuclear Security Administration Nevada Operations Office. 2002. Industrial Sites Quality Assurance Project Plan, Rev. 3, DOE/NV--372--REV. 3. Las Vegas, NV.

U.S. Department of Energy, National Nuclear Security Administration Nevada Site Office. 2004. Mud Pit Risk-Based Closure Strategy Report, Nevada Test Site, Nevada, DOE/NV--991. Las Vegas, NV.

U.S. Department of Energy, National Nuclear Security Administration Nevada Site Office. 2006. Closure Report for Corrective Action Units 530, 531, 532, 533, 534, 535: NTS Mud Pits, Nevada Test Site, Nevada, Rev. 0, DOE/NV--1131. Las Vegas, NV. 
U.S. Department of Energy, National Nuclear Security Administration Nevada Site Office. 2010. Streamlined Approach for Environmental Restoration (SAFER) for Corrective Action Unit 544: Cellars, Mud Pits, and Oil Spills, Nevada Test Site, Nevada, Rev. 0, DOE/NV--1393.

Las Vegas, NV.

U.S. Environmental Protection Agency. 2006. Guidance on Systematic Planning Using the Data Quality Objectives Process, EPA QA/G-4, EPA/240/B-06/001. Washington, DC: Office of Environmental Information.

U.S. Geological Survey and U.S. Department of Energy. 2009. "USGS/DOE Cooperative Studies in Nevada; Water-Level Wells Site Map.” As accessed at http://nevada.usgs.gov/doe_nv/levelsmap1.htm on 3 March 2010. 


\section{Appendix A}

\section{Data Quality Objectives as Developed in the SAFER Plan}

Note: This appendix contains the DQOs presented in CAU 544 SAFER Plan and consists of Appendix B of the SAFER Plan. Therefore, all cross-references, page numbers, and header information in this appendix refer to the original document. 


\section{B.1.0 Introduction}

The DQO process described in this appendix is a seven-step strategic systematic planning method used to plan data collection activities and define performance criteria for the CAU 544, Cellars, Mud Pits, and Oil Spills, field investigation. The DQOs are designed to ensure that the data collected will provide sufficient and reliable information to determine the appropriate corrective actions, to verify the adequacy of existing information, to provide sufficient data to implement the corrective actions, and to verify that closure was achieved.

The CAU 544 field investigation will be based on the DQOs presented in this appendix as developed by representatives of NDEP and NNSA/NSO. The seven steps of the DQO process presented in Sections B.2.0 through B.8.0 were developed in accordance with EPA Guidance on Systematic Planning Using the Data Quality Objectives Process (EPA, 2006b) and the CAS-specific information presented in Section B.2.0.

The DQO process presents a combination of probabilistic and judgmental sampling approaches. In general, the procedures used in the DQO process provide:

- A method to establish performance or acceptance criteria, which serve as the basis for designing a plan for collecting data of sufficient quality and quantity to support the goals of a study.

- Criteria that will be used to establish the final data collection design such as:

- The nature of the problem that has initiated the study and a conceptual model of the environmental hazard to be investigated.

- The decisions or estimates that need to be made and the order of priority for resolving them.

- $\quad$ The type of data needed.

- An analytic approach or decision rule that defines the logic for how the data will be used to draw conclusions from the study findings.

- Acceptable quantitative criteria on the quality and quantity of the data to be collected, relative to the ultimate use of the data. 
- A data collection design that will generate data meeting the quantitative and qualitative criteria specified. A data collection design specifies the type, number, location, and physical quantity of samples and data, as well as the QA and QC activities that will ensure that sampling design and measurement errors are managed sufficiently to meet the performance or acceptance criteria specified in the DQOs.

- Acceptable process knowledge and historical information to support the closure of the mud pits that have not been radiologically impacted and meet the criteria specified in the mud pit RBCSR (NNSA/NSO, 2004). 


\section{B.2.0 Step 1 - State the Problem}

Step 1 of the DQO process defines the problem that requires study, identifies the planning team, and develops a conceptual model of the environmental hazard to be investigated.

The problem statement for the CAU 544 CASs is: "Existing information on the nature and extent of contamination is incomplete to evaluate and confirm closure of all the CASs in CAU 544.”

\section{B.2.1 Planning Team Members}

The DQO planning team consists of representatives from NDEP and NNSA/NSO. The planning team met on April 27, 2010, for the DQO meeting.

\section{B.2.2 Conceptual Site Model}

The CSM is used to organize and communicate information about site characteristics. It reflects the best interpretation of available information at a point in time. The CSM is a primary vehicle for communicating assumptions about release mechanisms, potential migration pathways, or specific constraints. It provides a summary of how and where contaminants are expected to move and what impacts such movement may have. It is the basis for assessing how contaminants could reach receptors both in the present and future. The CSM describes the most probable scenario for current conditions at each site and defines the assumptions that are the basis for identifying appropriate sampling strategy and data collection methods. An accurate CSM is important as it serves as the basis for all subsequent inputs and decisions throughout the DQO process.

The CSM was developed for CAU 544 using information from the physical setting, potential contaminant sources, release information, historical background information, knowledge from similar sites, and physical and chemical properties of the potentially affected media and COPCs.

The CSM consists of:

- $\quad$ Potential contaminant releases, including media subsequently affected. 
- Release mechanisms (the conditions associated with the release).

- Potential contaminant source characteristics, including contaminants suspected to be present and contaminant-specific properties.

- Site characteristics, including physical, topographical, and meteorological information.

- Migration pathways and transport mechanisms that describe the potential for migration and where the contamination may be transported.

- The locations of points of exposure where individuals or populations may come in contact with a COC associated with a CAS.

- Routes of exposure where contaminants may enter the receptor.

If additional elements are identified during the CAI that are outside the scope of the CSM, the situation will be reviewed and a recommendation will be made as to how to proceed. In such cases, NDEP and NNSA/NSO will be notified and given the opportunity to comment on, and concur with, the recommendation.

The applicability of the CSM to mud pits and cellars, and oil/waste spills is summarized in Table B.2-1 and discussed below. Table B.2-1 provides information on CSM elements that will be used throughout the remaining steps of the DQO process. Figure B.2-1 represents site conditions applicable to the CSM.

\section{B.2.2.1 Contaminant Release}

Releases of contamination to the environment at the oil/waste spills are to the soils directly below or adjacent to the spill location. Any contaminants migrating from spills, regardless of physical or chemical characteristics, are expected to exist at interfaces, and in the soil adjacent to disposal features in lateral and vertical directions.

The radiologically impacted mud pits and cellars in the CASs of CAU 544 are suspected to contain contaminated media generated by activities associated with nuclear testing. The current radiological postings serve as the indication for identifying the radiologically impacted CASs or CAS components. 
Table B.2-1

Conceptual Site Model Description of Elements for Each CAS Feature in CAU 544 (Page 1 of 3 )

\begin{tabular}{|c|c|}
\hline CAU Description & Cellars, Mud Pits, and Oil Spills \\
\hline Site Status & Sites are inactive and/or abandoned \\
\hline Exposure Scenario & Occasional Use \\
\hline $\begin{array}{l}\text { Sources of Potential } \\
\text { Soil Contamination }\end{array}$ & $\begin{array}{l}\text { Mud Pit: Primary source for radiological contamination is a release of drilling mud } \\
\text { associated with post-test drilling activities subsequent to underground nuclear testing. } \\
\text { Other contributors to contamination may include a release of radiological effluents from } \\
\text { an underground test or fallout from an atmospheric test. Organic or inorganic } \\
\text { contamination is not expected at mud pits. Radioactive contamination may be expected at } \\
\text { radiologically posted mud pits. All non-posted mud pits are not expected to contain } \\
\text { radiological contamination. } \\
\text { Cellar: Primary source for chemical contamination is a direct release of drill rig fluids } \\
\text { (hydraulic fluid, oils, greases, diesel fuel). Other contributors may include the } \\
\text { decontamination of drilling equipment over the cellar cavity or discarding of potentially } \\
\text { hazardous drilling materials. The primary source for radiological contamination is an } \\
\text { accidental release of contaminated drilling mud via spills, or leaks from drilling hoses or } \\
\text { tubing. Other contributors may include a release of radiological effluents from an } \\
\text { underground test or fallout from an atmospheric test. } \\
\text { Oil/Waste Spill: Primary source for chemical contamination is a direct release of oil/waste } \\
\text { to environmental media. }\end{array}$ \\
\hline $\begin{array}{l}\text { Location of } \\
\text { Contaminationl } \\
\text { Release Point }\end{array}$ & $\begin{array}{l}\text { Mud Pit: Residual drilling mud contained within the boundaries of the radiologically posted } \\
\text { mud pit walls/berms. If a backfilled mud pit, the mud would be located directly beneath the } \\
\text { cover material (typically } 4-5 \mathrm{ft} \text { bgs). } \\
\text { Cellar: Surface and shallow subsurface soils at the base of the cellar } \\
\text { (typically } 10-12 \mathrm{ft} \text { bgs) contained within the boundaries of the corrugated metal casing } \\
\text { (typically } 10 \mathrm{ft} \text { in diameter). } \\
\text { Oil/Waste Spill: Surface and shallow subsurface soils. }\end{array}$ \\
\hline Amount Released & Unknown \\
\hline Affected Media & $\begin{array}{l}\text { Mud Pit: Residual mud contained in the boundaries of the radiologically posted mud pits. } \\
\text { Underlying soils are not expected to have been affected due to properties of drilling mud. } \\
\text { Cellar: Surface and shallow subsurface soil at the base of the cellar. } \\
\text { Oil/Waste Spill: Surface and shallow subsurface soil underlying the spill. }\end{array}$ \\
\hline $\begin{array}{c}\text { Potential } \\
\text { Contaminants }\end{array}$ & $\begin{array}{l}\text { Mud Pit: Limited to radionuclides (gamma emitters, isotopic U, isotopic Pu, and Sr-90) } \\
\text { only at radiologically posted mud pits. } \\
\text { Cellar: Contaminants include VOCs, SVOCs, PCBs, metals, and radionuclides } \\
\text { (gamma emitters, isotopic U, isotopic Pu, and Sr-90). } \\
\text { Oil/Waste Spill: Contaminants include VOCs, SVOCs, PCBs, and metals. }\end{array}$ \\
\hline
\end{tabular}


Table B.2-1

Conceptual Site Model Description of Elements for Each CAS Feature in CAU 544 (Page 2 of 3)

\begin{tabular}{|c|c|}
\hline CAU Description & Cellars, Mud Pits, and Oil Spills \\
\hline $\begin{array}{c}\text { Transport } \\
\text { Mechanisms }\end{array}$ & $\begin{array}{l}\text { - Infiltration and percolation of precipitation through affected media serves as the major } \\
\text { driving force for contamination to migrate vertically. Due to the low precipitation and } \\
\text { high evaporation rates of the arid environment, percolation of infiltrated precipitation is } \\
\text { limited and is not considered a significant mechanism regarding the transport of } \\
\text { contaminants to groundwater. } \\
\text { - Lateral transportation of some contaminants may occur as a result of surface water } \\
\text { runoff or overflow of surface water accumulated in the mud pits and cellars. } \\
\text { - Evaporation of volatile components may release contaminants to the air. } \\
\text { - Wind blowing over open mud pits, cellars, and spills may resuspend contaminated } \\
\text { surface soil particles. }\end{array}$ \\
\hline Migration Pathways & $\begin{array}{l}\text { - Vertical migration of contaminants through the affected media is considered } \\
\text { insignificant due to the arid climate of the NTS. Cover material for backfilled mud pits } \\
\text { and cellars could also significantly prevent percolation of precipitation as a driving } \\
\text { force. Also, vertical migration of contaminants through drilling mud into the underlying } \\
\text { soil is not expected due to the physical properties of the drilling mud. } \\
\text { - Without a breach in the berms of a mud pit, or a large rainfall event that would cause } \\
\text { overtopping of the mud pit or cellar, potential lateral migration or overland flow is } \\
\text { considered to be limited. } \\
\text { - Evaporation as a migration pathway would only be applicable to open cellars and } \\
\text { oil/waste spills; however, this pathway is considered insignificant because the volatile } \\
\text { components of TPH are expected to have weathered away. Contaminants of potential } \\
\text { concern for mud pits do not include vapor phases. Previous sampling has eliminated } \\
\text { VOCs and SVOCs as COPCs for mud pits. } \\
\text { - Wind transport of resuspended particles is considered an insignificant pathway } \\
\text { because the affected media in mud pits and cellars is protected by berms and } \\
10-12 \mathrm{ft} \text { bgs metal casing, respectively. A release of contaminants to the air is not } \\
\text { considered a complete migration pathway for mud pits and cellars that have been } \\
\text { backfilled because the affected media is covered. Wind transport of resuspended } \\
\text { particles could be a potential pathway for the oil/waste spills. }\end{array}$ \\
\hline $\begin{array}{l}\text { Lateral and Vertical } \\
\text { Extent of } \\
\text { Contamination }\end{array}$ & $\begin{array}{l}\text { Mud Pit: The lateral extent of contamination in mud pits is expected to be limited to the } \\
\text { walls/berms of the mud pit unless there is a noticeable breach that would allow for } \\
\text { overland transport. The vertical extent of potential contamination at a mud pit is expected } \\
\text { to be bound within the residual mud and would not be expected to migrate vertically } \\
\text { downward into the underlying soil. } \\
\text { Cellar: The lateral extent of contamination in cellars is expected to be limited by the metal } \\
\text { casing that surrounds the cellar cavity. The lateral extent of contamination of the oil/waste } \\
\text { spills is expected to be contiguous to the release points. The vertical extent of potential } \\
\text { contamination in the affected media of a cellar is not expected to infiltrate more than a few } \\
\text { inches below the base of cellar, if at all. } \\
\text { Oil/Waste Spill: The vertical extent of potential contamination in the affected media at the } \\
\text { oil/waste spills is dependent upon the soil type immediately below the spill. Lateral and } \\
\text { vertical extent of COC contamination is assumed to be within the spatial boundaries. } \\
\text { Groundwater contamination is not expected because depth to groundwater varies } \\
\text { between } 725 \text { to } 3,100 \mathrm{ft} \text { bgs and averages approximately } 800 \mathrm{ft} \text { bgs } \\
\text { (USGS and DOE, 2009). }\end{array}$ \\
\hline
\end{tabular}


Table B.2-1

Conceptual Site Model Description of Elements for Each CAS Feature in CAU 544 (Page 3 of 3 )

\begin{tabular}{|c|l||}
\hline CAU Description & \multicolumn{1}{|c|}{ Cellars, Mud Pits, and Oil Spills } \\
\hline \hline Exposure Pathways & $\begin{array}{l}\text { The potential for contamination exposure is limited to industrial and construction } \\
\text { workers, and military personnel conducting training. These human receptors may be } \\
\text { exposed to COPCs through oral ingestion, inhalation, or dermal contact (absorption) of } \\
\text { soil and/or debris due to inadvertent disturbance of these materials, or irradiation by } \\
\text { radioactive materials. }\end{array}$ \\
\hline
\end{tabular}

There have been no inorganic or organic COPCs identified for NTS mud pits based on the conclusions of the RBCSR (NNSA/NSO, 2004) and the available documentation from the investigation of CAUs 530-535, Mud Pits (NNSA/NSO, 2006a). Results of the RBCSR have eliminated VOCs, SVOCs, PCBs, and metals as COPCs from NTS mud pits based on the conclusion that there is no analytical or process knowledge to suggest these constituents are present at significant concentrations in residual mud. Although TPH was detected in about 22 percent of the mud pits studied, the risk assessment concluded that TPH would not pose an unacceptable risk to human health or the environment. The CAUs 530-535 investigation verified that concentrations of TPH-DRO typically found in mud pits do not pose an unacceptable risk to human health or the environment, and therefore, it is eliminated as a COPC for CAU 544 mud pits.

For mud pits that are located in areas or craters that have not been impacted by radiological releases, no COPCs are identified. The RBCSR (NNSA/NSO, 2004) stated that based on process knowledge and previous sampling, these mud pits contained no COCs. The SAFER effort for CAUs 530-535 (NNSA/NSO, 2005) confirmed that there are no COCs present in the mud pits not impacted by radiological releases. It further recommended that if additional mud pits are identified that meet the established criteria, they should be closed and moved to FFACO Appendix IV without further investigation. The criteria are detailed in these reports, but in summary, include the following:

- The CAS is a single mud pit or a system of mud pits.

- The mud pit CAS is located in an area that is not radiologically posted (e.g., contaminated area, RMA, URMA).

- There are no biasing factors such as hydrocarbon staining or hazardous debris (e.g., lead bricks). 


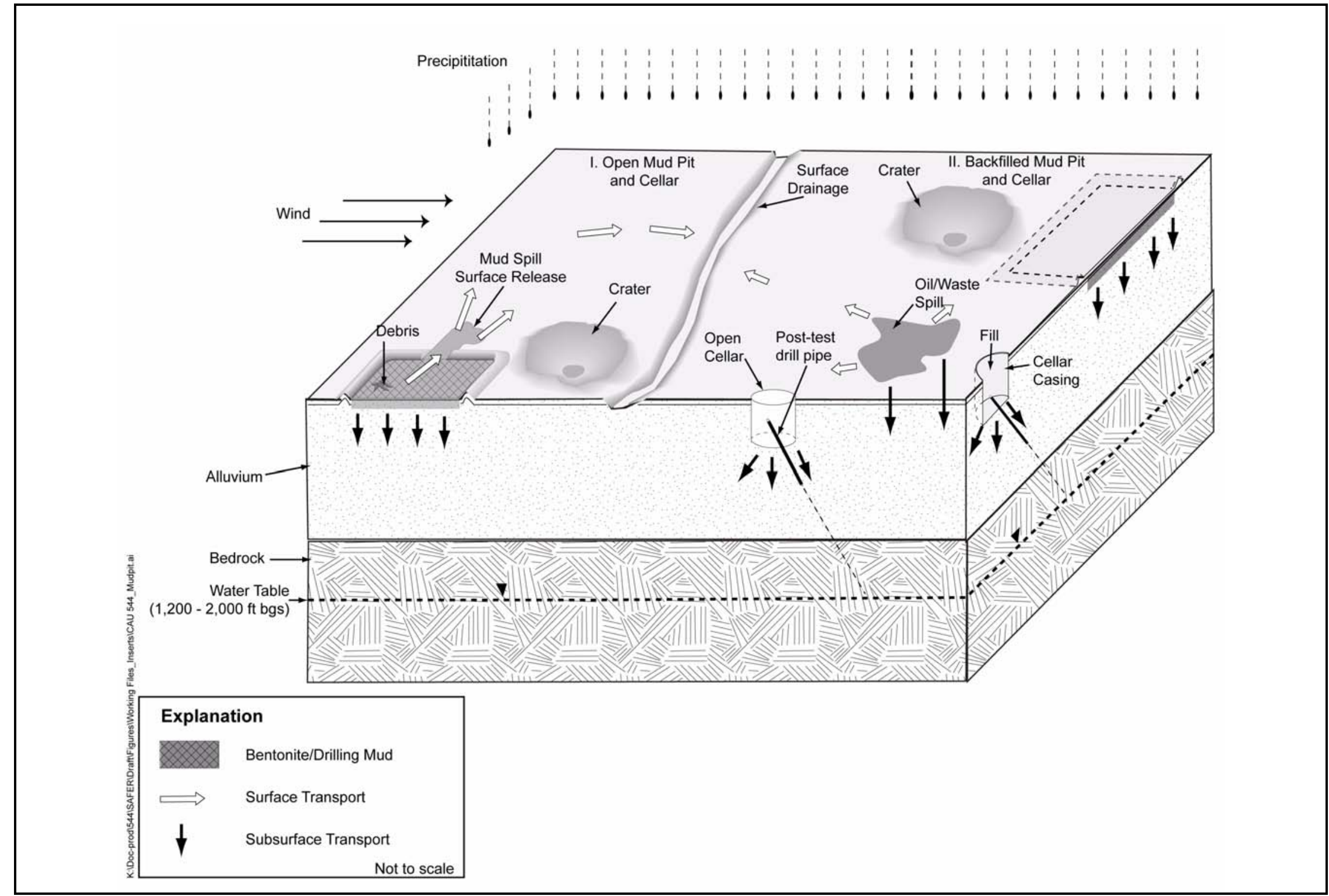

Figure B.2-1

Conceptual Site Model for CAU 544 CASs

UNCONTROLLED When Printed 
Based on the CAUs 530-535 approach, which has been reviewed and accepted by NDEP, all mud pits within CAU 544 that are single or systems of mud pits not located in radiologically posted area and have no visible biasing factors will be closed under the NFA alternative and promoted from Appendix III to Appendix IV of the FFACO without further sampling.

The only mud pits that would potentially be sampled would be any mud pit CAS within a radiologically posted area that can be accessed safely. This means that if a mud pit is in a crater and there has not been any study done on the crater to demonstrate its stability, an acceptable stability study must be completed and access to the crater authorized before any sampling activity may begin. If the stability study cannot be accomplished or results in a determination that the crater is unstable and thus shall not be entered, the mud pit will be closed with a use restriction and no sampling will be conducted.

Because complete information regarding activities performed at the CAU 544 cellars is not available, chemical constituents will be included as COPCs in addition to radionuclides to fully characterize cellars and reduce uncertainty.

The process associated with potential contamination at a mud pit is different from the process that may have contributed to contamination at a cellar or an oil/waste spill. Therefore, the following sections will address the release of contaminants associated with each feature separately.

\section{B.2.2.1 Mud Pits}

The primary source of potential radiological contamination is the release of drilling mud that may have been in contact with radioactive rock and circulated from the borehole to the mud pit during post-test drilling. The locations for a release of drilling mud are at the base of the excavated mud pit or at drilling mud spills adjacent to the pits. The media affected by a release is typically the surface and shallow subsurface soil; however, due to the binding properties of bentonite, contamination is expected to be bound within the mud with no migration to the native soil adjacent to the floor and walls of the mud pits. Contamination, if any, is expected to be evenly dispersed and present at relatively uniform concentrations because the mud was homogenized as it was circulated. This suggests that surface samples of the residual mud would be representative of the mud throughout the 
depth of the mud pit. Contamination unrelated to the mud pit process may be localized beneath potentially hazardous discarded drilling materials, if present.

\section{B.2.2.1.2 Cellars}

A release of radiological or chemical contaminants to media within a cellar is not expected based on cellar processes; however, contamination, if any, can be attributed to accidental spills and leaks, or materials discarded during drilling activities.

The primary source of a release of radionuclides is suspected to be radiologically contaminated drilling mud that either spilled or leaked into the cellar cavity as a result of careless activities or a failure of the circulation system. Typically, a release of drilling mud to the cellar would not occur because the drilling mud was recirculated from the borehole to the mud pit through a closed system. Although unlikely, another potential contributor to radiological contamination is a release of radiological effluents from underground tests through a vent or fissure, or fallout from an atmospheric test. The primary source of a chemical contaminant release is suspected to be drill rig fluids, such as hydraulic fluid, oils, greases, and potentially diesel fuel, that were directly introduced to the cellar cavity through either spills or leaks, decontamination of drilling equipment over the cellar cavity, or discarded drilling materials. The organic components of these materials would show up in the analyses as VOCs, SVOCs, PCBs, and TPH. If TPH is detected, the source may be either from drilling fluid known to contain diesel fuel as an additive (DOE/NV, 2001; NNSA/NSO, 2004), or from fluids associated with the drill rig as described above.

A release of either radiological or chemical contamination is expected to be located at the base of the cellar (typically 10 to $12 \mathrm{ft}$ bgs) and contained within the boundaries of the corrugated metal casing (typically $10 \mathrm{ft}$ in diameter). The affected media is expected to be the surface and shallow subsurface soil at the cellar bottom. Soil outside the cellar casing is not expected to have been impacted because the casing acts as a barrier to contaminant migration. In the event of a release immediately adjacent to the cellar, the concrete foundation that surrounds the cellar casing would provide a barrier to contaminants migrating into the underlying soil. Contamination, if present, is expected to be 
contiguous to the respective release locations described for cellars and is expected to decrease with horizontal and vertical distance from the source.

\section{B.2.2.2 Potential Contaminants}

Based on the results of the RBCSR and the sampling results from CAUs 530-535, single mud pits or two-mud-pit systems that are not within radiologically posted areas and that have no visible biasing factors are not considered contaminated, and therefore, will not be sampled during this effort. The mud pit sampling will be limited to the mud pits that are within radiologically posted areas (CASs 02-37-09 and 09-09-46). The COPCs were identified during the planning process through the review of site history, process knowledge, personal interviews, past investigation efforts (where available), and inferred activities associated with the CASs. Because complete information regarding activities performed at the CAU 544 cellars is not available, contaminants detected at similar NTS sites were included in the list of contaminants to reduce uncertainty. The list of COPCs is intended to encompass all of the contaminants that could potentially be present at each cellar CAS. The COPCs applicable to both Decision I and Decision II environmental samples from each of the CASs of CAU 544 are defined as the constituents reported from the analytical methods stipulated in Table B.2-2.

During the review of site history documentation, process knowledge information, personal interviews, past investigation efforts (where available), and inferred activities associated with the CASs, some of the COPCs were identified as targeted contaminants at specific CASs. Targeted contaminants are those COPCs for which evidence in the available site and process information suggests that they may be reasonably suspected to be present at a given CAS. The targeted contaminants are required to meet more stringent completeness criteria than other COPCs, thus providing greater protection against a decision error (see Section B.7.1). Targeted contaminants for each CAU 544 feature are identified in Table B.2-3. 
Table B.2-2

Analytical Program ${ }^{\mathrm{a}}$

\begin{tabular}{|c|c|c|c|}
\hline Analyses $^{b}$ & Mud Pit & Cellar & Oil/Waste Spil \\
\hline \multicolumn{4}{|c|}{ Organic COPCs } \\
\hline TPH-DRO ${ }^{\mathrm{C}}$ & -- & $x$ & $x$ \\
\hline PCBs & -- & $x$ & $x$ \\
\hline SVOCs $^{b}$ & -- & $x$ & $x$ \\
\hline VOCs $^{b}$ & -- & $x$ & $x$ \\
\hline \multicolumn{4}{|c|}{ Inorganic COPCs } \\
\hline Total RCRA Metals ${ }^{b}$ & -- & $X$ & $X$ \\
\hline \multicolumn{4}{|c|}{ Radionuclide COPCs } \\
\hline Gamma Spectroscopy $^{d}$ & $\mathrm{X}$ & $x$ & $\mathrm{X}$ \\
\hline Isotopic $U^{d}$ & $x$ & $x$ & -- \\
\hline Isotopic $\mathrm{Pu}^{\mathrm{d}}$ & $x$ & $x$ & -- \\
\hline $\operatorname{Sr}-90^{d}$ & $x$ & $x$ & -- \\
\hline
\end{tabular}

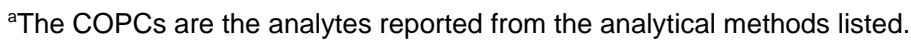

${ }^{b}$ May also include TCLP analytes if sample is collected for waste management purposes.

${ }^{\mathrm{C}} \mathrm{TPH}-\mathrm{DRO}$ analyses are for waste management purposes only.

${ }^{\mathrm{d}}$ Results of gamma analysis will be used to determine whether further isotopic analysis is warranted.

$X=$ Required analytical method

$--=$ Analyses will not be performed at this feature

Table B.2-3

Targeted Contaminants for CAU 544

\begin{tabular}{|c|c|c|}
\hline Feature & $\begin{array}{c}\text { Chemical } \\
\text { Targeted Contaminants }\end{array}$ & $\begin{array}{c}\text { Radiological } \\
\text { Targeted Contaminants }\end{array}$ \\
\hline \hline Mud Pit ${ }^{\mathrm{a}}$ & None & Gamma emitters, Sr-90, Isotopic U, Isotopic Pu \\
\hline Cellar & VOCs, SVOCs & None \\
\hline Oil/Waste Spill & VOCs, SVOCs & None \\
\hline
\end{tabular}

${ }^{a}$ Only mud pits in radiologically impacted areas will have targeted radiological contaminants. 


\section{B.2.2.3 Contaminant Characteristics}

Contaminant characteristics include, but are not limited to, solubility, density, and adsorption potential. In general, contaminants with large particle size, low solubility, high affinity for media, and/or high density can be expected to be found relatively close to release points. Contaminants with small particle size, high solubility, low affinity for media, and/or low density are found further from release points or in low areas where evaporation of ponding will concentrate dissolved contaminants.

\section{B.2.2.4 Site Characteristics}

Site characteristics are defined by the interaction of physical, topographical, and meteorological attributes and properties.

Physical properties include permeability, porosity, hydraulic conductivity, degree of saturation, sorting, chemical composition, and organic content. The mud pit CASs will have low permeability, porosity, hydraulic conductivity, and organic content due to the presence of bentonite in the drilling fluid. Additional information regarding the physical properties is not necessary for this investigation because contaminant fate and transport modeling has been completed previously (Appendix A, NNSA/NSO, 2004).

Topographical and meteorological properties and attributes include slope stability, precipitation frequency and amounts, runoff pathways, drainage channels and ephemeral streams, and evapotranspiration potential. This information is used to quantify the amount of infiltration expected at the mud pits. While the amount of infiltration generated at any specific mud pit is unknown, it is expected to be minimal because of the physical properties of bentonite as well as the low precipitation and high evapotranspiration rates common at the NTS.

The annual potential evapotranspiration at the Area 3 Radiological Waste Management Site has been estimated at 62.6 in. (Shott et al., 1997), but the annual precipitation for southern Nevada is between 3.5 and 6 in. (Winograd and Thordarson, 1975).

Groundwater contamination is not considered a likely scenario at any CAS based on the depth to groundwater in Areas 2, 7, 9, 10, 12, 19, and 20. Data from nearest wells indicate that groundwater 
levels may range from 725 to 1,725 ft bgs for the CASs in Areas 2, 9, and 10; average approximately 1,915 ft bgs for the Area 7 CAS; range from 1,520 to 3,100 ft bgs for the Area 12 CAS; average approximately 2,240 ft bgs for the Area 19 CASs; and range from 860 to 2,100 ft bgs for the Area 20 CASs (USGS and DOE, 2009). Surface migration is not expected to be significant because the engineered structure of a mud pit and cellar would limit surface migration to within the physical barriers (i.e, mud pit berms and cellar casing).

\section{B.2.2.5 Migration Pathways and Transport Mechanisms}

An important element of the CSM is the expected fate and transport of contaminants (i.e., how contaminants migrate through media and where they can be expected in the environment). Fate and transport of contaminants are presented in the CSM as the migration pathways and transport mechanism that could potentially move the contaminants vertically and laterally throughout the various media. The pathways include air, surface water, and groundwater, and are the routes through which possible contamination could migrate from the site(s) to locations where a receptor might receive an exposure. Fate and transport are influenced by physical and chemical characteristics of the contaminants and media described in Sections B.2.2.3 and B.2.2.4. For the mud pits and cellars, given the characteristics of both the contaminants and the bentonite drilling mud, contaminant migration is expected to be limited.

Infiltration and percolation of precipitation serves as a driving force for the downward vertical migration of contaminants through the mud or underlying soil in the mud pits and cellars, and oil/waste spills. Based on the high evaporation and low precipitation typical of the Mojave Desert, percolation of infiltrated precipitation at the NTS does not provide a significant mechanism for vertical migration of contaminants to groundwater (DOE/NV, 1992; NNSA/NSO, 2004). Cover material, depending on its thickness, for backfilled mud pits and cellars could significantly diminish infiltration and percolation of precipitation as a driving force for vertical migration of contaminants in the affected media. Also, if present, the concrete floor of a cellar would limit infiltration.

Lateral migration of contaminants through impacted media is expected to be limited to within the physical boundaries of the mud pits and cellars, identified as the walls/berms and metal casing, 
respectively. Lateral migration may occur as a result of overland flow or erosion and is dependent on the integrity of the mud pit berms and the depth to the base of the excavated cellar. Without a breach in the berm or a large rainfall event that would cause overtopping of the berm, lateral migration through media contained in or surrounding mud pits is expected to be insignificant. Similarly, without a large rainfall event that would cause the cellar cavity to be filled with water and overflow, lateral migration through media contained in or surrounding cellars is not expected. Lateral migration of contaminants through the soil from beneath the cellar casing (i.e., 10 to $12 \mathrm{ft}$ bgs) is possible; however, vertical migration would dominate due to infiltration of precipitation through the soil. Also, there applicable, the process of backfilling mud pits and cellars following the completion of drilling activities, or plug-back activities, would further limit the potential of lateral migration due to lack of a driving force. Lateral migration of contaminants at the oil/waste spills is dependent upon the soil type underlying the spill, and the contamination is expected to be found relatively close to the release point.

Releases to the air may result from resuspension of contaminated surface soil particles with wind movement, or evaporation of the volatile components of TPH in regard to the cellars and oil spills. Wind could potentially suspend surface soil particles and carry them beyond the boundaries of the mud pits, cellars, and spills. However, the mud pits were typically constructed by excavating native soils and creating a protective berm that surrounds the mud pits and reduces the potential for wind to disturb the mud pit surface. Similarly, the soil at the base of open cellars is protected by the metal casing located approximately 10 to $12 \mathrm{ft}$ bgs, thereby reducing the potential for wind disturbance. In regard to the open cellars and spills, given the fact that they have been weathered for many years, it is highly unlikely that evaporation of TPH components is a significant migration pathway. A release of contaminants to the air is not considered an active transport mechanism for mud pits and cellars that have been backfilled because the overlying fill would prevent the resuspension of impacted media. Overall, airborne migration of contaminants is considered a minor transport mechanism for CAU 544. 


\section{B.2.2.6 Exposure Scenarios}

Human receptors may be exposed to COPCs through oral ingestion, inhalation, or dermal contact (absorption) of drilling mud, soil, or debris due to inadvertent disturbance of these materials, or irradiation by radioactive materials. The land-use and exposure scenarios for the CAU 544 CASs are listed in Table B.2-4. These are based on NTS current and future land use (DOE/NV, 1998). All the CAU 544 CASs are at remote locations without any site improvements and where no regular work is performed. There is still the possibility, however, that site workers could occupy these locations on an occasional and temporary basis such as a military exercise. Therefore, these sites are classified as occasional work areas.

Table B.2-4

\section{Land Use and Exposure Scenarios}

\begin{tabular}{|c|c|c|}
\hline CAS & Record of Decision Land Use Zone & Exposure Scenario \\
\hline $\begin{array}{l}02-37-08 \\
02-37-09 \\
12-09-03\end{array}$ & $\begin{array}{l}\text { Nuclear and High Explosives Test } \\
\text { This area is designated within the Nuclear Test Zone } \\
\text { for additional underground nuclear weapons tests and } \\
\text { outdoor high-explosive tests. This zone includes } \\
\text { compatible defense and nondefense research, } \\
\text { development, and testing activities. }\end{array}$ & $\begin{array}{l}\text { Occasional Use Area } \\
\text { Worker will be exposed to the site occasionally } \\
\text { (up to } 80 \text { hours per year for } 5 \text { years). Site } \\
\text { structures are not present for shelter and } \\
\text { comfort of the worker. }\end{array}$ \\
\hline $\begin{array}{l}07-09-01 \\
09-09-46 \\
10-09-01 \\
19-09-01 \\
19-09-03 \\
19-09-04 \\
19-25-01 \\
19-99-06 \\
20-09-01 \\
20-09-02 \\
20-09-03 \\
20-09-04 \\
20-09-06 \\
20-09-07 \\
20-09-10 \\
20-25-04 \\
20-25-05\end{array}$ & $\begin{array}{l}\text { Nuclear Test } \\
\text { This area is reserved for dynamic experiments, } \\
\text { hydrodynamic tests, and underground nuclear } \\
\text { weapons and weapons effects tests. This zone } \\
\text { includes compatible defense and nondefense } \\
\text { research, development, and testing activities. }\end{array}$ & $\begin{array}{l}\text { Occasional Use Area } \\
\text { Worker will be exposed to the site occasionally } \\
\text { (up to } 80 \text { hours per year for } 5 \text { years). Site } \\
\text { structures are not present for shelter and } \\
\text { comfort of the worker. }\end{array}$ \\
\hline
\end{tabular}




\section{B.3.0 Step 2 - Identify the Goal of the Study}

Step 2 of the DQO process states how environmental data will be used in meeting objectives and solving the problem, identifies study questions or decision statement(s), and considers alternative outcomes or actions that can occur upon answering the question(s). Figure B.3-1 depicts the sequential flow of questions, answers, and action alternatives required to fulfill the objectives of the SAFER process.

\section{B.3.1 Decision Statements}

The Decision I statement is: “Is any COC present in environmental media within the CAS?” For judgmental sampling design, any analytical result for a COPC above the FAL will result in that COPC being designated as a COC. For probability (random) sampling design, any COPC that has a 95 percent UCL of the average concentration above the FAL will result in that COPC being designated as a COC. A COC may also be defined as a contaminant that, in combination with other like contaminants, is determined to jointly pose an unacceptable risk based on a multiple contaminant analysis (NNSA/NSO, 2006b). If a COC is detected, then Decision II must be resolved.

The Decision II statement is: "If a COC is present, is sufficient information available to meet the closure objectives?” Sufficient information is defined to include:

- Identifying the volume of media containing any COC bounded by analytical sample results in lateral and vertical directions.

- The information needed to characterize remediation wastes and IDW for disposal.

- The information needed to evaluate the feasibility of potential closure options.

The presence of a COC would require a corrective action. A corrective action may also be necessary if there is a potential for wastes that are present at a site to impose COCs into site environmental media if the wastes were to be released. To evaluate the potential for site wastes to result in the introduction of a COC to the surrounding environmental media, the following conservative assumptions were made: 


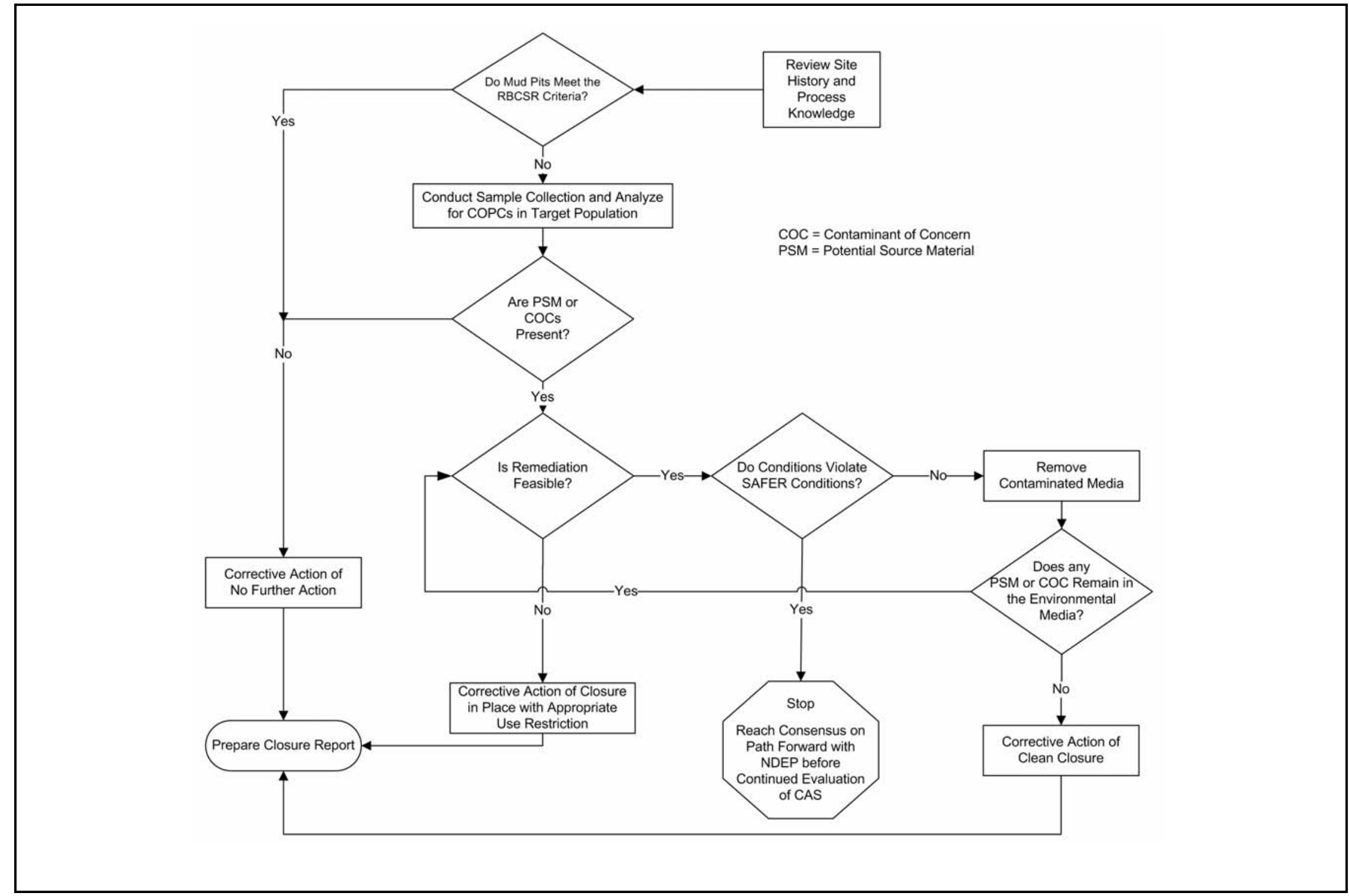

Figure B.3-1

SAFER Closure Decision Process for CAU 544 CASs 
- Any containment of the wastes would fail at some point and the wastes would be released to the surrounding media.

- The resulting concentration of contaminants in the surrounding media would be equal to the concentration of contaminants in the waste.

- For non-liquid wastes, the concentration of any chemical contaminant in soil (following degradation of the waste and release of contaminants into soil) would be equal to the mass of the contaminant in the waste divided by the mass of the waste.

- For liquid wastes, the resulting concentration of contaminants in the surrounding soil would be calculated based on the concentration of contaminants in the wastes and the liquid-holding capacity of the soil.

If sufficient information is not available to meet the closure objectives, then site conditions will be re-evaluated and additional samples will be collected (as long as the scope of the CAI is not exceeded and any CSM assumption has not been shown to be incorrect).

\section{B.3.2 Alternative Actions to the Decisions}

This section identifies actions that may be taken to solve the problem depending on the possible outcomes of the investigation.

\section{B.3.2.1 Alternative Actions to Decision I}

If no COC associated with a release from the CAS is detected, then further assessment of the CAS is not required and the CAA of NFA will be selected. If a COC associated with a release from the CAS is detected, then additional sampling will be conducted to determine the extent of COC contamination.

\section{B.3.2.2 Alternative Actions to Decision II}

If sufficient information is available to define the extent of COC contamination and confirm that closure objectives were met, then further assessment of the CAS is not required. If sufficient information is not available to define the extent of contamination or confirm that closure objectives were met, then additional samples will be collected until the extent is defined. 
If the extent of the contamination is defined and additional remediation can be accomplished, then clean close the site by removing the contaminated media until all contamination has been removed. If the extent of contamination has been determined and additional remediation cannot be accomplished during the SAFER, then the extent of contamination will be defined and the contaminated area will be closed in place with appropriate URs.

If the collection of verification samples confirms that all the contaminated media has been removed, then the clean closure objectives will have been met. If contamination still exists and additional remediation would violate the conditions of the SAFER, then work will stop and a consensus will be reached with NDEP on the path forward before the investigation of the CAS may resume. 


\section{B.4.0 Step 3 - Identify Information Inputs}

Step 3 of the DQO process identifies the information needed, determines sources for information, and identifies sampling and analysis methods that will allow reliable comparisons with FALs.

\section{B.4.1 Information Needs}

To resolve Decision I (determine whether a COC is present at a given CAS), samples need to be collected and analyzed following these two criteria:

- Samples must either (a) be collected in areas most likely to contain a COC (judgmental sampling) or (b) properly represent contamination at the CAS (probabilistic sampling).

- The analytical suite selected must be sufficient to identify any COCs present in the samples.

To resolve Decision II (determine whether sufficient information is available to confirm that closure objectives were met at each CAS), samples must be collected and analyzed to meet the following criteria:

- Samples must be collected in areas contiguous to the contamination but where contaminant concentrations are below FALs.

- Samples of the waste or environmental media must provide sufficient information to characterize remediation wastes or IDW for disposal.

- Samples of the waste must provide sufficient information to determine whether PSM is present.

- The analytical suites selected must be sufficient to detect contaminants at concentrations equal to or less than their corresponding FALs.

\section{B.4.2 Sources of Information}

Information to satisfy Decision I and Decision II will be generated by collecting environmental samples using grab sampling, backhoe excavation, or other appropriate sampling methods. These samples will be submitted to analytical laboratories meeting the quality criteria stipulated in the Industrial Sites QAPP (NNSA/NV, 2002). Only validated data from analytical laboratories will 
be used to make DQO decisions. Sample collection and handling activities will follow standard procedures.

\section{B.4.2.1 Sample Locations}

Design of the sampling approaches for the CAU 544 CASs must ensure that the data collected are sufficient for selection of the CAAs (EPA, 2002b). To meet this objective, the samples collected from each site should be from locations that either (1) most likely contain a COC, if present (judgmental), or (2) properly represent any contamination at the CAS (probabilistic).

A judgmental sampling approach will be implemented for all cellars and oil/waste spills, and for mud pits if biasing factors are identified. Biasing factors (including field screening results [FSRs]) will be used to select the most appropriate samples from a particular location for submittal to the analytical laboratory. Biasing factors to be used for selection of sampling locations are listed in Section B.4.2.1.1. Sample locations may be modified based on site conditions, obvious debris or staining of soils, FSRs, or professional judgment if the modified locations meet the DQO decision needs and criteria stipulated. As biasing factors are identified and used for selection of sampling locations, they will be recorded in the appropriate field documents.

A probabilistic sampling approach will be implemented for the radiologically impacted mud pits. Sample locations at mud pits are specified by the process presented in Appendix C, which reviews the methodology and computational approach for probabilistic sampling and lists the sample size and locations as calculated by the VSP software program (PNNL, 2007).

The following subsections discuss how judgmental and probabilistic approaches are each implemented in selecting sample locations for CAU 544.

\section{B.4.2.1.1 Judgmental Approach for Sample Location Selection}

Decision I sample locations at cellars and oil/waste spills, and where applicable, at mud pits, will be determined based upon the likelihood of the soil containing a COC, if present. These locations will be selected based on field-screening techniques, biasing factors, the CSM, and existing information. Analytical suites for Decision I samples will include all COPCs identified in Table B.2-2. 
Field-screening techniques may be used to select appropriate sampling locations by providing semiquantitative data that can be used to comparatively select samples to be submitted for laboratory analyses from several screening locations. The following field-screening method may be used to select biased sample locations at CAU 544:

- Walkover surface area radiological surveys: A radiological survey instrument may be used as permitted by terrain and field conditions to detect locations of elevated radioactivity.

Biasing factors may also be used to select samples to be submitted for laboratory analyses based on existing site information and site conditions discovered during the investigation. The following biasing factors will be considered in selecting locations for analytical samples at CAU 544:

- Documented process knowledge on source and location of release (e.g., volume of release).

- Stains: Any spot or area on the soil surface.

- Elevated radiation: Any location identified during radiological surveys that had alpha/beta/gamma levels significantly higher than surrounding background soil.

- Geophysical anomalies: Any location identified during geophysical surveys that had results indicating surface or subsurface materials existed, and were not consistent with the natural surroundings (e.g., buried concrete or metal, surface metallic objects).

- Drums, containers, equipment, or debris: Materials that may have contained or come in contact with hazardous or radioactive substances at some point during their use.

- Previous sample results from the site being investigated.

- Visual indicators such as textural discontinuities, disturbance of native soils, or any other indication of potential contamination.

- Other biasing factors: Factors not previously defined for the CAI, but become evident once the investigation of the site is under way.

Decision II sample step-out locations will be selected based on the CSM, biasing factors, and existing data. Analytical suites will include those parameters that exceeded FALs (i.e., COCs) in prior samples. 


\section{B.4.2.1.2 Probabilistic Approach for Sample Location Selection}

Decision I sample locations at radiologically impacted mud pits will be selected using a probabilistic approach. For each mud pit, sample locations will be randomly chosen using the VSP software (PNNL, 2007) based on a random start, triangular pattern (see Figure B.8-2 for an example of this sampling scheme). If sufficient sample material cannot be collected at a specified location (e.g., rock, caliche, or buried concrete), the SS will move the location to the nearest place where a surface sample can be obtained. Any necessary modification of sample locations will be recorded in the sample collection log and reported in the CR.

\section{B.4.2.2 Analytical Methods}

Analytical methods are available to provide the data needed to resolve the decision statements. The analytical methods and laboratory requirements (e.g., detection limits, precision, and accuracy) are provided in Tables 3-5 and B.2-3. 


\section{B.5.0 Step 4 - Define the Boundaries of the Study}

Step 4 of the DQO process defines the target population of interest and its relevant spatial boundaries, specifies temporal and other practical constraints associated with sample/data collection, and defines the sampling units on which decisions or estimates will be made.

\section{B.5.1 Target Populations of Interest}

The population of interest to resolve Decision I ("Is any COC present in environmental media within the CAS?”) is either (a) any location within the site that is contaminated with any contaminant above a FAL (judgmental sampling) or (b) locations representative of total site contamination (probabilistic sampling). The populations of interest to resolve Decision II ("If a COC is present, is sufficient information available to evaluate potential CAAs?”) are:

- Each one of a set of locations bounding contamination in lateral and vertical directions.

- IDW or environmental media that must be characterized for disposal.

Regardless of the sampling design, the population of interest for this investigation is surface soil defined as (a) the residual drilling fluid contained in a mud pit, (b) potentially impacted soil at the base of a cellar, or (c) potentially impacted soil underlying an oil or waste spill. For uncovered mud pits, the surface soil is defined as 0 to 6 in. in depth. For backfilled mud pits and cellars, the soil to be sampled resides within the first 6 in. directly below the fill material. For oil/waste spills, surface soil is defined as 0 to 6 in. in depth.

Following the approved risk-based approach, soil samples from the surface of the residual drilling fluid are considered sufficient to adequately characterize the risk posed by the mud pits. A review of data from previous mud pit investigations conducted under the complex process has demonstrated that TPH-DRO concentrations in surface soils are representative of the TPH-DRO concentrations throughout the depth of the residual drilling fluid (NNSA/NSO, 2004). The same process would apply to radiological constituents suspected to be present in the residual drilling fluid in the mud pits of CAU 544. In addition, considering future land uses, the surface soil is the primary exposure point 
for future workers. Thus, samples collected from subsurface soils would yield no additional information.

\section{B.5.2 Spatial Boundaries}

Spatial boundaries are the maximum lateral and vertical extent of expected contamination at each CAS, as shown in Table B.5-1. Contamination found beyond these boundaries may indicate a flaw in the CSM and may require re-evaluation of the CSM before the investigation could continue. Each CAS is considered geographically independent, and intrusive activities are not intended to extend into the boundaries of neighboring CASs.

Table B.5-1

Spatial Boundaries of CAU 544 CASs

\begin{tabular}{|c|l||}
\hline Feature & \multicolumn{1}{|c|}{ Spatial Boundaries } \\
\hline \hline Mud Pit & $\begin{array}{l}\text { The lateral boundaries are the walls/berms of each mud pit plus a 50-ft lateral buffer. The vertical } \\
\text { boundary is the depth of residual drilling mud in the mud pit, typically 1-3 } \mathrm{ft} .\end{array}$ \\
\hline Cellar & $\begin{array}{l}\text { The lateral boundary is the corrugated metal casing that lines each cellar, typically 10 } \mathrm{ft} \text { in diameter. } \\
\text { The vertical boundary is defined as 15 } \mathrm{ft} \text { below the base of the cellar. }\end{array}$ \\
\hline Oil/Waste Spill & $\begin{array}{l}\text { The lateral boundary is } 50 \mathrm{ft} \text { from release point. The vertical boundary is defined as 10 } \mathrm{ft} \text { below the } \\
\text { release point. }\end{array}$ \\
\hline
\end{tabular}

\section{B.5.3 Practical Constraints}

Investigation of these CASs may be constrained by a lack of an acceptable stability study for craters, underground utilities, and overhead power lines. Underground utilities will be surveyed at each CAS before starting investigation activities to determine whether utilities exist, and if so, the limit for intrusive activities.

\section{B.5.4 Define the Sampling Units}

The scale of decision making for resolving Decision I and Decision II statements is defined as the individual mud pit, cellar, or spill. This allows for individual mud pits and cellars within a CAS to be closed independent of one another.

For resolving the Decision II statement, the scale of decision making for a cellar or spill is defined as a contiguous area contaminated with any COC likely originating from the cellar or spill. 


\section{B.6.0 Step 5 - Develop the Analytic Approach}

Step 5 of the DQO process specifies appropriate population parameters for making decisions, defines action levels and generates an "If ... then ... else" decision rule that defines the conditions under which possible alternative actions will be chosen. This step also specifies the parameters that characterize the population of interest, specifies the FALs, and confirms that the analytical detection limits are capable of detecting FALs.

\section{B.6.1 Population Parameters}

Population parameters are defined for judgmental and probabilistic sampling designs in the following sections. Population parameters are the values that will be compared to decision criteria in order to resolve the DQO decisions.

\section{B.6.1.1 Judgmental Sampling Design}

For judgmental sampling results, the population parameter is the observed concentration of each contaminant from each individual analytical sample. Each sample result will be compared to the FALs to determine the appropriate resolution to Decision I and Decision II. A single sample result for any contaminant exceeding a FAL would cause a determination that a COC is present within the CAS (for Decision I), or that the COC is not bounded (for Decision II).

\section{B.6.1.2 Probabilistic Sampling Design}

For probabilistic sampling results, the population parameter is the true contaminant concentration of each detected contaminant over the entire contaminant release area. Resolution of DQO decisions associated with the probabilistic sampling design requires determining, with a specified degree of confidence, whether the true contaminant concentration at the site in question exceeds the FAL. Because a measured average contaminant concentration is an estimate of the true (unknown) contaminant concentration, it is uncertain how well the calculated average contaminant concentration represents the true contaminant concentration. If the measured average contaminant concentration were significantly different than the true contaminant concentration, a decision based on the 
measured average contaminant concentration could result in a decision error. To reduce the probability of making a false negative decision error, a conservative estimate of the true contaminant concentration is used to compare to the FAL instead of the measured average contaminant concentration. This conservative estimate (overestimation) of the true contaminant concentration will be calculated as the 95 percent UCL of the average contaminant concentration measurements. By definition, there will be a 95 percent probability that the true contaminant concentration is less than the 95 percent UCL of the measured contaminant concentration.

The computation of appropriate UCLs depends upon the data distribution, the number of samples, the variability of the dataset, and the skewness associated with the dataset. A statistical package will be used to determine the appropriate probability distribution (e.g., normal, lognormal, gamma) and/or a suitable nonparametric distribution-free method and then to compute appropriate UCLs. To ensure that the appropriate UCL computational method is used, the sample data will be tested for goodness-of-fit to all of the parametric and nonparametric UCL computation methods described in Calculating the Upper Confidence Limits for Exposure Point Concentrations at Hazardous Waste Sites (EPA, 2002a).

Computation of an appropriate UCL for each of the calculated contaminant concentration averages requires that:

- A minimum number of samples are collected.

- The data originate from a symmetric, but not necessarily normally distributed, population.

- The estimation of the variability is reasonable and representative of the population being sampled.

- The population values are not spatially correlated.

\section{B.6.2 Action Levels}

The PALs presented in this section are to be used for site screening purposes. They are not necessarily intended to be used as cleanup action levels or FALs. However, they are useful in screening out contaminants that are not present in sufficient concentrations to warrant further 
evaluation and, therefore, streamline the consideration of remedial alternatives. The RBCA process used to establish FALs is described in the Industrial Sites Project Establishment of Final Action Levels (NNSA/NSO, 2006b). This process conforms with NAC Section 445A.227, which lists the requirements for sites with soil contamination (NAC, 2008a). For the evaluation of corrective actions, NAC Section 445A.22705 (NAC, 2008b) requires the use of ASTM Method E1739 (ASTM, 1995) to "conduct an evaluation of the site, based on the risk it poses to public health and the environment, to determine the necessary remediation standards (i.e., FALs) or to establish that corrective action is not necessary."

This RBCA process defines three tiers (or levels) of evaluation involving increasingly sophisticated analyses:

- Tier 1 evaluation - sample results from source areas (highest concentrations) are compared to action levels based on generic (non-site-specific) conditions (i.e., the PALs established in the SAFER Plan). The FALs may then be established as the Tier 1 action levels or the FALs may be calculated using a Tier 2 evaluation.

- Tier 2 evaluation - conducted by calculating Tier 2 SSTLs using site-specific information as inputs to the same or similar methodology used to calculate Tier 1 action levels. The Tier 2 SSTLs are then compared to individual sample results from reasonable points of exposure (as opposed to the source areas as is done in Tier 1) on a point-by-point basis. Total petroleum hydrocarbon concentrations will not be used for risk-based decisions under Tier 2 or Tier 3. Rather, the individual chemicals of concern will be compared to the SSTLs.

- Tier 3 evaluation - conducted by calculating Tier 3 SSTLs on the basis of more sophisticated risk analyses using methodologies described in Method E1739 that consider site-, pathway-, and receptor-specific parameters.

The comparison of laboratory results to FALs and the evaluation of potential corrective actions will be included in the investigation report. The FALs will be defined (along with the basis for their definition) in the investigation report.

\section{B.6.2.1 Chemical PALs}

Except as noted herein, the chemical PALs are defined as the EPA Regions 3, 6, and 9 RSLs for chemical contaminants in industrial soils (EPA, 2009). Background concentrations for RCRA metals and zinc will be used instead of RSLs when natural background concentrations exceed the RSL, as is 
often the case with arsenic on the NTS. Background is considered the average concentration plus two standard deviations of the average concentration for sediment samples collected by the Nevada Bureau of Mines and Geology throughout the Nevada Test and Training Range (formerly the Nellis Air Force Range) (NBMG, 1998; Moore, 1999). For detected chemical COPCs without established screening levels, the protocol used by the EPA Region 9 in establishing RSLs (or similar) will be used to establish PALs. If used, this process will be documented in the investigation report.

\section{B.6.2.2 Radionuclide PALS}

The PALs for radiological contaminants are based on the screening limits recommended in NCRP Report No. 129 for construction, commercial, and industrial land-use scenarios (NCRP, 1999) scaled to the 25-mrem/yr dose constraint (Murphy, 2004) and the generic guidelines for residual concentration of radionuclides in DOE Order 5400.5 (DOE, 1993). These PALs are based on the construction, commercial, and industrial land-use scenarios provided in the NCRP guidance and are appropriate for the NTS based on future land-use scenarios as presented in Section B.2.2.

\section{B.6.3 Decision Rules}

The decision rules applicable to both Decision I and Decision II are:

- If COC contamination is inconsistent with the CSM or extends beyond the spatial boundaries identified in Section B.5.2, then work will be suspended and the investigation strategy will be reconsidered, else the decision will be to continue sampling to define the extent.

The decision rules for Decision I are:

- If the population parameter of any COPC in the Decision I population of interest (defined in Step 4) exceeds the corresponding FAL, then that contaminant is identified as a COC, the contaminated material will be removed, or Decision II will be resolved.

- If a waste is present that, if released, has the potential to cause the future contamination of site environmental media, then a corrective action will be determined, else no further action will be necessary. 
The decision rules for Decision II are:

- If the population parameter (the observed concentration of any COC) in the Decision II population of interest (defined in Step 4) exceeds the corresponding FAL, then additional samples will be collected to complete the Decision II evaluation. If sufficient information is available to define the extent of COC contamination and confirm that closure objectives were met, then further assessment of the CAS is not required. If sufficient information is not available to define the extent of contamination or confirm that closure objectives were met, then additional samples will be collected until the extent is defined.

- If valid analytical results are available for the waste characterization samples defined in Section B.8.0, then the decision will be that sufficient information exists to characterize wastes and IDW for disposal, else collect additional waste characterization samples. 


\section{B.7.0 Step 6 - Specify Performance or Acceptance Criteria}

Step 6 of the DQO process defines the decision hypotheses, specifies controls against false rejection and false acceptance decision errors, examines consequences of making incorrect decisions from the test, and places acceptable limits on the likelihood of making decision errors.

\section{B.7.1 Decision Hypotheses}

The baseline condition (i.e., null hypothesis) and alternative condition for Decision I are:

- $\quad$ Baseline condition - A COC is present.

- Alternative condition - A COC is not present.

The baseline condition (i.e., null hypothesis) and alternative condition for Decision II are as follows:

- $\quad$ Baseline condition - The extent of a COC has not been defined.

- Alternative condition - The extent of a COC has been defined.

Decisions and/or criteria have false negative or false positive errors associated with their determination. The impact of these decision errors and the methods that will be used to control these errors are discussed in the following subsections. In general terms, confidence in DQO decisions based on judgmental sampling results will be established qualitatively by:

- Developing and achieving concurrence of CSMs (based on process knowledge) by stakeholder participants during the DQO process.

- Conducting validity testing of CSMs based on investigation results.

- $\quad$ Evaluating data quality based on DQI parameters.

\section{B.7.2 False Negative Decision Error}

The false negative decision error would mean deciding that a COC is not present when it actually is (Decision I), or deciding that the extent of a COC has been defined when it has not (Decision II). In both cases the potential consequence is an increased risk to human health and the environment. 


\section{B.7.2.1 False Negative Decision Error for Judgmental Sampling}

In judgmental sampling, the selection of the number and location of samples is based on knowledge of the feature or condition under investigation and on professional judgment (EPA, 2002b).

Judgmental sampling conclusions about the target population depend upon the validity and accuracy of professional judgment.

The false negative decision error (where consequences are more severe) for judgmental sampling designs is controlled by meeting these criteria:

- For Decision I, having a high degree of confidence that the sample locations selected will identify COCs if present anywhere within the CAS. For Decision II, having a high degree of confidence that the sample locations selected will identify the extent of COCs.

- Having a high degree of confidence that analyses conducted will be sufficient to detect any COCs present in the samples.

- Having a high degree of confidence that the dataset is of sufficient quality and completeness.

To satisfy the first criterion, Decision I samples must be collected in areas most likely to be contaminated by COCs (supplemented by random samples where appropriate). Decision II samples must be collected in areas that represent the lateral and vertical extent of contamination (above FALs). The following characteristics must be considered to control decision errors for the first criterion:

- Source and location of release

- Chemical nature and fate properties

- Physical transport pathways and properties

- Hydrologic drivers

These characteristics were considered during the development of the CSMs and selection of sampling locations. The field-screening methods and biasing factors listed in Section B.4.2.1 will be used to further ensure that appropriate sampling locations are selected to meet these criteria. Radiological survey instruments and field-screening equipment will be calibrated and checked in accordance with the manufacturer's instructions and approved procedures. The investigation report will present an 
assessment on the DQI of representativeness that samples were collected from those locations that best represent the populations of interest as defined in Section B.5.1.

To satisfy the second criterion, Decision I samples will be analyzed for the chemical and radiological parameters listed in Section 3.2 of the SAFER Plan. Decision II samples will be analyzed for those chemical and radiological parameters that identified unbounded COCs. The DQI of sensitivity will be assessed for all analytical results to ensure that all sample analyses had measurement sensitivities (detection limits) that were less than or equal to the corresponding FALs. If this criterion is not achieved, the affected data will be assessed (for usability and potential impacts on meeting site characterization objectives) in the investigation report.

To satisfy the third criterion, the entire dataset, as well as individual sample results, will be assessed against the DQIs of precision, accuracy, comparability, and completeness as defined in the Industrial Sites QAPP (NNSA/NV, 2002) and in Section 7.2 of the SAFER Plan. The DQIs of precision and accuracy will be used to assess overall analytical method performance as well as to assess the need to potentially "flag” (qualify) individual contaminant results when corresponding QC sample results are not within the established control limits for precision and accuracy. Data qualified as estimated for reasons of precision or accuracy may be considered to meet the constituent performance criteria based on an assessment of the data. The DQI for completeness will be assessed to ensure that all data needs identified in the DQO have been met. The DQI of comparability will be assessed to ensure that all analytical methods used are equivalent to standard EPA methods so that results will be comparable to regulatory action levels that have been established using those procedures. Strict adherence to established procedures and QA/QC protocol protects against false negatives. Site-specific DQIs are discussed in more detail in Section 7.2 of the SAFER Plan.

To provide information for the assessment of the DQIs of precision and accuracy, the following QC samples will be collected as required by the Industrial Sites QAPP (NNSA/NV, 2002):

- Field duplicates (minimum of 1 per matrix per 20 environmental samples)

- Laboratory QC samples (minimum of 1 per matrix per 20 environmental samples or 1 per CAS per matrix, if less than 20 collected) 


\section{B.7.2.2 False Negative Decision Error for Probabilistic Sampling}

Control of the false negative decision error under a probabilistic sampling design is quantitatively established through the selection of the false negative error rate goal (PNNL, 2007). The false negative error rate goal for all CASs was established by the DQO meeting participants at 0.05 (or 5 percent probability). Upon validation of the analytical results, statistical parameters will be calculated for each significant COPC identified at each site. Maintenance of a false negative error rate of 0.05 is contingent upon:

- Population distribution

- Sample size

- Actual variability

- Measurement error

Control of the false negative decision error, therefore, for probabilistic sampling designs is accomplished by ensuring (for each significant COPC) that:

- The population distributions fit the applied UCL determination method.

- A sufficient sample size was collected.

- The actual standard deviation is calculated.

- Analyses conducted were sufficient to detect any COCs present in samples.

As determination of the minimum sample size cannot be accomplished until after the data have been generated, the sufficiency of the number of samples collected will be evaluated in the investigation report. This will be evaluated based on analytical results of significant contaminants. The required number of samples will be calculated using the statistical protocols described in Data Quality Assessment: Statistical Methods for Practitioners (EPA, 2006a). This determination is based on the type of test to be performed, the distribution of the data, the variability of the data, and the acceptable false positive and false negative error rates.

The input parameters to be used in calculating the minimum sample size are:

- A 95 percent confidence level that a false negative error will not occur.

- An 80 percent confidence level that a false positive error will not occur.

- A gray region width equal to 50 percent of the FAL.

- The standard deviation of the contaminant concentrations at each CAS. 
All calculations for the determination of sample size sufficiency will be provided in the investigation report. If the criteria established in this section result in a determination that the minimum sample size was not met for a plot, one of the following actions may be taken:

- Collect additional composite sample(s).

- Conservatively assume that the contaminant concentration for the plot exceeds the FAL.

If the criteria cannot be met, justifications for using the resulting contaminant concentration without meeting the criteria will be made in the $\mathrm{CR}$.

\section{B.7.3 False Positive Decision Error}

The false positive decision error would mean deciding that a COC is present when it is not, or a COC is unbounded when it is not, resulting in increased costs for unnecessary sampling and analysis.

False positive results are typically attributed to laboratory and/or sampling/handling errors that could cause cross contamination. To control against cross contamination, decontamination of sampling equipment will be conducted according to established and approved procedures and only clean sample containers will be used. To determine whether a false positive analytical result may have occurred, the following QC samples will be collected as required by the Industrial Sites QAPP (NNSA/NV, 2002):

- Trip blanks (one per sample cooler containing VOC environmental samples)

- Equipment blanks (one per sampling event for each type of decontamination procedure)

- Source blanks (one per source lot per sampling event)

- Field duplicates (1 per 20 environmental samples or 1 per CAS per matrix, if less than 20 collected)

- Field blanks (minimum of one per CAS, additional if field conditions change)

- Laboratory QC samples (1 per 20 environmental samples or 1 per CAS per matrix, if less than 20 collected) 
For probabilistic sampling, false positive decision error rate goal was established by the DQO meeting participants at 0.20 (or 20 percent probability). Protection against this decision error is also afforded by the controls listed in Section B.7.2 for probabilistic sampling designs. 


\section{B.8.0 Step 7 - Develop the Plan for Obtaining Data}

Step 7 of the DQO process selects and documents a design that will yield data that will best achieve performance or acceptance criteria. Judgmental and probabilistic sampling schemes will be implemented to select sample locations and evaluate analytical results for CAU 544. Section B.8.1.1 provides the judgmental sampling approach that will be implemented to select sample locations and evaluate analytical results at the cellars. Section B.8.1.2 provides the judgmental sampling approach that will be implemented to select sample locations and evaluate analytical results at the oil and waste spills. Judgmental sampling allows the methodical selection of sample locations that target the populations of interest (defined in Step 4). Section B.8.2.1 provides the probabilistic sampling approach that will be implemented to select sample locations and evaluate analytical results in all mud pits. A summary of the sampling approach and data evaluation for each CAS is presented in Table B.8-1.

Table B.8-1

Summary of Sampling Approach and Data Evaluation (Page 1 of 2)

\begin{tabular}{|c|c|c|c|}
\hline $\begin{array}{c}\text { Feature with } \\
\text { Applicable CASs }\end{array}$ & Description & Sample Locations & Evaluation of Data \\
\hline $\begin{array}{c}\text { Mud Pit } \\
(02-37-09,09-09-46)\end{array}$ & $\begin{array}{l}\text { Probabilistic } \\
\text { Sampling } \\
\text { Approach }\end{array}$ & $\begin{array}{l}\text { - Initial number of locations: } \\
10 \text { random } \\
\text { - Soil profile depth(s): surface } \\
\text { (0-6 in. or first } 6 \text { in. below } \\
\text { cover material if backfilled) }\end{array}$ & $\begin{array}{l}\text { Comparison of the } \\
95 \text { percent UCL of the average } \\
\text { concentration } \\
\text { of each significant contaminant } \\
\text { to the FAL }\end{array}$ \\
\hline $\begin{array}{c}\text { Cellar } \\
(02-37-08,02-37-09)\end{array}$ & $\begin{array}{l}\text { Judgmental } \\
\text { Sampling } \\
\text { Approach }\end{array}$ & $\begin{array}{l}\text { - Initial number of locations: } 2 \\
\text { equally distributed locations } \\
\text { - Soil profile depth(s): surface } \\
\text { (0-6 in. or first } 12 \text { in. below } \\
\text { cover material if backfilled) at } \\
\text { biasing factor or distributed at } \\
\text { the accessible area of the } \\
\text { cellar in the absence of } \\
\text { biasing factors }\end{array}$ & $\begin{array}{l}\text { Point-by-point } \\
\text { comparison of each analytical } \\
\text { result to the FAL }\end{array}$ \\
\hline
\end{tabular}


Table B.8-1

\section{Summary of Sampling Approach and Data Evaluation}

(Page 2 of 2)

\begin{tabular}{|c|c|c|c|}
\hline $\begin{array}{c}\text { Feature with } \\
\text { Applicable CASs }\end{array}$ & Description & Sample Locations & Evaluation of Data \\
\hline $\begin{array}{c}\text { Oil/Waste Spill } \\
(19-25-01,19-99-06 \\
20-25-04,20-25-05)\end{array}$ & $\begin{array}{l}\text { Judgmental } \\
\text { Sampling } \\
\text { Approach }\end{array}$ & $\begin{array}{l}\text { Initial number of locations: } 2 \\
\text { (one location from beneath } \\
\text { the heaviest stained soil } \\
\text { within spill area, and one near } \\
\text { the edge of the spill) } \\
\text { - Soil profile depth(s): surface } \\
\text { (0-6 in.) at biasing factor }\end{array}$ & $\begin{array}{c}\text { Point-by-point comparison of } \\
\text { each analytical result } \\
\text { to the FAL }\end{array}$ \\
\hline
\end{tabular}

All sample locations will be selected to satisfy the DQI of representativeness in that samples collected from selected locations will best represent the populations of interest as defined in Section B.5.1.

\section{B.8.1 Judgmental Sampling}

A judgmental sampling design will be implemented at the cellar CASs and the oil/waste spill CASs, and is described in the following sections. To meet the criterion for judgmentally sampled sites, a biased sampling strategy will be used for Decision I samples to target areas with the highest potential to contain a COC, if a COC is present anywhere in the CAS. Sample locations will be determined based on process knowledge, previously acquired data, or the field-screening and biasing factors listed in Section B.4.2.1. If biasing factors are present in soils below locations where Decision I samples were removed, additional Decision I soil samples will be collected at depth intervals selected by the SS based on biasing factors to a depth where the biasing factors are no longer present. The SS has the discretion to modify the sample locations or order additional biased samples to be collected, but only if the new locations meet the decision needs and criteria stipulated in this DQO.

\section{B.8.1.1 Cellar Sampling Design}

The cellars will be investigated based on the potential for chemical and radioactive contamination of surface soil at the cellar base. Judgmental samples will be collected at the first 6 in. of soil directly beneath the cover material in the backfilled cellars based on biasing factors. Samples will be submitted for analysis in accordance with the analytical program listed in Table 3-1. 
Based on the sampling design from CAU 177, Mud Pits and Cellars, a minimum of four samples, two surface and two subsurface, would be sufficient to determine whether contamination exists (NNSA/NSO, 2006c). The subsurface samples will be collected to avoid complications with accessing cellar samples at a later time. The subsurface samples may also provide potential information on vertical migration of contaminants, if any. The locations of the surface samples will be restricted to within the boundaries of the cellar casing because contamination is not expected to have migrated laterally out of this boundary. The presence and orientation (i.e., direction and angle of installation) of drill stemming left within the cellar cavity may laterally and vertically restrict access to surface and subsurface sample locations. The common post-test drilling situation was to drill at an angle to access the zone of rock affected by the test associated with post-test drilling (LLNL, 1984). With this information, it is possible to determine the direction at which the drill stemming trends below the ground surface. Sample locations may therefore vary and will be dependent on the following criteria:

- For the two backfilled cellars, biasing factors are not expected to be apparent. In the expected absence of obvious biasing factors, planned sample locations will be either (a) equally distributed on each side of the drill stemming if the entire cellar area is accessible (Figure B.8-1, item [a]), or (b) equally distributed on the side of the cellar that will be accessible for the appropriate sample collection method (Figure B.8-1, item [b]). It will be assumed that drill stemming has been left in place for backfilled cellars in order to avoid contact with the stemming during excavation and sample collection. Access restrictions related to the presence of drill stemming will also be considered when selecting sample locations in backfilled cellars.

Samples will be obtained through either excavation or other appropriate method. For the backfilled cellars, the cover material/surface soil interface is expected to be encountered near a depth of 10 to $12 \mathrm{ft}$ bgs (Figure B.8-1) based on the assumption that this is the typical depth to the base of a cellar as determined from the sampling that occurred during the CAU 177 investigation (NNSA/NSO, 2007). However, this transition horizon between cover material and the underlying surface soil may not be distinguishable. The following lists the procedure for obtaining samples from the potentially impacted subsurface soil in the cellars:

- Soil will be monitored for lithology changes during excavation to determine the cover material/surface soil interface. 
(a)

Plan View

Full Access

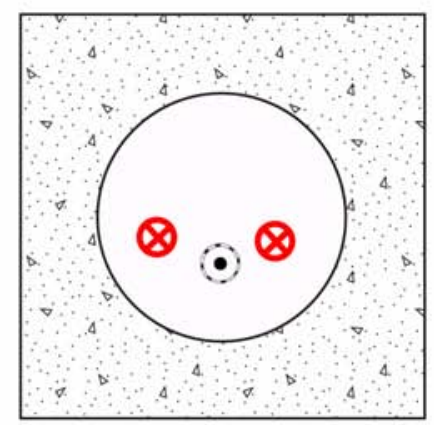

(b)

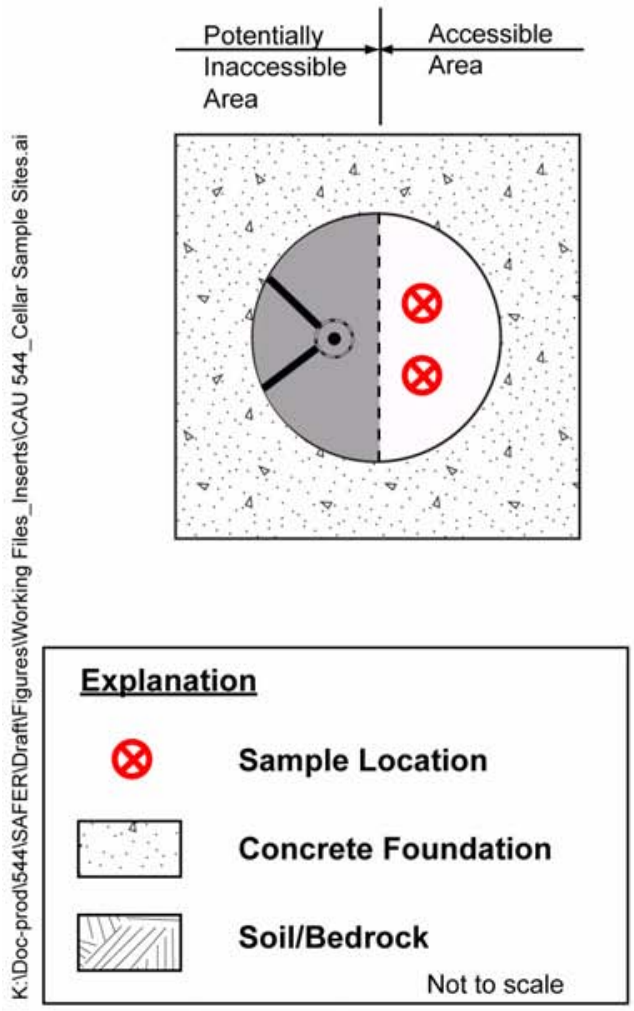

Cross-Section View

Full Access

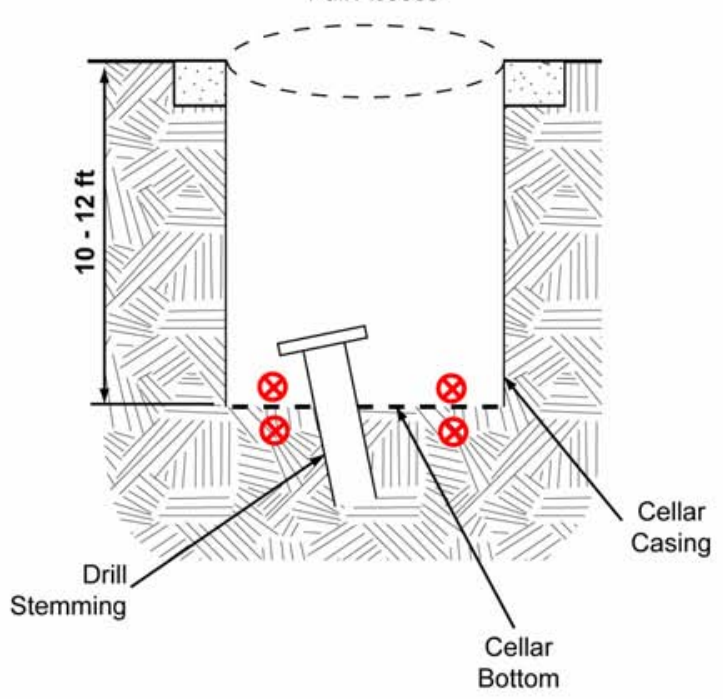

Cross-Section View

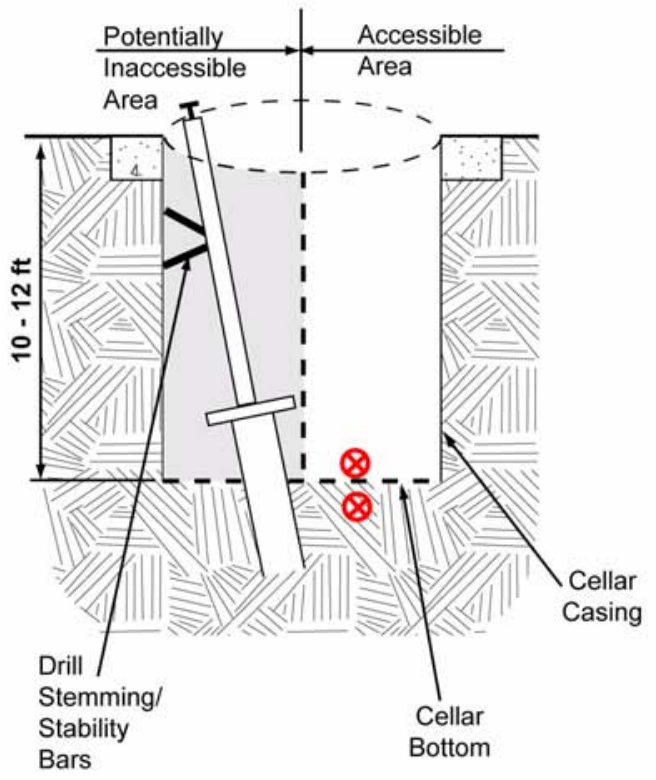

Figure B.8-1

Proposed Sample Locations at Cellars 
- If the interface is recognizable, then a sample will be collected from the first 6 in. of soil directly below the interface.

- If the interface is not recognizable, then a sample will be collected at the depth where the potentially impacted surface soil is expected to be located (i.e., 10 to $12 \mathrm{ft}$ bgs) based on the observations from open cellars.

- If the interface has not been identified and a layer of caliche or a cement bottom is encountered, then a sample will be collected directly above that layer.

The SS will use professional judgment to determine whether biasing factors (e.g., stains, elevated screening levels) are found that might indicate the need to take additional depth samples.

\section{B.8.1.2 Oil/Waste Spill Sampling Design}

The Decision I sampling approach at the oil and waste spills will be based on a typical CSM for a surface spill. The oil and waste spills will be investigated based on the potential for chemical contamination of surface soil. A total of two judgmental samples will be collected from surface soil (0 to 6 in. bgs) at the spills based on biasing factors (visual observations and FSRs). The samples will be collected from areas of suspected highest contaminant concentrations. Samples will be submitted for analysis in accordance with the analytical program listed in Table 3-1.

The SS will use professional judgment to determine whether biasing factors (e.g., stains, elevated screening levels) are found that might indicate the need to take additional depth samples.

\section{B.8.2 Probabilistic Sampling Design}

A probabilistic sampling scheme will be implemented to select sample locations and evaluate analytical results for radiologically impacted mud pits. For probabilistically sampled sites, randomly selected sample locations will be chosen, with locations specified by the VSP software (PNNL, 2007). If a location contains a shallow, hard object (e.g., rock, caliche, or buried concrete), or is located on the mud pit berm, the SS will establish the location at the nearest place that a surface sample can be obtained. 
Statistical methods that generate site characteristics will be used at the mud pits CASs. The information provided from probabilistic sampling allows for establishing contaminant concentrations that represent the site as a whole.

\section{B.8.2.1 Mud Pit Sampling Design}

The mud pits will be investigated based on the potential for radiological contamination of the residual drilling mud contained within the mud pit. A total of 10 samples per mud pit will be collected from the surface (0 to 6 in. bgs) of the residual drilling mud, or 0 to 6 in. below cover material or at the expected depth of mud for backfilled mud pits. The number of samples has been estimated to sufficiently satisfy the criteria of establishing the 95 percent UCL of the average COPC concentration. Appendix C reviews the methodology and computational approach of the VSP software program for determining the sample size and locations for probabilistic sampling (PNNL, 2007). The samples will be configured in a triangular pattern to ensure that all areas of the pit are represented. The initial sample location will be randomly chosen and will serve as the basis for the triangular grid that is established by VSP. Figure B.8-2 shows the predetermined layout of surface sample locations to be collected at a mud pit.

Samples to be collected at open mud pits will be obtained through hand scoop, backhoe excavation, or other appropriate method. Samples to be collected at backfilled mud pits will be obtained through backhoe excavation or other appropriate method. For backfilled mud pits, the cover material/residual mud interface is expected to be easily recognized and encountered at a depth typical of other NTS excavated mud pits (4 to $5 \mathrm{ft}$ bgs based on observations from previous mud pit investigations). Although the cover material/residual mud interface was well recognized at most previously investigated backfilled mud pits, the transition between these layers may not be distinguishable for reasons such as (a) the mud pit was not used or only partially used; and (b) because boundaries of backfilled mud pits are approximated, some unbiased samples may be located in the former mud pit berm. The following, therefore, lists a procedure for obtaining samples from residual mud:

- Soil will be monitored for lithology changes during excavation to identify the cover material/residual mud interface. 


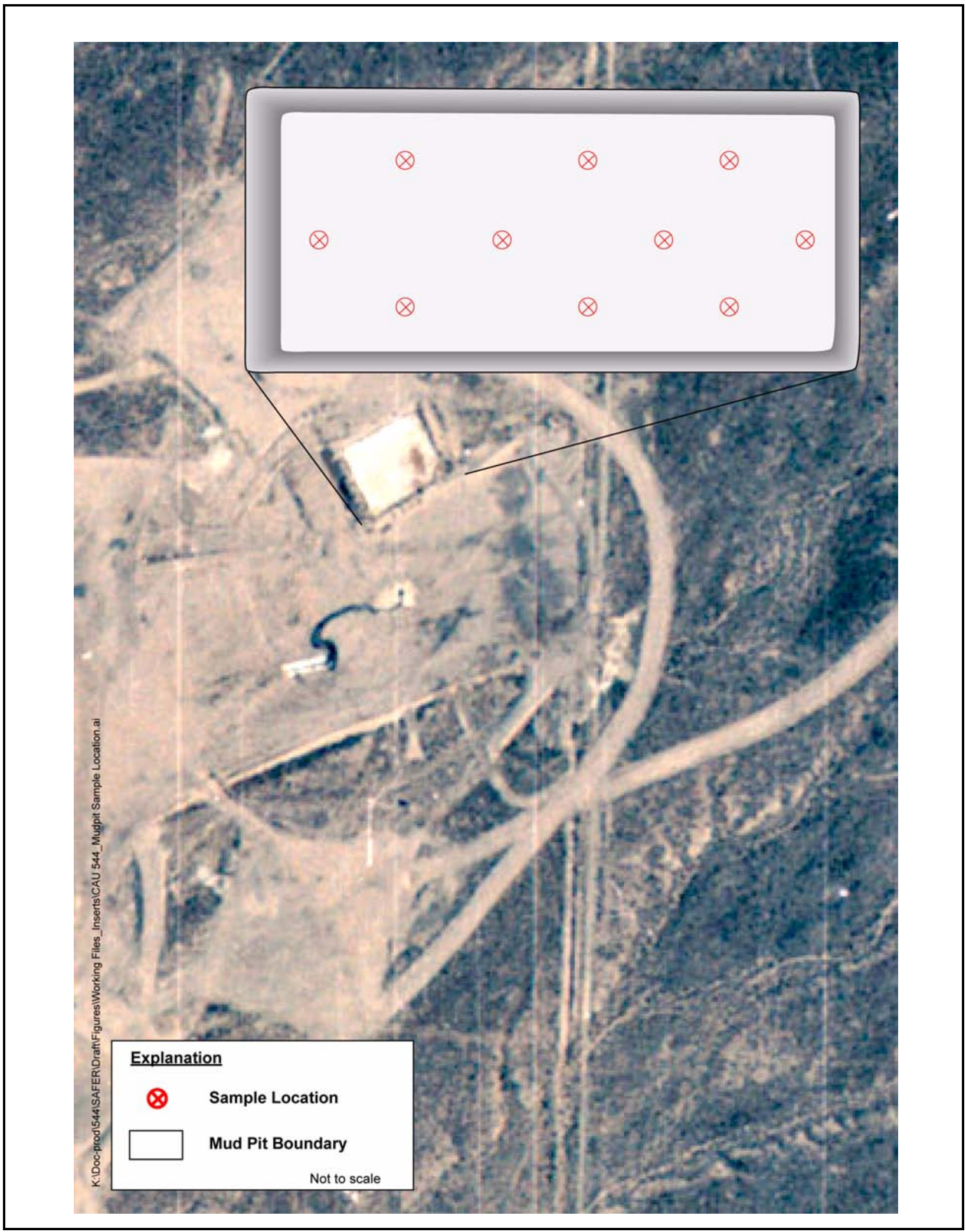

Figure B.8-2

Proposed Sample Locations at Mud Pits 
- If the interface is recognizable, then a sample will be collected from the first 6 in. of mud/cuttings directly below the interface.

- If the interface is not recognizable, then a sample will be collected at the depth where the residual mud is expected to be located based on the observations from other mud pits.

- If the interface has not been identified and a layer of caliche is encountered, then a sample will be collected directly above the caliche.

In addition to the 10 unbiased samples to be collected from each mud pit, additional biased samples may be collected in areas of obvious spills or staining located either within or adjacent to the mud pit. The SS has the discretion to modify the sample locations or order additional biased samples to be collected, but only if the new locations meet the decision needs and criteria stipulated in this DQO. The SS will use professional judgment to determine whether biasing factors (e.g., stains, elevated screening levels) are found that might indicate the need to take additional depth samples. Samples will be submitted for analysis in accordance with the analytical program listed in Table 3-1.

\section{B.8.3 Decision II Sampling}

To meet the DQI of representativeness for Decision II samples (that Decision II sample locations represent the population of interest as defined in Section B.5.1), judgmental sampling locations will be selected based on the outer boundary sample locations where COCs were detected, the CSM, and other field-screening and biasing factors listed in Section B.4.2. In general, sample locations will be arranged in a triangular pattern around the Decision I location or area at distances based on site conditions, process knowledge, and biasing factors. If COCs extend beyond the initial step-outs, Decision II samples will be collected from incremental step-outs. Initial step-outs will be at least as deep as the vertical extent of contamination defined at the Decision I location, and the depth of the incremental step-outs will be based on the deepest contamination observed at all locations. A clean sample (i.e., COCs less than FALs) collected from each step-out direction (lateral or vertical) will define the extent of contamination in that direction. The number, location, and spacing of step-outs may be modified by the SS, as warranted by site conditions. 
For cellars, Decision II step-out samples will be collected only in the vertical direction because the lateral migration is restricted to inside the cellar casing. If a concrete bottom is encountered, then Decision II step-out samples in the vertical direction may not be collected. 


\section{B.9.0 References}

ASTM, see American Society for Testing and Materials.

American Society for Testing and Materials. 1995 (reapproved 2002). Standard Guide for Risk-Based Corrective Action Applied at Petroleum Release Sites, ASTM E1739 - 96(2002).

Philadelphia, PA.

DOE, see U.S. Department of Energy.

DOE/NV, see U.S. Department of Energy, Nevada Operations Office.

EPA, see U.S. Environmental Protection Agency.

LLNL, see Lawrence Livermore National Laboratory.

Lawrence Livermore National Laboratory. 1984. Postshot Drilling Handbook, January. Livermore, CA.

Moore, J., Science Applications International Corporation. 1999. Memorandum to M Todd (SAIC) titled "Background Concentrations for NTS and TTR Soil Samples," 3 February.

Las Vegas, NV: IT Corporation.

Murphy, T., Bureau of Federal Facilities. 2004. Letter to R. Bangerter (NNSA/NSO) titled "Review of Industrial Sites Project Document Guidance for Calculating Industrial Sites Project

Remediation Goals for Radionuclides in Soil Using the Residual Radiation (RESRAD) Computer Code,” 19 November. Las Vegas, NV.

NAC, see Nevada Administrative Code.

NBMG, see Nevada Bureau of Mines and Geology.

NCRP, see National Council on Radiation Protection and Measurements.

NNSA/NSO, see U.S. Department of Energy, National Nuclear Security Administration Nevada Site Office.

NNSA/NV, see U.S. Department of Energy, National Nuclear Security Administration Nevada Operations Office.

National Council on Radiation Protection and Measurements. 1999. Recommended Screening Limits for Contaminated Surface Soil and Review of Factors Relevant to Site-Specific Studies, NCRP Report No. 129. Bethesda, MD. 
Nevada Administrative Code. 2008a. NAC 445A.227, “Contamination of Soil: Order by Director for Corrective Action; Factors To Be Considered in Determining Whether Corrective Action Required.” As accessed at http://www.leg.state.nv.us/nac 3 March 2010.

Nevada Administrative Code. 2008b. NAC 445A.22705, “Contamination of Soil: Evaluation of Site by Owner or Operator; Review of Evaluation by Division.” As accessed at http://www.leg.state.nv.us/nac 3 March 2010.

Nevada Bureau of Mines and Geology. 1998. Mineral and Energy Resource Assessment of the Nellis Air Force Range, Open-File Report 98-1. Reno, NV.

PNNL, see Pacific Northwest National Laboratory.

Pacific Northwest National Laboratory. 2007. Visual Sample Plan, Version 5.0 User's Guide, PNNL-16939. Richland, WA.

Shott, G.J., V. Yucel, M.J. Sully, L.E. Barker, S.E. Rawlinson, and B.A. Moore. 1997. Performance Assessment/Composite Analysis for the Area 3 Radioactive Waste Management Site at the Nevada Test Site, Nye County, Nevada, Rev. 2.0. Las Vegas, NV.

USGS and DOE, see U.S. Geological Survey and U.S. Department of Energy.

U.S. Department of Energy. 1993. Radiation Protection of the Public and the Environment, DOE Order 5400.5, Change 2. Washington, DC: U.S. Government Printing Office.

U.S. Department of Energy, National Nuclear Security Administration Nevada Operations Office. 2002. Industrial Sites Quality Assurance Project Plan, Nevada Test Site, Nevada, Rev. 3, DOE/NV--372. Las Vegas, NV.

U.S. Department of Energy, National Nuclear Security Administration Nevada Site Office. 2004. Mud Pit Risk-Based Closure Strategy Report, Nevada Test Site, Nevada, DOE/NV--991. Las Vegas, NV.

U.S. Department of Energy, National Nuclear Security Administration Nevada Site Office. 2005. Streamlined Approach for Environmental Restoration Plan for Corrective Action Units 530, 531, 532, 533, 534, and 535, Nevada Test Site Mud Pits, Nevada Test Site, Nevada, DOE/NV--1057. Las Vegas, NV.

U.S. Department of Energy, National Nuclear Security Administration Nevada Site Office. 2006a. Closure Report for Corrective Action Units 530, 531, 532, 533, 534, 535: NTS Mud Pits, Nevada Test Site, Nevada, DOE/NV--1131. Las Vegas, NV.

U.S. Department of Energy, National Nuclear Security Administration Nevada Site Office. 2006b. Industrial Sites Project Establishment of Final Action Levels, DOE/NV--1107, Rev. 0. Las Vegas, NV. 
U.S. Department of Energy, National Nuclear Security Administration Nevada Site Office. 2006c. Streamlined Approach for Environmental Restoration Plan for Corrective Action Unit 177: Mud Pits and Cellars, Nevada Test Site, Nevada, DOE/NV--1126. Las Vegas, NV.

U.S. Department of Energy, National Nuclear Security Administration Nevada Site Office. 2007. Closure Report for Corrective Action Unit 177: Mud Pits and Cellars, Nevada Test Site, Nevada, DOE/NV--1186. Las Vegas, NV.

U.S. Department of Energy, Nevada Operations Office. 1992. Remedial Investigation and Feasibility Study for the Plutonium Contaminated Soils at Nevada Test Site, Nellis Air Force Range and Tonopah Test Range. April. Las Vegas, NV.

U.S. Department of Energy, Nevada Operations Office. 1998. Nevada Test Site Resource Management Plan, DOE/NV--518. Las Vegas, NV.

U.S. Department of Energy, Nevada Operations Office. 2001. Mud Pit Strategy, Nevada Test Site, Nevada, DOE/NV-684. Las Vegas, NV.

U.S. Environmental Protection Agency. 2002a. Calculating the Upper Confidence Limits for Exposure Point Concentrations at Hazardous Waste Sites, OSWER 9285.6-10. Washington, DC: Office of Emergency and Remedial Response.

U.S. Environmental Protection Agency. 2002b. Guidance for Quality Assurance Project Plans, EPA QA/G5, EPA/240/R-02/009. Washington, DC.

U.S. Environmental Protection Agency. 2006a. Data Quality Assessment: Statistical Methods for Practitioners, EPA QA/G-9S, EPA/240/B-06/003. Washington, DC.

U.S. Environmental Protection Agency. 2006b. EPA Guidance on Systematic Planning Using the Data Quality Objectives Process, EPA QA/G-4. Washington, DC.

U.S. Environmental Protection Agency. 2009. Regions 3, 6, and 9 Regional Screening Levels for Chemical Contaminants at Superfund Sites. As accessed at http://www.epa.gov/region09/superfund/prg/index.html on 3 March 2010.

U.S. Geological Survey and U.S. Department of Energy. 2009. "USGS/USDOE Cooperative Studies in Nevada; Water-Level Wells, Nevada Test Site.” As accessed at http://nevada.usgs.gov/doe_nv/ntsmap.htm on 25 February 2010.

Winograd, I.J., and W. Thordarson. 1975. Hydrogeologic and Hydrochemical Framework, South-Central Great Basin, Nevada-California, with Special Reference to the Nevada Test Site, USGS Professional Paper 712-C. Denver, CO. 


\section{Appendix B}

\section{Confirmation Sampling Test Results}




\section{B.1.0 Introduction}

This appendix presents the CAI activities and analytical results for CAU 544. Corrective Action Unit 544 is located in Areas 2, 7, 9, 10, 12, 19, and 20 of the NNSS (Figure 1-1) and comprises the 20 CASs listed below:

- 02-37-08, Cellar \& Mud Pit

- 02-37-09, Cellar \& Mud Pit

- 07-09-01, Mud Pit

- 09-09-46, U-9itsx20 PS \#1A Mud Pit

- 10-09-01, Mud Pit

- 12-09-03, Mud Pit

- 19-09-01, Mud Pits (2)

- 19-09-03, Mud Pit

- 19-09-04, Mud Pit

- 19-25-01, Oil Spill

- 19-99-06, Waste Spill

- 20-09-01, Mud Pits (2)

- 20-09-02, Mud Pit

- 20-09-03, Mud Pit

- 20-09-04, Mud Pits (2)

- 20-09-06, Mud Pit

- 20-09-07, Mud Pit

- 20-09-10, Mud Pit

- 20-25-04, Oil Spills

- 20-25-05, Oil Spills

The CAU consists of a total of 20 CASs-2 CASs in Area 2, 5 CASs in Area 19, 9 CASs in Area 20, and 1 CAS each in Areas 7, 9, 10, and 12. The 20 CASs in CAU 544 comprise oil/waste spills, and as seen from the above listing, the majority (16 of 20) of the CASs in CAU 544 are mud pits or have a mud pit component.

The mud pit CASs are in-ground structures used during drilling activities that supported the underground nuclear weapons testing program conducted at the NNSS. Drilling activities were conducted to place the device, obtain lithologic data on the geologic material in which the test was being conducted, emplace monitoring devices both before and after the test, or collect post-test data on the effects of the test. Drilling fluids were typically used during these drilling activities to cool and lubricate the drill bit, stabilize the wall of the drill hole to keep it from collapsing, and suspend the 
drill cuttings and bring them to the surface (NNSA/NSO, 2006a). The drilling fluid used was primarily a bentonite, polymer, or detergent mixture, but was sometimes supplemented with diesel fuel to lubricate the drill bit or to increase the viscosity of the drilling mud and provide better lift for removing the drill cuttings (NNSA/NSO, 2006a). Typically, mud containing suspended drill cuttings would be deposited in a return mud pit where the cuttings would settle out. Then the mud would be transferred to the suction mud pit where it would be recirculated to the drill hole.

There have not been inorganic or organic COCs identified for NNSS mud pits based on the conclusions of the RBCSR (NNSA/NSO, 2004) and the results of the CAUs 530-535 mud pits investigation (NNSA/NSO, 2006a). These efforts have eliminated VOCs, SVOCs, PCBs, and metals as COPCs in NNSS mud pits. Furthermore, based on process knowledge and previous sampling, mud pits located in areas that have no radiological postings contained no radiological, organic, or inorganic COCs. Table B.1-1 provides a listing of the mud pits that are recommended for NFA based on the RBCSR and the CAUs 530-535 results and recommendations.

Using the RBCSR (NNSA/NSO, 2004) and the approach approved for previous mud pit investigations (CAUs 530-535) (NNSA/NSO, 2006a), 14 of the 16 mud pits are recommended for NFA without field investigations because they meet the criteria specified in the RBCSR. The criteria included the following:

- CAS is either a single mud pit or system of mud pits.

- CAS is not located in a radiological or radioactive material posted area.

- $\quad$ There are no biasing factors evident at the mud pits based on visual inspections.

The following section describes the mud pits recommended for NFA and the seven CASs that were recommended for sampling in the SAFER Plan (NNSA/NSO, 2010).

\section{B.1.1 CAU 544 CASs}

\section{B.1.1.1 Mud Pit CASs Recommended for No Further Action Based on the RBCSR}

Based on the criteria presented in the RBCSR (NNSA/NSO, 2004) and CAUs 530-535 closure document (NNSA/NSO, 2006a), 13 mud pit CASs and 1 mud pit CAS component have been recommended for closure without sampling. The evaluation of these mud pit CASs followed the criteria and processes discussed in the RBCSR, and as such, each of these CASs was identified by the 
Table B.1-1

CAU 544 CASs Recommended for No Further Action Based on the RBCSR

\begin{tabular}{|c|c|c|c|c|c|c|}
\hline CAS & Location & $\begin{array}{c}\text { Radiological } \\
\text { Postings }\end{array}$ & Closure Strategy & $\begin{array}{l}\text { Laboratory } \\
\text { Responsible } \\
\text { for the Test }\end{array}$ & $\begin{array}{l}\text { Mud Pit } \\
\text { Category }^{\mathrm{a}}\end{array}$ & Recommendation \\
\hline $\begin{array}{l}\text { 02-37-08, } \\
\text { Cellar \& Mud Pit }\end{array}$ & $U-2 c n$ & $\begin{array}{l}\text { Cellar: URMA } \\
\text { Mud Pit: None }\end{array}$ & Close mud pit under RBCSR criteria & LLNL & 4 & $\begin{array}{l}\text { Cellar: Sampled } \\
\text { Mud Pit: NFA; move to Appendix IV }\end{array}$ \\
\hline 07-09-01, Mud Pit & U-7bi & None & Close mud pit under RBCSR criteria & LANL & 1 & NFA; move to Appendix IV \\
\hline 10-09-01, Mud Pit & U-10cb & None & Close mud pit under RBCSR criteria & LLNL & 3 & NFA; move to Appendix IV \\
\hline 12-09-03, Mud Pit & U-12e.14 PS \#1A & None & Close mud pit under RBCSR criteria & LLNL & 4 & NFA; move to Appendix IV \\
\hline 19-09-01, Mud Pits (2) & U-19ab & None & Close mud pit under RBCSR criteria & LANL & 1 & NFA; move to Appendix IV \\
\hline 19-09-03, Mud Pit & U-19ar & None & Close mud pit under RBCSR criteria & LANL & 1 & NFA; move to Appendix IV \\
\hline 19-09-04, Mud Pit & U-19ad & None & Close mud pit under RBCSR criteria & LANL & 1 & NFA; move to Appendix IV \\
\hline 20-09-01, Mud Pits (2) & $\begin{array}{l}\text { RSM } 20 \mathrm{~J} \text { 35, } \\
\text { U-20m PS area }\end{array}$ & None & Close mud pit under RBCSR criteria & LLNL & 4 & NFA; move to Appendix IV \\
\hline 20-09-02, Mud Pit & $\begin{array}{l}\text { RSM } 20 \mathrm{~J} 36, \\
\text { U-20m PS area }\end{array}$ & None & Close mud pit under RBCSR criteria & LLNL & 3 & NFA; move to Appendix IV \\
\hline 20-09-03, Mud Pit & $U-20 p$ & None & Close mud pit under RBCSR criteria & LLNL & 3 & NFA; move to Appendix IV \\
\hline 20-09-04, Mud Pits (2) & $U-20 p$ & None & Close mud pit under RBCSR criteria & LLNL & 3 & NFA; move to Appendix IV \\
\hline 20-09-06, Mud Pit & $U-20 z$ & None & Close mud pit under RBCSR criteria & LLNL & 3 & NFA; move to Appendix IV \\
\hline 20-09-07, Mud Pit & U-20aw & None & Close mud pit under RBCSR criteria & LLNL & 3 & NFA; move to Appendix IV \\
\hline 20-09-10, Mud Pit & U-20bg & None & Close mud pit under RBCSR criteria & LLNL & 3 & NFA; move to Appendix IV \\
\hline
\end{tabular}

${ }^{a}$ Mud Pit RBCSR (NNSA/NSO, 2004)

${ }^{\mathrm{b}}$ The mud pit is a component of CAS 02-37-08 that contained a mud pit and a cellar. The mud pit met the RBCSR criteria, so this CAS component was not sampled and is recommended for NFA. The cellar was sampled. 
laboratory that conducted the test and whether it was a pretest boring or post-test boring. The CASs, laboratories that conducted the tests, and the categories are presented in Table B.1-1.

\section{B.1.1.1.1 Los Alamos National Laboratory Pretest Mud Pits}

Four CAU 544 mud pit CASs were constructed as part of LANL pretest drilling activities. Three of the CASs are located in Area 19, and one CAS is located in Area 7 (Tables 1-1 and B.1-1). All four CASs are recommended for NFA. The LANL pretest mud pit generally consisted of one earthen, large-return mud pit or two earthen mud pits (a return pit and a suction pit) with a connecting trench or piping. The mud pits were typically covered with native soils after use (NNSA/NSO, 2006a).

\section{B.1.1.1.2 Lawrence Livermore National Laboratory Pretest Mud Pits}

Seven CAU 544 mud pit CASs were constructed as part of the LLNL pretest drilling activities. Six of the LLNL pretest mud pit CASs are located in Area 20, and one CAS is located in Area 10. All seven CASs are recommended for NFA. The LLNL mud pit generally consisted of one earthen, large-return mud pit that was not covered with native soils after use. A metal tank was commonly used as the suction pit for these systems, but it was removed after drilling was completed, leaving only the return mud pit (NNSA/NSO, 2006a).

\section{B.1.1.1.3 Lawrence Livermore National Laboratory Post-test Mud Pits}

Five CAU 544 mud pit CASs were constructed as part of the LLNL post-test drilling activities. Two of the CASs are located in Area 2, and one CAS each is located in Areas 9, 12, and 20. Of these five LLNL post-test mud pit CASs, two (CASs 02-37-09 and 09-09-46) were sampled during the CAI because these two pits did not meet the RBCSR criteria. These two mud pits are radiologically posted areas, one in a radioactive material area and the other in a CA. The LLNL post-test mud pit generally consisted of one earthen, small-return mud pit. After use, these return mud pits were commonly allowed to dry out, surveyed for radiation, and covered with native soils (NNSA/NSO, 2006a).

Additional information regarding the history of each site, planning, and the scope of the investigation is presented in the CAU 544 SAFER Plan (NNSA/NSO, 2010). 


\section{B.1.1.2 CASs Recommended for Sampling}

\section{B.1.1.2.1 CAS 02-37-08, Cellar \& Mud Pit}

Corrective Action Site 02-37-08 is located in Area 2 of the NNSS and consists of potential environmental releases from the drilling equipment into the backfilled cellar located in the vicinity of the U-2cn crater. The cellar is located within a fenced area posted with URMA signs. The mud pit component of this CAS meets the criteria specified in the RBCSR and is recommended for closure without sampling.

\section{B.1.1.2.2 CAS 02-37-09, Cellar \& Mud Pit}

Corrective Action Site 02-37-09 is located in Area 2 of the NNSS and consists of potential environmental releases from drilling activities associated with the backfilled cellar and mud pit. The cellar and mud pit are located in the vicinity of the U-2dc4a (Tyg-D) crater. Both the cellar and mud pit are located within a fenced, posted URMA.

\section{B.1.1.2.3 CAS 09-09-46, U-9itsx20 PS \#1A Mud Pit}

Corrective Action Site 09-09-46 is located in Area 9 of the NNSS and consists of potential releases associated with the drilling mud in the pit. The uncovered mud pit is located on the eastern edge of the U-9itsx20 crater within the fenced crater area. The mud pit and area within the crater are posted as a CA.

\section{B.1.1.2.4 CAS 19-25-01, Oil Spill}

Corrective Action Site 19-25-01 is located approximately 1,800 ft southwest of the U-19ab crater in Area 19 of the NNSS. The CAS consists of a suspected release of hydrocarbons to the soil associated with an oil spill.

\section{B.1.1.2.5 CAS 19-99-06, Waste Spill}

Corrective Action Site 19-99-06 is located east of the U-19j emplacement hole in Area 19 of the NNSS. The environmental concern at this CAS consists of potential environmental releases 
associated with several large spills of dry, light gray cement grout that were suspected to have occurred during the completion of the U19j emplacement hole.

\section{B.1.1.2.6 CAS 20-25-04, Oil Spills}

Corrective Action Site 20-25-04 is located in Area 20 of the NNSS and consists of potential releases of hydrocarbons to the soil near U-20aw. The reported oil spills cover several square feet of soil and are located within a potential crater area. Because the crater has been reported to be potentially unstable, sampling was not conducted at this CAS for safety concerns.

\section{B.1.1.2.7 Corrective Action Site 20-25-05, Oil Spills}

Corrective Action Site 20-25-05 is located in Area 20 of the NNSS and consists of potential releases of hydrocarbons to the soil from reported numerous oil spills. The CAS is located near U-20be in the area formerly used as the trailer park for the nuclear test.

\section{B.1.2 Project Objectives}

The primary objective of the investigation was to provide sufficient information to validate the assumptions used to select the corrective actions and to verify that closure objectives were met for each CAS in CAU 544. This objective was achieved by determining the presence of COCs and the vertical and lateral extent of the COCs, if present.

The selection of soil sample locations was based on site conditions and the strategy developed during the DQO process as presented in the CAU 544 SAFER Plan (Appendix A). The sampling strategy involved a probabilistic sampling approach at the mud pit CASs (02-37-09 and 09-09-46), and a judgmental sampling approach at the cellar CASs (02-37-08 and 02-37-09) and at the oil/waste spill CASs (19-25-01, 19-99-06, and 20-25-05). Corrective Action Site 20-25-04 was not sampled due to its location within a potential crater area. Although LLNL conducted a stability study and deemed the crater stable in its current configuration, LLNL is less confident in this conclusion than for other craters (Pawloski, 2003). Therefore, for safety reasons, personnel did not enter the crater to collect samples. 


\section{B.1.3 Contents}

This appendix contains information and data in sufficient detail to justify that no further corrective action is required at CAU 544. The contents of this appendix are as follows:

- Section B.1.0 describes the investigation background, objectives, and content.

- Section B.2.0 provides an investigation overview.

- Sections B.3.0 through B.10.0 provide CAS-specific information regarding the field activities, sampling methods, and laboratory analytical results from investigation sampling.

- Section B.11.0 summarizes waste management activities.

- Section B.12.0 discusses the QA and QC procedures followed and results of the QA/QC activities.

- Section B.13.0 is a summary of the investigation results.

- Section B.14.0 lists the cited references.

The complete field documentation and laboratory data -including field activity daily logs (FADLs), sample collection logs (SCLs), analysis request/chain-of-custody forms, soil sample descriptions, laboratory certificates of analyses, analytical results, and surveillance results-are retained in project files as hard copy files or electronic media. 


\section{B.2.0 Investigation Overview}

Field investigation and sampling activities for the CAU 544 CAI were conducted from December 7, 2010, through April 4, 2011. Table B.2-1 lists the CAI activities that were conducted at each of the seven CASs listed in Section B.1.1.2.

Table B.2-1

Corrective Action Investigation Activities Conducted at Each CAS To Meet SAFER Plan Requirements for CAU 544

\begin{tabular}{|c|c|c|c|c|c|c|c|c|}
\hline \multirow[b]{2}{*}{ CAl Activities } & \multicolumn{8}{|c|}{ CAS } \\
\hline & 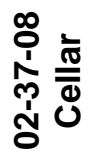 & 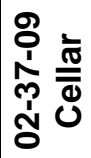 & 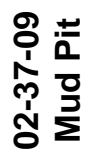 & $\begin{array}{l}\text { o } \\
\text { ó } \\
\text { ó } \\
\text { ó }\end{array}$ & $\begin{array}{l}\text { ○' } \\
\text { ஸे } \\
\text { ஸे }\end{array}$ & $\begin{array}{l}\text { o } \\
\text { ơ } \\
\text { ơ } \\
\text { ல் }\end{array}$ & $\begin{array}{l}\text { ठ } \\
\text { ம் } \\
\text { ஸे } \\
\text { ஸे }\end{array}$ & $\begin{array}{l}\text { L } \\
\text { ஸे } \\
\text { ஸे }\end{array}$ \\
\hline Visually inspected spill area boundaries. & -- & -- & -- & -- & $\mathrm{X}$ & $\mathrm{X}$ & -- & $\mathrm{x}$ \\
\hline $\begin{array}{l}\text { Collected subsurface soil samples from biased locations } \\
\text { at cellars. }\end{array}$ & $\mathrm{X}$ & 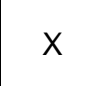 & -- & -- & -- & -- & -- & -- \\
\hline $\begin{array}{l}\text { Collected surface soil samples from biased locations at } \\
\text { oil/waste spills. }\end{array}$ & -- & -- & -- & -- & $\mathrm{X}$ & $\mathrm{X}$ & -- & $x$ \\
\hline $\begin{array}{l}\text { Collected soil samples from random locations at } \\
\text { mud pits. }\end{array}$ & -- & -- & $\mathrm{X}$ & $\mathrm{X}$ & -- & -- & -- & -- \\
\hline Recorded GPS coordinates of each location. & $x$ & $x$ & $x$ & $\mathrm{X}$ & $x$ & $x$ & -- & $x$ \\
\hline $\begin{array}{l}\text { Field screened samples for alpha and beta/gamma } \\
\text { radiation using a handheld survey instrument. }\end{array}$ & $x$ & $\mathrm{X}$ & $X$ & $\mathrm{X}$ & $x$ & $\mathrm{X}$ & -- & $x$ \\
\hline Submitted select samples for offsite laboratory analysis. & $X$ & $X$ & $X$ & $X$ & $x$ & $X$ & -- & $X$ \\
\hline
\end{tabular}

$\mathrm{X}=$ Activity conducted

-- = Activity not applicable or conducted

The investigation and sampling program was managed in accordance with the requirements set forth in the CAU 544 SAFER Plan (NNSA/NSO, 2010). Field activities were performed in compliance with safety documents that are consistent with the DOE Integrated Safety Management System. Samples were collected and documented following approved protocols and procedures. Quality control samples (e.g., field blanks, equipment rinsate blanks, trip blanks, and duplicate samples) were collected as required by the Industrial Sites QAPP (NNSA/NV, 2002a) and the CAU 544 SAFER Plan (NNSA/NSO, 2010). During field activities, waste minimization practices were followed according to approved procedures, including segregation of waste by waste stream. 
Weather conditions at the site varied to include sun to intermittent cloudiness, moderate to low temperatures, and light to medium winds, and weather did not cause delays in site operations.

The CASs were investigated by sampling surface and subsurface soils. Surface soil samples were collected using disposable scoops. Subsurface soil samples were collected using a hand auger or Geoprobe. All soil samples were field screened for alpha and beta/gamma radiation. The results were compared against screening levels to guide in the CAS-specific investigations. Field screening was also used for health and safety controls and to meet sample transportation requirements. All CAU 544 Decision I sampling locations were accessible, except for CAS 20-25-04, which is located inside a potentially unstable crater area. Sampling activities at planned locations at the other CASs were not restricted.

Sections B.2.1 through B.2.4 provide the investigation methodology and laboratory analytical information.

\section{B.2.1 Sample Locations}

The sampling locations selected for the CAU 544 investigation were based primarily on information obtained during site visits, site conditions, and process knowledge regarding pretest and post-test drilling and the construction of mud pits and cellars. The planned probabilistic and judgmental sampling plans that were applied to the mud pits, and cellars and oil/waste spills, respectively, are discussed in the CAU 544 SAFER Plan (NNSA/NSO, 2010).

The random sample locations at the two mud pits were identified before sampling efforts using the VSP model (PNNL, 2007). These sample locations were staked at both mud pits using a GPS. These locations were configured in a triangular grid pattern with the location of the initial sample randomly chosen. Some of the sample locations at the mud pit at CAS 02-37-09 were moved because the sample locations were in the berms, outside the suspected mud pit, or too close to the fence line to allow Geoprobe access. There were no biasing factors identified at either mud pit that required additional biased sample collection.

Selection of biased sample locations at the backfilled cellars followed the approach specified in the CAU 544 SAFER Plan (NNSA/NSO, 2010). Sample locations at each cellar were equally spaced on 
each side of the borehole casing. At the backfilled cellars, two subsurface samples were collected at each borehole; one on each side of the cellar from 2 to $3 \mathrm{ft}$ immediately above the identified cellar bottom. The presence of borehole casing was assumed, and its orientation was assessed at each backfilled cellar location.

Selection of biased sample locations at the oil/waste spills followed the approach provided in the SAFER Plan (NNSA/NSO, 2010). Samples were collected from locations of the heaviest stained soil and on the outside edge of the spills. At CAS 20-25-05, the spills were not located; therefore, the samples were collected at the CAS marker and at the approximate boundary of the spill.

Actual environmental sample locations are shown on the figures included in Sections B.3.0 through B.9.0. Some locations were modified slightly from planned positions due to field conditions and observations. Sample locations were staked where appropriate and labeled. The sample locations were recorded using a GPS instrument.

\section{B.2.2 Investigation Activities}

The investigation activities performed were based on field investigation activities discussed in the CAU 544 SAFER Plan (NNSA/NSO, 2010). The technical approach consisted of the activities listed in Table B.2-1. The investigation strategy allowed the nature and extent of contamination associated with each CAS to be established. The following sections describe the specific investigation activities that took place at CAU 544.

\section{B.2.2.1 Field Screening}

Field-screening activities for alpha and beta/gamma radiation were performed as specified in the CAU 544 SAFER Plan (NNSA/NSO, 2010). All sample locations were initially field screened for alpha and beta/gamma radiation before the start of sampling. Site-specific field-screening levels (FSLs) for alpha and beta/gamma radiation were defined as the mean background activity level plus two times the standard deviation of readings from 10 background locations selected near each CAS. The FSLs are instrument specific and were established for each instrument and CAS before use. 
The CAS-specific sections of this document identify the CASs where field screening was conducted and how the FSLs were used to aid in the selection of samples that were submitted for laboratory analysis.

\section{B.2.2.2 Surface and Subsurface Soil Sampling}

Surface soil samples at the uncovered mud pit and the oil/waste spills were collected using scoop and trowel (surface hand-grab sampling). The subsurface soil samples at the backfilled cellars and covered mud pit were collected using Geoprobe direct-push equipment or hand auger. Volatile organic compound samples were collected directly into the sample bottles. Additional soil was then transferred into an aluminium pan, homogenized, and field screened for alpha and beta/gamma radiation. Sample containers for all other analyses were then filled with the homogenized soil. Excess soil was returned to its original location, and the disposable sampling equipment was appropriately discarded (based on field screening).

At the oil/waste spills, surface soil samples were collected at varying depths based on visual inspections. Biased locations focused on stained soil or areas with elevated radiological measurements. At CAS 19-25-01, samples were collected from 0 to 3 in. bgs, 3 to 6 in. bgs, and 6 to 12 in. bgs. At CAS 19-99-06, samples were collected from 4 to 6 in. bgs and 6 to 12 in. bgs. At CAS 20-25-05, samples were collected from 0 to 6 in. bgs and 6 to 12 in. bgs. Surface samples at the uncovered mud pit were collected from 0.0 to $0.5 \mathrm{ft}$ bgs at sample locations generated using the VSP program (PNNL, 2007).

Subsurface soil samples from the covered mud pit were collected from sample locations generated using the VSP program (PNNL, 2007). The sample depth was based upon the presence of dried drilling mud, which was observed at depths ranging from 3.5 to $5.0 \mathrm{ft}$ bgs. Subsurface soil samples from the backfilled cellars were collected on either side of the buried post-test drill pipe. The samples were collected from the 2-to-3-ft interval immediately above the cellar floor as evidenced by refusal of the Geoprobe/hand auger. Geoprobe operations were terminated at refusal to avoid creating a migration pathway through the concrete bottom; therefore, no samples were collected from below the cellar. 


\section{B.2.2.3 Waste Characterization Sampling}

No waste characterization samples were collected during the investigation. The waste streams generated included disposable PPE, disposable sampling equipment, and rinsate water from the decontamination of the Geoprobe sleeves and shoe. Decontamination rinsate was generated in small volumes that evaporated before the rinsate could be sampled or transferred to the waste container.

\section{B.2.3 Laboratory Analytical Information}

Chemical and radiological analyses were performed by General Engineering Laboratories, LLC, Charleston, South Carolina. The analytical suites and laboratory analytical methods used to analyze investigation samples are listed in Table B.2-2. Analytical results are reported in this appendix if detected above the MDCs. The complete laboratory data packages are available in the project files.

Table B.2-2

Laboratory Analyses and Methods, CAU 544 Investigation Samples ${ }^{a}$

\begin{tabular}{|c|c|}
\hline Analysis & Analytical Method $^{b}$ \\
\hline VOCs & Aqueous/Non-aqueous - EPA SW- $846^{c} 8260$ \\
\hline SVOCs & Aqueous/Non-aqueous - EPA SW- $846^{c} 8270$ \\
\hline PCBs & Aqueous/Non-aqueous - EPA SW-846' 8082 \\
\hline Metals & $\begin{array}{c}\text { Aqueous - EPA SW-846 6010/6020/7470 } \\
\text { Non-aqueous - EPA SW-846 } 6010 / 6020 / 7471\end{array}$ \\
\hline Isotopic U & Aqueous/Non-aqueous - DOE EML HASL-300 ${ }^{d}$ U-02-RC \\
\hline Isotopic Pu & $\begin{array}{c}\text { Aqueous - DOE EML HASL-300 } \mathrm{Pu}-10-\mathrm{RC} \\
\text { Non-aqueous - DOE EML HASL-300 } \mathrm{Pu}-02-\mathrm{RC}\end{array}$ \\
\hline Gamma Spectroscopy & $\begin{array}{c}\text { Aqueous - EPA } 901.1^{\mathrm{e}} \\
\text { Non-aqueous - DOE EML HASL-300 }{ }^{\mathrm{d}} \text {, Ga-01-R }\end{array}$ \\
\hline Sr-90 & $\begin{array}{l}\text { Aqueous - EPA } 905.0^{\mathrm{e}} \\
\text { Non-aqueous - DOE EML HASL-300 } \mathrm{Sr}-02-\mathrm{RC}\end{array}$ \\
\hline
\end{tabular}

anvestigation samples include both environmental and waste characterization samples and associated QC samples.

${ }^{\mathrm{b}}$ The most current analytical method accepted by EPA, DOE, ASTM, NIOSH, or equivalent may be used, including Laboratory

Standard Operating Procedures approved by N-I in accordance with industry standards and the N-I Statement of Work requirements (NNES, 2009).

${ }^{\mathrm{c} T e s t}$ Methods for Evaluating Solid Waste, Physical/Chemical Methods (EPA, 2009).

${ }^{\mathrm{d}}$ The Procedures Manual of the Environmental Measurements Laboratory (DOE, 1997).

${ }^{\mathrm{e}}$ Prescribed Procedures for Measurement of Radioactivity in Drinking Water (EPA, 1980).

ASTM = ASTM International

$E M L=$ Environmental Measurements Laboratory

$\mathrm{EPA}=$ U.S. Environmental Protection Agency
HASL = Health and Safety Laboratory

$\mathrm{N}-\mathrm{I}=$ Navarro-Intera, LLC

$\mathrm{NIOSH}=$ National Institute for Occupational Safety and Health 
Validated analytical data for CAU 544 investigation samples have been compiled and evaluated to confirm the presence and define the extent of contamination, if present. The analytical results for each CAS are presented in Sections B.3.0 through B.9.0.

The analytical parameters are CAS-specific and were selected through the application of site process knowledge in accordance with the Guidance on Systematic Planning Using the Data Quality Objectives Process (EPA, 2006).

\section{B.2.4 Comparison to Action Levels}

A COC is defined as any contaminant present in environmental media exceeding a FAL. A COC may also be defined as a contaminant that, in combination with other like contaminants, is determined to jointly pose an unacceptable risk based on a multiple constituent analysis (NNSA/NSO, 2006b). Multiple constituent analyses are presented in Appendix D.

If COCs are present, corrective action must be considered for the CAS. The FALs for the CAU 544 investigation are defined for each CAS in Appendix D. Results that are equal to or greater than FALs are identified by bold text in the CAS-specific results tables (Sections B.3.0 through B.9.0). 


\section{B.3.0 CAS 02-37-08, Cellar \& Mud Pit, Investigation Results}

Corrective Action Site 02-37-08 is located in Area 2 of the NNSS (Figure 1-1) and consists of potential environmental releases associated with a backfilled cellar located in the vicinity of the U-2cn crater. The cellar is located within a fenced area posted with URMA signs. Additional detail is provided in the SAFER Plan (NNSA/NSO, 2010).

\section{B.3.1 SAFER Activities}

A total of three characterization samples (including one FD) were collected during investigation activities at CAS 02-37-08. The sample identifications (IDs), locations, types, and analyses are listed in Table B.3-1. The specific CAI activities conducted to satisfy the SAFER Plan requirements at this CAS are described in the following sections.

Table B.3-1

Samples Collected at CAS 02-37-08, Cellar \& Mud Pit

\begin{tabular}{|c|c|c|c|c|c|c|c|c|c|c|c|c|c|}
\hline $\begin{array}{l}\text { Sample } \\
\text { Location }\end{array}$ & $\begin{array}{l}\text { Sample } \\
\text { Number }\end{array}$ & $\begin{array}{l}\text { Depth } \\
\text { (ft bgs) }\end{array}$ & Matrix & Purpose & 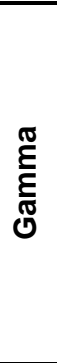 & 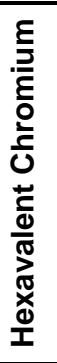 & $\begin{array}{l}\frac{n}{\pi} \\
\frac{\pi}{2}\end{array}$ & 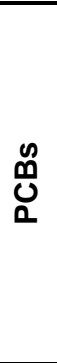 & 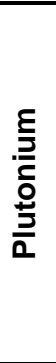 & 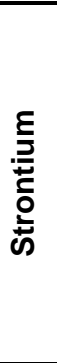 & $\overbrace{\infty}^{\infty}$ & 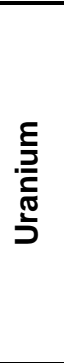 & $\begin{array}{l}\text { o } \\
\text { § }\end{array}$ \\
\hline \multirow{2}{*}{ A01 } & 544A001 & $10.0-13.0$ & Soil & Environmental & $x$ & $x$ & $x$ & $x$ & $x$ & $x$ & $x$ & $x$ & $x$ \\
\hline & 544A002 & $10.0-13.0$ & Soil & $\begin{array}{l}\text { Field Duplicate } \\
\text { of } \# 544 A 001\end{array}$ & $x$ & $x$ & $x$ & $x$ & $\mathrm{x}$ & $x$ & $x$ & $x$ & $x$ \\
\hline A02 & 544A003 & 8.0-10.0 & Soil & Environmental & $x$ & $x$ & $x$ & $x$ & $x$ & $x$ & $x$ & $x$ & $x$ \\
\hline N/A & 544A301 & N/A & Water & Trip Blank & -- & -- & -- & -- & -- & -- & -- & -- & $x$ \\
\hline
\end{tabular}

$X=$ Required

$--=$ Not required 


\section{B.3.1.1 Field Screening}

Investigation samples were field screened for alpha and beta/gamma radiation. The FSRs were compared to FSLs to guide subsequent sampling decisions where appropriate. All soil samples from this CAS were below background radiological FSLs for alpha and beta/gamma.

\section{B.3.1.2 Visual Inspections}

No spills, staining, disturbances of soil, or other indications of potential contamination were identified during the inspection of CAS 02-37-08, and site conditions were unchanged from previous field visits. The post-test drill pipe was visible and was extended out of the backfilled cellar.

\section{B.3.1.3 Sample Collection}

Decision I environmental sampling included the collection of biased subsurface soil samples at two locations within the backfilled cellar. Environmental samples were collected using Geoprobe techniques.

Three Decision I environmental samples (including one FD) were collected at the cellar. One subsurface sample was collected from each borehole (A01 and A02, Figure B.3-1). Each borehole was pushed to refusal at the cellar bottom. Core material was monitored during drilling, and the interface with the cellar bottom was identified at $13.0 \mathrm{ft}$ bgs on the west side of the cellar and at $10.0 \mathrm{ft}$ bgs on the east side of the cellar as evidenced by cement in the bottom of the cores. The sample from location A01 (west side) was collected from 10.0 to $13.0 \mathrm{ft}$ bgs, and the sample from location A02 (east side) was collected from 8.0 to $10.0 \mathrm{ft}$ bgs. Multiple pushes of the Geoprobe tool were necessary to obtain the volume of soil necessary for the required analysis.

\section{B.3.1.4 Deviations}

There were no deviations from the activities outlined in the CAU 544 SAFER Plan (NNSA/NSO, 2010). The environmental samples collected were submitted for laboratory analysis. 


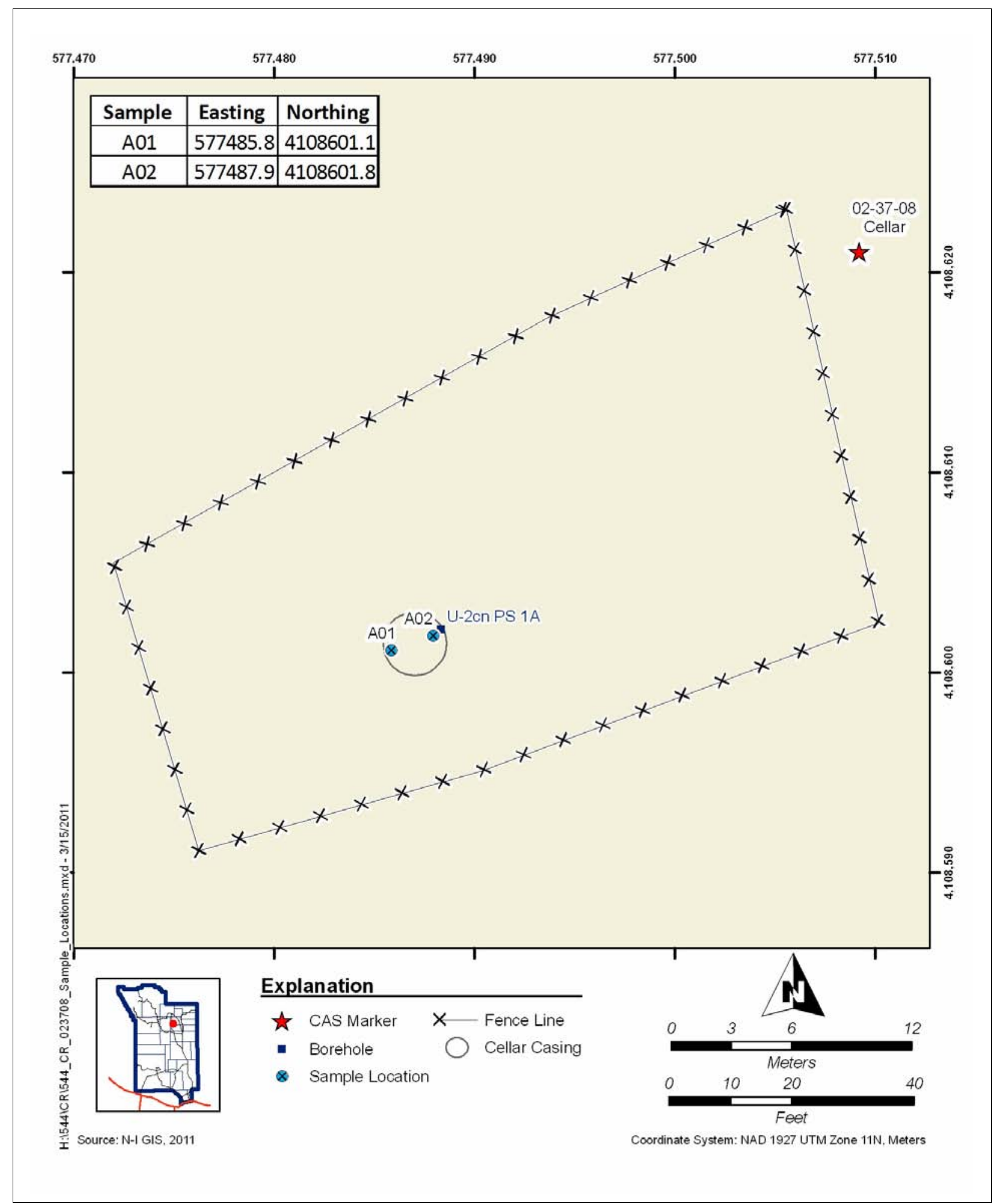

Figure B.3-1

Sample Locations at CAS 02-37-08, Cellar \& Mud Pit 


\section{B.3.2 Investigation Results}

The following sections provide analytical results from the samples collected to complete investigation activities as outlined in the SAFER Plan (NNSA/NSO, 2010). Samples were analyzed for the COPCs identified in the SAFER Plan and included VOCs, SVOCs, Resource Conservation and Recovery Act (RCRA) metals and hexavalent chromium, gamma-emitting radionuclides, isotopic $\mathrm{U}$, isotopic $\mathrm{Pu}$, and Sr-90; PCBs are added parameters because PCBs are a common concern at the NNSS. The analytical parameters and laboratory methods used to analyze the investigation samples are listed in Table B.2-2. Table B.3-1 lists the sample-specific analytical suite for CAS 02-37-08. No waste characterization samples were collected at this CAS.

Analytical results from the soil samples with concentrations exceeding MDCs are summarized in the following sections. An evaluation was conducted on all contaminants detected above MDCs by comparing individual concentration or activity results against the FALs. Establishment of the FALs is presented in Appendix D. The FALs were established as the corresponding PAL concentrations or activities if the contaminant concentrations were below their respective PALs.

\section{B.3.2.1 Volatile Organic Compounds}

The only VOC detected at a concentration exceeding the MDC was acetone at a depth of 10.0 to $13.0 \mathrm{ft}$ bgs (Table B.3-2). The concentrations are well below the PAL of 630,000 mg/kg. Therefore, the FAL was established at the corresponding PAL.

Table B.3-2

Sample Results for VOCs Detected above MDCs at CAS 02-37-08, Cellar \& Mud Pit

\begin{tabular}{|c|c|c|c||}
\hline \multirow{2}{*}{$\begin{array}{c}\text { Sample } \\
\text { Location }\end{array}$} & \multirow{2}{*}{$\begin{array}{c}\text { Sample } \\
\text { Number }\end{array}$} & $\begin{array}{c}\text { Depth } \\
\text { (ft bgs) }\end{array}$ & COPC (mg/kg) \\
\cline { 4 - 4 } & & & Acetone \\
\hline \multicolumn{3}{|c|}{ FAL } & $\mathbf{6 3 0 , 0 0 0}$ \\
\hline \hline \multirow{2}{*}{ A01 } & $544 A 001$ & $10.0-13.0$ & $0.00221(\mathrm{~J})$ \\
\cline { 2 - 4 } & $544 A 002$ & $10.0-13.0$ & $0.00205(\mathrm{~J})$ \\
\hline
\end{tabular}

$\mathrm{J}=$ Estimated value 


\section{B.3.2.2 Semivolatile Organic Compounds}

The only SVOC detected at a concentration exceeding the MDC was benzo(b)fluoranthene at a depth of 10.0 to $13.0 \mathrm{ft}$ bgs (Table B.3-3). The concentration is well below the PAL of $2.1 \mathrm{mg} / \mathrm{kg}$. Therefore, the FAL was established at the corresponding PAL.

Table B.3-3

Sample Results for SVOCs Detected above MDCs at CAS 02-37-08, Cellar \& Mud Pit

\begin{tabular}{|c|c|c|c|}
\hline \multirow{2}{*}{$\begin{array}{c}\text { Sample } \\
\text { Location }\end{array}$} & $\begin{array}{c}\text { Sample } \\
\text { Number }\end{array}$ & $\begin{array}{c}\text { Depth } \\
\text { (ft bgs) }\end{array}$ & COPC (mg/kg) \\
\cline { 4 - 4 } & & & Benzo(b)fluoranthene \\
\hline \multicolumn{3}{|c|}{ FAL } & $\mathbf{2 . 1}$ \\
\hline \hline A01 & $544 A 001$ & $10.0-13.0$ & $0.0193(\mathrm{~J})$ \\
\hline
\end{tabular}

$\mathrm{J}=$ Estimated value

\section{B.3.2.3 RCRA Metals}

Analytical results for RCRA metals in soil samples collected at this CAS that were detected above MDCs are presented in Table B.3-4. No metals were detected at concentrations exceeding their PALs, and the FALs were established at the PAL concentrations.

Table B.3-4

Sample Results for Metals Detected above MDCs at CAS 02-37-08, Cellar \& Mud Pit

\begin{tabular}{|c|c|c|c|c|c|c|c|c||}
\hline \multirow{2}{*}{$\begin{array}{c}\text { Sample } \\
\text { Location }\end{array}$} & \multirow{2}{*}{$\begin{array}{c}\text { Sample } \\
\text { Number }\end{array}$} & \multirow{2}{*}{$\begin{array}{c}\text { Depth } \\
\text { (ft bgs) }\end{array}$} & \multicolumn{7}{|c|}{ COPCs (mg/kg) } \\
\cline { 4 - 10 } & & & Arsenic & Barium & Cadmium & Chromium & Lead & Mercury \\
\hline \multicolumn{3}{|c|}{ FALs } & $\mathbf{2 3}$ & $\mathbf{1 9 0 , 0 0 0}$ & $\mathbf{8 0 0}$ & N/A & $\mathbf{8 0 0}$ & $\mathbf{3 4}$ \\
\hline \hline \multirow{2}{*}{$\mathrm{A} 01$} & $544 \mathrm{~A} 001$ & $10.0-13.0$ & 3.21 & $128(\mathrm{~J})$ & -- & 5.47 & $10.8(\mathrm{~J})$ & 0.028 \\
\cline { 2 - 10 } & $544 \mathrm{~A} 002$ & $10.0-13.0$ & 3.48 & $230(\mathrm{~J})$ & -- & 5.65 & $12.7(\mathrm{~J})$ & 0.0244 \\
\hline $\mathrm{A} 02$ & $544 \mathrm{~A} 003$ & $8.0-10.0$ & 1.43 & $144(\mathrm{~J})$ & $0.117(\mathrm{~J})$ & 6.63 & $11.5(\mathrm{~J})$ & 0.0223 \\
\hline
\end{tabular}

$\mathrm{J}=$ Estimated value

-- = Not detected above MDCs 


\section{B.3.2.4 Polychlorinated Biphenyls}

No PCBs were detected in soil samples collected at this CAS at concentrations exceeding the MDCs or PALs. Therefore, the FALs were established at the corresponding PAL concentrations.

\section{B.3.2.5 Gamma-Emitting Radionuclides}

Analytical results for gamma-emitting radionuclides in soil samples collected at this CAS that were detected above MDCs are presented in Table B.3-5. No gamma-emitting radionuclides were detected at concentrations exceeding their PALs. The FALs were established at the PAL concentrations.

Table B.3-5

Sample Results for Gamma-Emitting Radionuclides Detected above MDCs at CAS 02-37-08, Cellar \& Mud Pit

\begin{tabular}{|c|c|c|c|c||}
\hline \multirow{2}{*}{$\begin{array}{c}\text { Sample } \\
\text { Location }\end{array}$} & \multirow{2}{*}{$\begin{array}{c}\text { Sample } \\
\text { Number }\end{array}$} & \multirow{2}{*}{$\begin{array}{c}\text { Depth } \\
\text { (ft bgs) }\end{array}$} & \multicolumn{2}{|c|}{ COPCs (pCi/g) } \\
\cline { 4 - 5 } & & & Ac-228 & Cs-137 \\
\hline \multicolumn{3}{|c|}{ FALs } & $\mathbf{5}$ & $\mathbf{1 2 . 2}$ \\
\hline \hline \multirow{2}{*}{$\mathrm{A} 01$} & $544 \mathrm{~A} 001$ & $10.0-13.0$ & 1.54 & 0.23 \\
\cline { 2 - 5 } & $544 \mathrm{~A} 002$ & $10.0-13.0$ & 1.56 & 0.136 \\
\hline $\mathrm{A} 02$ & $544 \mathrm{~A} 003$ & $8.0-10.0$ & 1.77 & 0.278 \\
\hline
\end{tabular}

Ac $=$ Actinium

Cs $=$ Cesium

\section{B.3.2.6 Plutonium and Uranium Isotopes, and Strontium-90}

Analytical results for the Pu and $\mathrm{U}$ isotopes and Sr-90 in soil samples collected at this CAS that were detected above MDCs are presented in Table B.3-6. None of the Pu and U isotopes or Sr-90 exceeded the PALs. Isotopic Pu and Sr-90 above the MDCs or PALs were not detected in soil samples. The FALs were established at the PAL concentrations.

\section{B.3.3 Nature and Extent of Contamination}

Based on the analytical results for soil samples collected within CAS 02-37-08, no COCs were identified. 
Table B.3-6

Sample Results for Isotopes Detected above MDCs at CAS 02-37-08, Cellar \& and Mud Pit

\begin{tabular}{||c|c|c|c|c|c|}
\hline \multirow{2}{*}{$\begin{array}{c}\text { Sample } \\
\text { Location }\end{array}$} & \multirow{2}{*}{$\begin{array}{c}\text { Sample } \\
\text { Number }\end{array}$} & \multirow{2}{*}{$\begin{array}{c}\text { Depth } \\
\text { (ft bgs) }\end{array}$} & \multicolumn{3}{c|}{ COPCs (pCi/g) } \\
\cline { 4 - 6 } & & & $\mathbf{U}-234$ & U-235 & U-238 \\
\hline \hline \multirow{2}{*}{ A01 } & 544 FALs & 1001 & 17.6 & 105 \\
\cline { 2 - 6 } & $544 A 002$ & $10.0-13.0$ & 0.891 & -- & 0.987 \\
\hline A02 & 544 A003 & $8.0-10.0$ & 0.813 & 0.0584 & 0.994 \\
\hline
\end{tabular}

-- = Not detected above MDCs

\section{B.3.4 Revised Conceptual Site Model}

The SAFER Plan requirements were met at this CAS, and no revisions were necessary to the CSM. 


\section{B.4.0 CAS 02-37-09, Cellar \& Mud Pit, Investigation Results}

Corrective Action Site 02-37-09 is located in Area 2 of the NNSS and consists of potential environmental releases associated with the backfilled cellar and backfilled mud pit. The cellar and mud pit are located in the vicinity of the U-2dc4a (Tyg-D) crater. Both the cellar and mud pit are located within a fenced, posted URMA. Additional detail is provided in the SAFER Plan (NNSA/NSO, 2010).

\section{B.4.1 SAFER Activities}

A total of 13 characterization samples (including 1 FD) were collected during investigation activities at CAS 02-37-09. The sample IDs, locations, types, and analyses are listed in Table B.4-1. The specific CAI activities conducted to satisfy the SAFER Plan requirements at this CAS are described in the following sections.

Table B.4-1

Samples Collected at CAS 02-37-09, Cellar \& Mud Pit

(Page 1 of 2)

\begin{tabular}{|c|c|c|c|c|c|c|c|c|c|c|c|c|c|}
\hline $\begin{array}{l}\text { Sample } \\
\text { Location }\end{array}$ & $\begin{array}{l}\text { Sample } \\
\text { Number }\end{array}$ & $\begin{array}{l}\text { Depth } \\
\text { (ft bgs) }\end{array}$ & Matrix & Purpose & 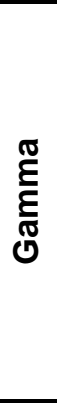 & 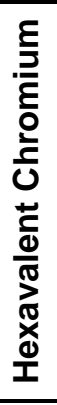 & $\frac{\frac{00}{\pi}}{\frac{\pi}{0}}$ & 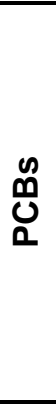 & 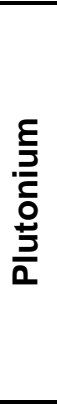 & 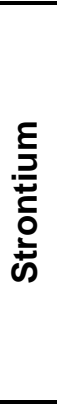 & $\overbrace{\infty}^{0}$ & 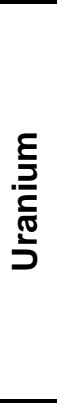 & $\begin{array}{l}\text { Uू } \\
\text { O }\end{array}$ \\
\hline B01 & 544B001 & $3.5-4.5$ & Soil & Environmental & $x$ & - & - & - & $\mathrm{x}$ & $x$ & -- & $\mathrm{x}$ & -- \\
\hline B02 & 544B002 & $4.0-5.0$ & Soil & Environmental & $x$ & -- & -- & -- & $x$ & $x$ & -- & $x$ & -- \\
\hline B03 & 544B003 & $14.0-16.0$ & Soil & Environmental & $x$ & $x$ & $x$ & $x$ & $x$ & $x$ & $x$ & $\mathrm{x}$ & $\mathrm{x}$ \\
\hline B04 & 544B005 & $4.5-5.0$ & Soil & Environmental & $x$ & -- & -- & -- & $x$ & $x$ & -- & $x$ & -- \\
\hline B05 & 544B006 & $3.5-4.0$ & Soil & Environmental & $x$ & -- & -- & -- & $x$ & $x$ & -- & $x$ & -- \\
\hline B06 & 544B007 & $4.0-4.5$ & Soil & Environmental & $x$ & -- & -- & -- & $x$ & $x$ & -- & $x$ & -- \\
\hline B07 & 544B008 & $4.0-4.5$ & Soil & Environmental & $x$ & -- & -- & -- & $x$ & $x$ & -- & $x$ & -- \\
\hline B08 & 544B009 & $4.0-4.5$ & Soil & Environmental & $x$ & -- & -- & -- & $x$ & $x$ & -- & $x$ & -- \\
\hline B09 & 544B010 & $4.0-4.5$ & Soil & Environmental & $x$ & -- & -- & -- & $x$ & $x$ & -- & $x$ & -- \\
\hline
\end{tabular}


Table B.4-1

\section{Samples Collected at CAS 02-37-09, Cellar \& Mud Pit}

(Page 2 of 2)

\begin{tabular}{|c|c|c|c|c|c|c|c|c|c|c|c|c|c|}
\hline $\begin{array}{l}\text { Sample } \\
\text { Location }\end{array}$ & $\begin{array}{l}\text { Sample } \\
\text { Number }\end{array}$ & $\begin{array}{l}\text { Depth } \\
\text { (ft bgs) }\end{array}$ & Matrix & Purpose & 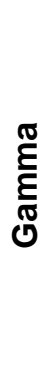 & 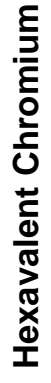 & $\begin{array}{l}\frac{\infty}{\mathbb{J}} \\
\frac{\mathbb{d}}{\Sigma}\end{array}$ & $\begin{array}{l}\boldsymbol{n} \\
\text { M } \\
\text { Un }\end{array}$ & 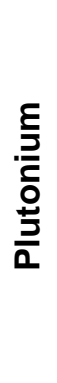 & 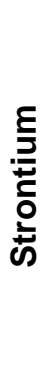 & $\begin{array}{l}\text { ơ } \\
\text { un }\end{array}$ & 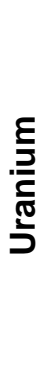 & $\begin{array}{l}\text { Uू } \\
\text { O̊ }\end{array}$ \\
\hline B10 & 544B011 & $4.0-4.5$ & Soil & Environmental & $X$ & -- & -- & -- & $X$ & $x$ & -- & $X$ & -- \\
\hline B11 & 544B012 & $3.5-4.0$ & Soil & Environmental & $x$ & -- & -- & -- & $x$ & $x$ & -- & $x$ & -- \\
\hline \multirow[b]{2}{*}{ B12 } & 544B013 & 9.0-11.0 & Soil & Environmental & $X$ & $x$ & $x$ & $x$ & $x$ & $x$ & $x$ & $X$ & $X$ \\
\hline & 544B014 & 9.0-11.0 & Soil & $\begin{array}{c}\text { Field Duplicate } \\
\text { of \#544B013 }\end{array}$ & $x$ & $X$ & $x$ & $x$ & $X$ & $x$ & $x$ & $x$ & $x$ \\
\hline N/A & 544B301 & $\mathrm{N} / \mathrm{A}$ & Water & Trip Blank & -- & -- & -- & -- & -- & -- & -- & -- & $X$ \\
\hline $\mathrm{N} / \mathrm{A}$ & 544B302 & $N / A$ & Water & Trip Blank & -- & -- & -- & -- & -- & -- & -- & -- & $X$ \\
\hline $\mathrm{N} / \mathrm{A}$ & 544B303 & $\mathrm{N} / \mathrm{A}$ & Water & Field Blank & $X$ & $X$ & $x$ & $x$ & $x$ & $X$ & $X$ & $x$ & $X$ \\
\hline $\mathrm{N} / \mathrm{A}$ & 544B304 & N/A & Water & $\begin{array}{l}\text { Equipment } \\
\text { Rinsate }\end{array}$ & $X$ & $X$ & $x$ & $x$ & $X$ & $X$ & $x$ & $x$ & $X$ \\
\hline N/A & 544B305 & N/A & Water & Trip Blank & -- & -- & -- & -- & -- & -- & -- & -- & $x$ \\
\hline
\end{tabular}

NOTE: Sample 544B004 was not collected due to a broken bit on the Geoprobe equipment.

$X=$ Required

$--=$ Not required

\section{B.4.1.1 Field Screening}

Investigation samples were field screened for alpha and beta/gamma radiation. The FSRs were compared to FSLs to guide subsequent sampling decisions where appropriate. Gross alpha radiation FSLs were exceeded in one sample. All soil samples were below background radiological FSLs for beta/gamma.

\section{B.4.1.2 Visual Inspections}

No spills, staining, disturbances of soil, or other indications of potential contamination were identified during the inspection of the backfilled cellar and covered mud pit at CAS 02-37-09, and site 
conditions were unchanged from previous field visits. The post-test drill pipe was not visible in the backfilled cellar.

\section{B.4.1.3 Sample Collection}

Decision I environmental sampling included the collection of biased subsurface soil samples at 2 locations within the backfilled cellar and 10 random locations within the covered mud pit (Figure B.4-1). Samples were collected using a Geoprobe and hand auger.

A total of 10 Decision I soil samples were collected from 10 locations (B01, B02, B04 through B11) within the covered mud pit. The soil collected consisted primarily of a silty sand with gravel. Dry, light brownish-gray mud was identified in the soil collected only at locations B01, B02, and B10.

Three Decision I environmental samples (including one FD) were collected at the cellar. One subsurface sample was collected from each borehole (B03 and B12). Each borehole was drilled to refusal at the cellar bottom. Core material was monitored during drilling, and the interface with the cellar bottom was identified at $16.0 \mathrm{ft}$ bgs on the north side of the cellar and at $11.0 \mathrm{ft}$ bgs on the south side of the cellar as evidenced by cement in the bottom of the cores. The sample from location B03 (north side) was collected from 14.0 to $16.0 \mathrm{ft}$ bgs using Geoprobe equipment, and the sample from location B12 (south side) was collected from 9.0 to $11.0 \mathrm{ft}$ bgs using a hand auger. Multiple pushes of the Geoprobe tool were necessary to obtain the volume of soil necessary for the required analysis at location B03.

\section{B.4.1.4 Deviations}

There were no deviations from the planned activities. Investigation samples were collected as outlined in the CAU 544 SAFER Plan (NNSA/NSO, 2010) and submitted for laboratory analysis.

\section{B.4.2 Investigation Results}

The following sections provide analytical results from the samples collected to complete investigation activities as outlined in the SAFER Plan (NNSA/NSO, 2010). Investigation samples collected at the cellar were analyzed for the SAFER Plan-specified COPCs, which included VOCs, SVOCs, RCRA metals and hexavalent chromium, gamma-emitting radionuclides, isotopic U, 


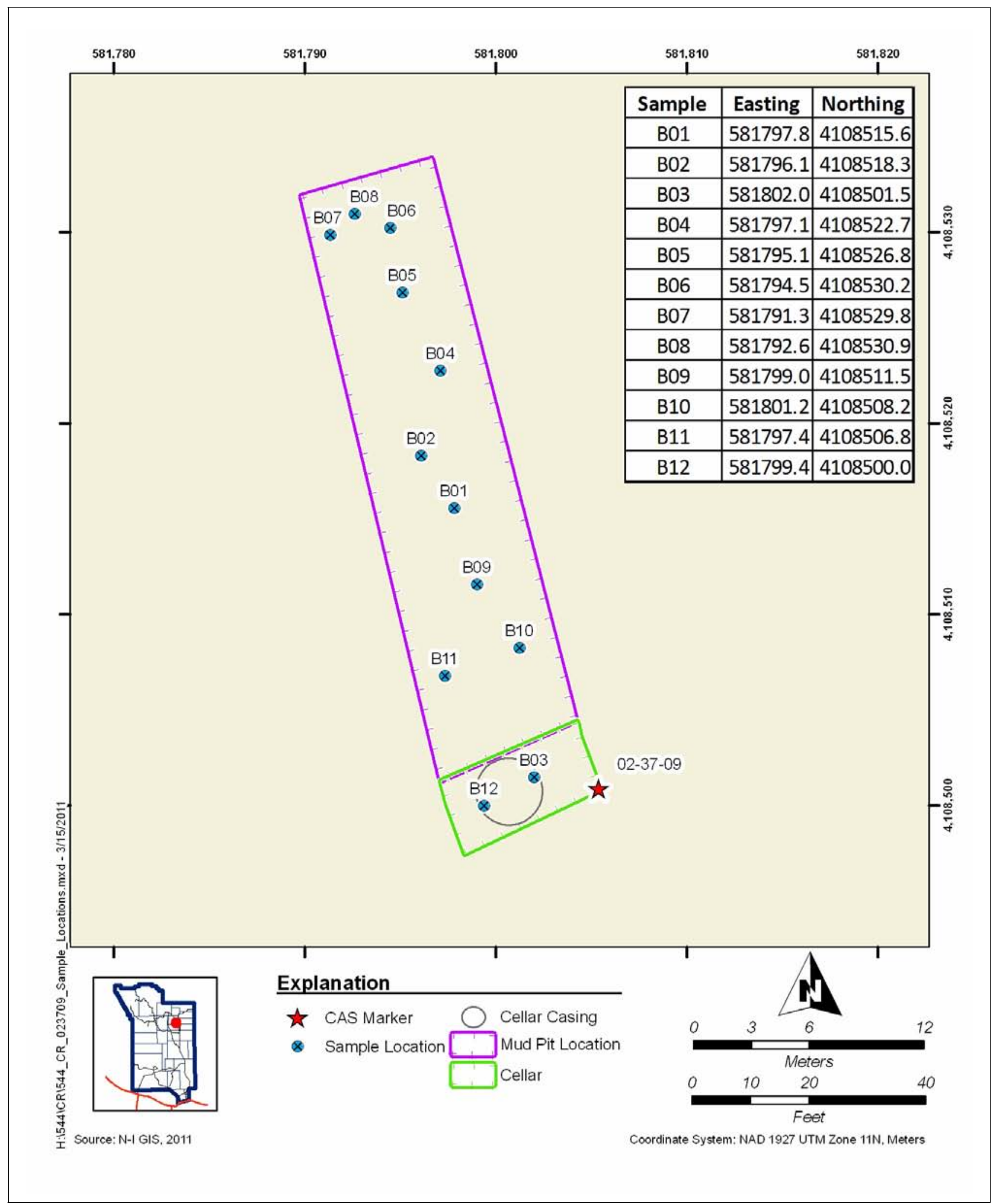

Figure B.4-1

Sample Locations at CAS 02-37-09, Cellar \& Mud Pit 
isotopic $\mathrm{Pu}$, and $\mathrm{Sr}-90$; PCBs are added parameters because these contaminants are a common concern at the NNSS. Samples collected at the mud pit were analyzed for gamma-emitting radionuclides, isotopic $\mathrm{U}$, isotopic $\mathrm{Pu}$, and Sr-90. The analytical parameters and laboratory methods used to analyze the investigation samples are listed in Table B.2-2. Table B.4-1 lists the sample-specific analytical suite for CAS 02-37-09. No waste characterization samples were collected at this CAS.

For the judgmental samples at the cellar component of CAS 02-37-09, an evaluation was conducted on all contaminants detected above MDCs by comparing individual concentration or activity results against the FALs to determine whether a constituent is a COC. The FALs were established as the corresponding PAL concentrations or activities if the contaminant concentrations were below respective PALs. Establishment of the FALs is presented in Appendix D.

For the probabilistic samples at the mud pit, any COPC that had a 95 percent UCL of the average concentration exceeding the FAL would result in that COPC being designated as a COC. As stipulated in Section C.1.2.1 of the CAU 544 SAFER Plan, UCLs were only calculated for a COPC if it was detected in any sample within any CAS at a concentration equal to or exceeding the PAL. If COPCs are not detected in any mud pit sample at a concentration exceeding the PAL, then it will be concluded that no COCs are present.

\section{B.4.2.1 Volatile Organic Compounds}

Volatile organic compounds above the MDCs or PALs were not detected in soil samples. Therefore, the FALs were established at the corresponding PAL concentrations.

\section{B.4.2.2 Semivolatile Organic Compounds}

Semivolatile organic compounds above the MDCs or PALs were not detected in soil samples. Therefore, the FALs were established at the corresponding PAL concentrations. 


\section{B.4.2.3 RCRA Metals}

Analytical results for RCRA metals in soil samples collected at this CAS that were detected above MDCs are presented in Table B.4-2. No metals were detected at concentrations exceeding their PALs. The FALs were established at the PAL concentrations.

Table B.4-2

Sample Results for Metals Detected above MDCs at CAS 02-37-09, Cellar \& Mud Pit

\begin{tabular}{|c|c|c|c|c|c|c|c|c|}
\hline \multirow{2}{*}{$\begin{array}{l}\text { Sample } \\
\text { Location }\end{array}$} & \multirow{2}{*}{$\begin{array}{l}\text { Sample } \\
\text { Number }\end{array}$} & \multirow{2}{*}{$\begin{array}{c}\text { Depth } \\
\text { (ft bgs) }\end{array}$} & \multicolumn{6}{|c|}{ COPCs (mg/kg) } \\
\hline & & & Arsenic & Barium & Cadmium & Chromium & Lead & Mercury \\
\hline \multicolumn{3}{|c|}{ FALs } & 23 & 190,000 & 800 & N/A & 800 & 34 \\
\hline B03 & 544B003 & $14.0-16.0$ & 1.88 & $103(\mathrm{~J}+)$ & $0.112(\mathrm{~J})$ & 7.01 & $10.1(\mathrm{~J})$ & $0.0112(\mathrm{~J})$ \\
\hline \multirow{2}{*}{ B12 } & 544B013 & $9.0-11.0$ & 1.94 & 115 & -- & 5.63 & 9.82 & $0.0119(\mathrm{~J})$ \\
\hline & 544B014 & $9.0-11.0$ & 2.11 & 127 & -- & 4.87 & 10.2 & $0.0113(\mathrm{~J})$ \\
\hline
\end{tabular}

$\mathrm{J}=$ Estimated value

$\mathrm{J}+=$ Estimated bias high

-- = Not detected above MDCs

\section{B.4.2.4 Polychlorinated Biphenyls}

The only PCB detected at a concentration exceeding the MDC was Aroclor 1254 at a depth of 14.0 to $16.0 \mathrm{ft}$ bgs (Table B.4-3). The concentration is well below the PAL of $0.74 \mathrm{mg} / \mathrm{kg}$. Therefore, the FAL was established at the corresponding PAL.

Table B.4-3

Sample Results for PCBs Detected above MDCs at CAS 02-37-09, Cellar \& Mud Pit

\begin{tabular}{||c|c|c|c|}
\hline \multirow{2}{*}{$\begin{array}{c}\text { Sample } \\
\text { Location }\end{array}$} & \multirow{2}{*}{$\begin{array}{c}\text { Sample } \\
\text { Number }\end{array}$} & $\begin{array}{c}\text { Depth } \\
\text { (ft bgs) }\end{array}$ & COPC (mg/kg) \\
\cline { 4 - 4 } & & & Aroclor 1254 \\
\hline \multicolumn{3}{|c|}{ FAL } & $\mathbf{0 . 7 4}$ \\
\hline \hline B03 & $544 \mathrm{~B} 003$ & $14.0-16.0$ & $0.0036(\mathrm{~J})$ \\
\hline
\end{tabular}

$\mathrm{J}=$ Estimated value 


\section{B.4.2.5 Gamma-Emitting Radionuclides}

Analytical results for gamma-emitting radionuclides in soil samples collected at this CAS that were detected above MDCs are presented in Table B.4-4. No gamma-emitting radionuclides exceeded the PALs. The FALs were established at the PAL concentrations.

Table B.4-4

Sample Results for Gamma-Emitting Radionuclides Detected above MDCs at CAS 02-37-09, Cellar \& Mud Pit

\begin{tabular}{|c|c|c|c|c|c|}
\hline \multirow{2}{*}{$\begin{array}{l}\text { Sample } \\
\text { Location }\end{array}$} & \multirow{2}{*}{$\begin{array}{l}\text { Sample } \\
\text { Number }\end{array}$} & \multirow{2}{*}{$\begin{array}{c}\text { Depth } \\
\text { (ft bgs) }\end{array}$} & \multicolumn{3}{|c|}{ COPCs (pCi/g) } \\
\hline & & & Ac-228 & Cs-137 & Th-234 \\
\hline \multicolumn{3}{|c|}{ FALs } & 5 & 12.2 & 105 \\
\hline B01 & 544B001 & $3.5-4.5$ & 2.18 & 0.154 & -- \\
\hline B02 & 544B002 & $4.0-5.0$ & 0.722 & -- & -- \\
\hline B03 & 544B003 & 14.0-16.0 & 2.18 & 0.3 & -- \\
\hline B04 & 544B005 & $4.5-5.0$ & 2.2 & -- & -- \\
\hline B05 & 544B006 & $3.5-4.0$ & 2.46 & -- & $2.08(\mathrm{~J})$ \\
\hline B06 & 544B007 & $4.0-4.5$ & 2.1 & -- & -- \\
\hline B07 & 544B008 & $4.0-4.5$ & 2.15 & -- & -- \\
\hline B08 & 544B009 & $4.0-4.5$ & 2.07 & 0.328 & -- \\
\hline B09 & 544B010 & $4.0-4.5$ & 2.37 & -- & $4.49(\mathrm{~J})$ \\
\hline B10 & 544B011 & $4.0-4.5$ & 2.27 & -- & -- \\
\hline B11 & 544B012 & $3.5-4.0$ & 2.08 & -- & -- \\
\hline \multirow{2}{*}{ B12 } & 544B013 & $9.0-11.0$ & 1.96 & -- & -- \\
\hline & 544B014 & 9.0-11.0 & 2 & -- & -- \\
\hline
\end{tabular}

$\mathrm{J}=$ Estimated value

$--=$ Not detected above MDCs

Th $=$ Thorium

\section{B.4.2.6 Plutonium and Uranium Isotopes, and Strontium-90}

Analytical results for the Pu and $\mathrm{U}$ isotopes and Sr-90 in soil samples collected at this CAS that were detected above MDCs are presented in Table B.4-5. None of the Pu and U isotopes or Sr-90 exceeded the PALs, and the FALs were established at the PAL concentrations. 
Table B.4-5

Sample Results for Isotopes Detected

above MDCs at CAS 02-37-09, Cellar \& Mud Pit

\begin{tabular}{|c|c|c|c|c|c|}
\hline \multirow{2}{*}{$\begin{array}{l}\text { Sample } \\
\text { Location }\end{array}$} & \multirow{2}{*}{$\begin{array}{l}\text { Sample } \\
\text { Number }\end{array}$} & \multirow{2}{*}{$\begin{array}{l}\text { Depth } \\
\text { (ft bgs) }\end{array}$} & \multicolumn{3}{|c|}{ COPCs (pCi/g) } \\
\hline & & & U-234 & U-235 & U-238 \\
\hline \multicolumn{3}{|c|}{ FALs } & 143 & 17.6 & 105 \\
\hline B01 & 544B001 & $3.5-4.5$ & 1.62 & 0.105 & 1.35 \\
\hline B02 & 544B002 & $4.0-5.0$ & 0.885 & 0.0523 & 0.892 \\
\hline B03 & 544B003 & 14.0-16.0 & 1.06 & $0.0594(\mathrm{~J})$ & 1.01 \\
\hline B04 & 544B005 & $4.5-5.0$ & 1.27 & $0.0855(\mathrm{~J})$ & 1.25 \\
\hline B05 & 544B006 & $3.5-4.0$ & 1.12 & $0.109(\mathrm{~J})$ & 1.16 \\
\hline B06 & 544B007 & $4.0-4.5$ & 0.993 & $0.0504(\mathrm{~J})$ & 1.01 \\
\hline B07 & 544B008 & $4.0-4.5$ & 1.14 & $0.0698(\mathrm{~J})$ & 1.13 \\
\hline B08 & 544B009 & $4.0-4.5$ & 1.19 & $0.151(\mathrm{~J})$ & 1.16 \\
\hline B09 & 544B010 & $4.0-4.5$ & 1.44 & $0.124(\mathrm{~J})$ & 1.25 \\
\hline B10 & 544B011 & $4.0-4.5$ & 1.17 & $0.0796(\mathrm{~J})$ & 1.2 \\
\hline B11 & 544B012 & $3.5-4.0$ & 0.974 & -- & 0.934 \\
\hline \multirow{2}{*}{ B12 } & 544B013 & 9.0-11.0 & 1.1 & 0.0702 & 0.944 \\
\hline & 544B014 & $9.0-11.0$ & 1.14 & 0.0622 & 0.981 \\
\hline
\end{tabular}

$\mathrm{J}=$ Estimated value

-- = Not detected above MDCs

\section{B.4.3 Nature and Extent of Contamination}

Based on the analytical results for soil samples collected within CAS 02-37-09, no COCs were identified.

\section{B.4.4 Revised Conceptual Site Model}

The SAFER Plan requirements were met at this CAS, and no revisions were necessary to the CSM. 


\section{B.5.0 CAS 09-09-46, U-9itsx20 PS \#1A Mud Pit, Investigation Results}

Corrective Action Site 09-09-46 is located in Area 9 of the NNSS and consists of potential releases associated with the mud pit. The uncovered mud pit is located on the eastern edge of the U-9itsx20 crater within the fenced crater area. The mud pit and area within the crater are posted as a CA. Additional detail is provided in the SAFER Plan (NNSA/NSO, 2010).

\section{B.5.1 SAFER Activities}

A total of 11 characterization samples (including 1 FD) were collected during investigation activities at CAS 09-09-46. The sample IDs, locations, types, and analyses are listed in Table B.5-1. The specific CAI activities conducted to satisfy the SAFER Plan requirements at this CAS are described in the following sections.

Table B.5-1

Samples Collected at CAS 09-09-46, U-9itsx20 PS \#1A Mud Pit

\begin{tabular}{|c|c|c|c|c|c|c|c|c|}
\hline $\begin{array}{l}\text { Sample } \\
\text { Location }\end{array}$ & $\begin{array}{l}\text { Sample } \\
\text { Number }\end{array}$ & $\begin{array}{l}\text { Depth } \\
\text { (in. bgs) }\end{array}$ & Matrix & Purpose & 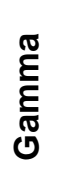 & 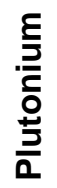 & 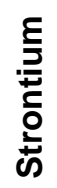 & 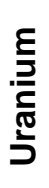 \\
\hline \multirow[b]{2}{*}{ F01 } & 544F001 & $0-6$ & Soil & Environmental & $x$ & $X$ & $\mathrm{X}$ & $x$ \\
\hline & 544F002 & $0-6$ & Soil & $\begin{array}{c}\text { Field Duplicate } \\
\text { of \#544F001 }\end{array}$ & $X$ & $X$ & $X$ & $x$ \\
\hline F02 & 544F003 & $0-6$ & Soil & Environmental & $x$ & $x$ & $x$ & $x$ \\
\hline F03 & 544F004 & $0-6$ & Soil & Environmental & $x$ & $x$ & $X$ & $x$ \\
\hline F04 & 544F005 & $0-6$ & Soil & Environmental & $X$ & $x$ & $X$ & $x$ \\
\hline F05 & 544F006 & $0-6$ & Soil & Environmental & $x$ & $x$ & $x$ & $x$ \\
\hline F06 & 544F007 & $0-6$ & Soil & Environmental & $x$ & $x$ & $x$ & $x$ \\
\hline F07 & 544F008 & $0-6$ & Soil & Environmental & $X$ & $X$ & $x$ & $x$ \\
\hline F08 & 544F009 & $0-6$ & Soil & Environmental & $X$ & $X$ & $x$ & $x$ \\
\hline F09 & 544F010 & $0-6$ & Soil & Environmental & $X$ & $X$ & $x$ & $x$ \\
\hline F10 & 544F011 & $0-6$ & Soil & Environmental & $X$ & $X$ & $x$ & $x$ \\
\hline
\end{tabular}

$X=$ Required 


\section{B.5.1.1 Field Screening}

Investigation samples were field screened for alpha and beta/gamma radiation. The FSRs were compared to FSLs to guide subsequent sampling decisions where appropriate. All soil samples were below background radiological FSLs for alpha and beta/gamma.

\section{B.5.1.2 Visual Inspections}

No spills, staining, disturbances of soil, or other indications of potential contamination were identified during the inspection of the uncovered mud pit of CAS 09-09-46, and site conditions were unchanged from previous field visits.

\section{B.5.1.3 Sample Collection}

Decision I environmental sampling included the collection of 11 randomly placed surface soil samples, including 1 FD, at 10 locations within the covered mud pit (Figure B.5-1). Collected drilling mud consisted primarily of a light brown clayey silt and was identified in all locations. Samples were collected using hand-sampling methods (scoops and trowels).

\section{B.5.1.4 Deviations}

Investigation samples were collected as outlined in the CAU 544 SAFER Plan (NNSA/NSO, 2010) and submitted for laboratory analysis.

\section{B.5.2 Investigation Results}

The following sections provide analytical results from the samples collected to complete investigation activities as outlined in the SAFER Plan (NNSA/NSO, 2010). Investigation samples collected at the mud pit were analyzed for the SAFER Plan-specified COPCs, which included gamma-emitting radionuclides, isotopic $\mathrm{U}$, isotopic $\mathrm{Pu}$, and $\mathrm{Sr}-90$. The analytical parameters and laboratory methods used to analyze the investigation samples are listed in Table B.2-2. Table B.5-1 lists the sample-specific analytical suite for CAS 09-09-46. No waste was generated at this CAS; therefore, no waste characterization samples were collected at this CAS. 


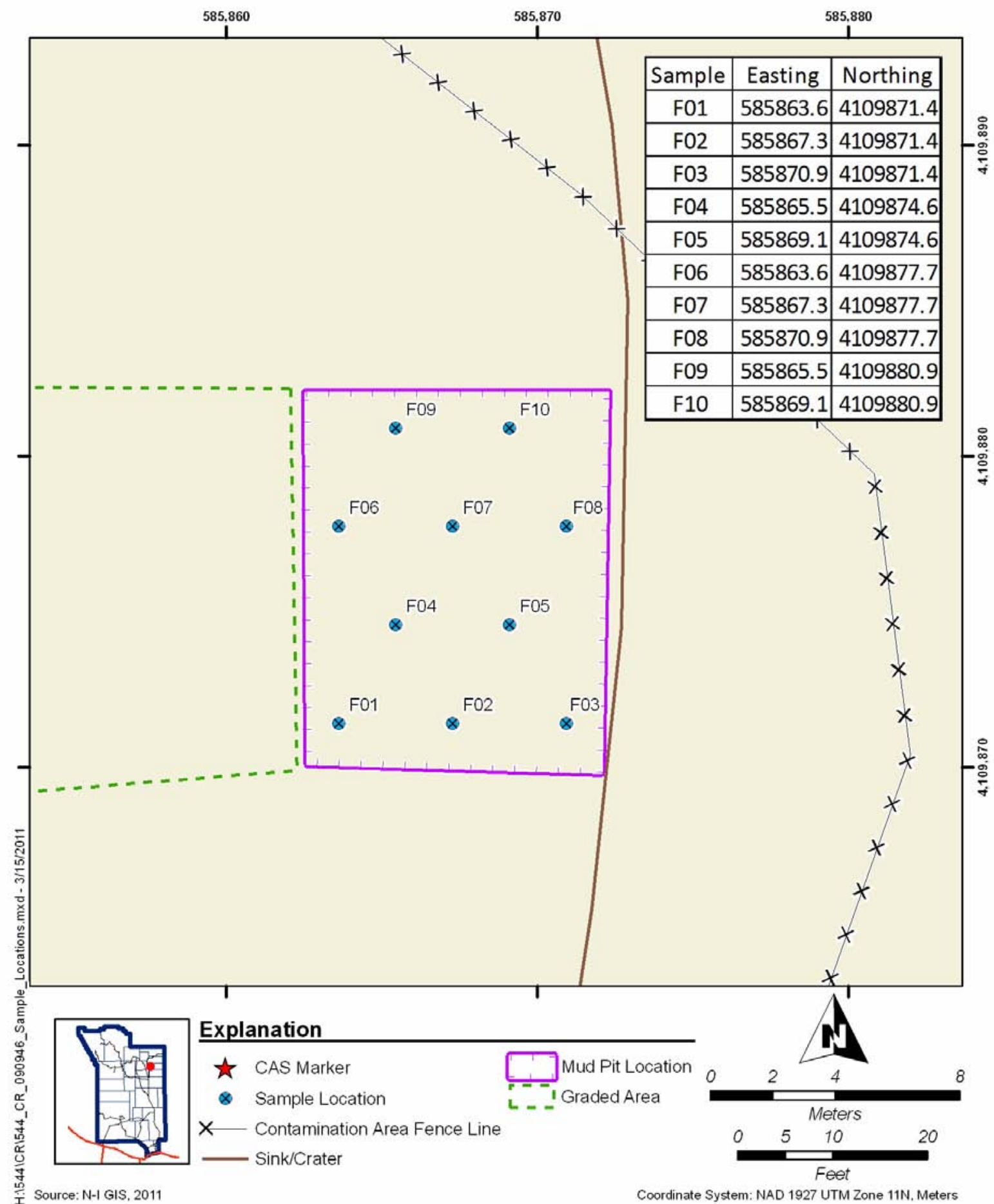

Figure B.5-1

Sample Locations at CAS 09-09-46, U-9itsx20 PS \#1A Mud Pit 
For the probabilistic samples at the mud pit at CAS 09-09-46, any COPC that had a 95 percent UCL of the average concentration exceeding the FAL would result in that COPC being designated as a COC. As stipulated in Section C.1.2.1 of the CAU 544 SAFER Plan, UCLs were only calculated for a COPC if it was detected in any sample within any CAS at a concentration equal to or exceeding the PAL. If COPCs were not detected in any mud pit sample at a concentration exceeding the PAL, then it will be concluded that no COCs are present.

\section{B.5.2.1 Gamma-Emitting Radionuclides}

Analytical results for gamma-emitting radionuclides in soil samples collected at this CAS that were detected above MDCs are presented in Table B.5-2. No gamma-emitting radionuclides exceeded the PALs; therefore, the FALs were established at the PAL concentrations.

Table B.5-2

Samples Results for Gamma-Emitting Radionuclides Detected above MDCs at CAS 09-09-46, U-9itsx20 PS \#1A Mud Pit

\begin{tabular}{|c|c|c|c|c|c|c|}
\hline \multirow{2}{*}{$\begin{array}{l}\text { Sample } \\
\text { Location }\end{array}$} & \multirow{2}{*}{$\begin{array}{l}\text { Sample } \\
\text { Number }\end{array}$} & \multirow{2}{*}{$\begin{array}{l}\text { Depth } \\
\text { (in. bgs) }\end{array}$} & \multicolumn{4}{|c|}{ COPCs (pCi/g) } \\
\hline & & & Ac-228 & Am-241 & Cs-137 & Th-234 \\
\hline \multicolumn{3}{|c|}{ FALs } & 5 & 12.7 & 12.2 & 105 \\
\hline \multirow{2}{*}{ F01 } & 544F001 & $0-6$ & 2.04 & -- & -- & -- \\
\hline & 544F002 & $0-6$ & 2.17 & -- & -- & -- \\
\hline F02 & 544F003 & $0-6$ & 2.28 & $0.459(\mathrm{~J})$ & -- & -- \\
\hline F03 & 544F004 & $0-6$ & 1.96 & $0.755(\mathrm{~J})$ & 0.115 & -- \\
\hline F04 & 544F005 & $0-6$ & 2.77 & -- & -- & -- \\
\hline F05 & 544F006 & $0-6$ & $2.42(\mathrm{~J})$ & -- & -- & -- \\
\hline F06 & 544F007 & $0-6$ & 1.75 & -- & -- & -- \\
\hline F07 & 544F008 & $0-6$ & 2.63 & -- & -- & -- \\
\hline F08 & 544F009 & $0-6$ & 2.35 & -- & -- & -- \\
\hline F09 & 544F010 & $0-6$ & 2.3 & -- & -- & $2.71(\mathrm{~J})$ \\
\hline F10 & 544F011 & $0-6$ & 2.06 & -- & -- & -- \\
\hline
\end{tabular}

$\mathrm{J}=$ Estimated value

-- = Not detected above MDCs

$\mathrm{Am}=$ Americium 


\section{B.5.2.2 Plutonium and Uranium Isotopes, and Strontium-90}

Analytical results for the Pu and U isotopes and Sr-90 in soil samples collected at this CAS that were detected above MDCs are presented in Table B.5-3. Because Sr-90 was not detected above the MDC, the results are not included in the table. No Pu or U isotopes exceeded the PALs; therefore, the FALs were established at the PAL concentrations.

Table B.5-3

Sample Results for Isotopes Detected above MDCs at CAS 09-09-46, U-9itsx20 PS \#1A Mud Pit

\begin{tabular}{|c|c|c|c|c|c|c|}
\hline \multirow{2}{*}{$\begin{array}{l}\text { Sample } \\
\text { Location }\end{array}$} & \multirow{2}{*}{$\begin{array}{l}\text { Sample } \\
\text { Number }\end{array}$} & \multirow{2}{*}{$\begin{array}{l}\text { Depth } \\
\text { (in. bgs) }\end{array}$} & \multicolumn{4}{|c|}{ COPCs (pCi/g) } \\
\hline & & & Pu-239/240 & U-234 & U-235 & U-238 \\
\hline \multicolumn{3}{|c|}{ FALs } & 12.7 & 143 & 17.6 & 105 \\
\hline \multirow{2}{*}{ F01 } & 544F001 & $0-6$ & 0.0832 & 1.23 & 0.113 & 1.42 \\
\hline & 544F002 & $0-6$ & 0.137 & 1.07 & -- & 0.947 \\
\hline F02 & 544F003 & $0-6$ & 0.0539 & 1.15 & 0.0913 & 1.22 \\
\hline F03 & 544F004 & $0-6$ & 0.335 & 1.07 & 0.127 & 1.25 \\
\hline F04 & 544F005 & $0-6$ & -- & 1.56 & 0.105 & 1.65 \\
\hline F05 & 544F006 & $0-6$ & -- & 1.46 & 0.0614 & 1.65 \\
\hline F06 & 544F007 & $0-6$ & 0.0363 & 1.42 & 0.0836 & 1.21 \\
\hline F07 & 544F008 & $0-6$ & -- & 1.37 & 0.103 & 1.39 \\
\hline F08 & 544F009 & $0-6$ & -- & 1.28 & 0.112 & 1.26 \\
\hline F09 & 544F010 & $0-6$ & -- & 1.32 & -- & 1.14 \\
\hline F10 & 544F011 & $0-6$ & -- & 1.53 & 0.069 & 1.3 \\
\hline
\end{tabular}

-- = Not detected above MDCs

\section{B.5.3 Nature and Extent of Contamination}

Based on the analytical results for soil samples collected within CAS 09-09-46, no COCs were identified.

\section{B.5.4 Revised Conceptual Site Model}

The SAFER Plan requirements were met at this CAS, and no revisions were necessary to the CSM. 


\section{B.6.0 CAS 19-25-01, Oil Spill, Investigation Results}

Corrective Action Site 19-25-01 is approximately 1,800 ft southwest of the U-19ab crater in Area 19 of the NNSS. The CAS consists of a suspected release of hydrocarbons to the soil associated with an oil spill. Additional detail is provided in the SAFER Plan (NNSA/NSO, 2010).

\section{B.6.1 SAFER Activities}

A total of 17 characterization samples (including one FD) were collected during investigation activities at CAS 19-25-01. The sample IDs, locations, types, and analyses are listed in Table B.6-1. The specific CAI activities conducted to satisfy the SAFER Plan requirements at this CAS are described in the following sections.

Table B.6-1

Samples Collected at CAS 19-25-01, Oil Spill

(Page 1 of 2)

\begin{tabular}{|c|c|c|c|c|c|c|c|c|c|c|}
\hline $\begin{array}{l}\text { Sample } \\
\text { Location }\end{array}$ & $\begin{array}{l}\text { Sample } \\
\text { Number }\end{array}$ & $\begin{array}{l}\text { Depth } \\
\text { (in. bgs) }\end{array}$ & Matrix & Purpose & 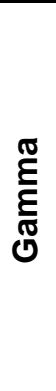 & 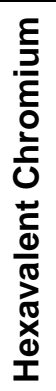 & $\begin{array}{l}\frac{n}{\pi} \\
\frac{\pi}{20}\end{array}$ & $\begin{array}{c}\mathscr{n} \\
\text { Oٌ } \\
\text { Un }\end{array}$ & 品 & 仓ू \\
\hline \multirow{3}{*}{ C01 } & $544 C 001$ & $0-3$ & Soil & Environmental & $\mathrm{X}$ & $\mathrm{X}$ & $\bar{x}$ & $\bar{x}$ & $x$ & $x$ \\
\hline & $544 \mathrm{C} 002$ & $0-3$ & Soil & $\begin{array}{c}\text { Field Duplicate } \\
\text { of \#544C001 }\end{array}$ & $x$ & $x$ & $x$ & $\mathrm{x}$ & $x$ & $x$ \\
\hline & $544 C 003$ & $3-6$ & Soil & Environmental & $x$ & $x$ & $\mathrm{x}$ & $x$ & $x$ & $x$ \\
\hline \multirow{2}{*}{$\mathrm{C} 02$} & $544 C 004$ & $0-3$ & Soil & Environmental & $x$ & $x$ & $\mathrm{x}$ & $x$ & $x$ & $x$ \\
\hline & $544 C 005$ & $3-6$ & Soil & Environmental & $x$ & $x$ & $x$ & $\mathrm{x}$ & $x$ & $\mathrm{x}$ \\
\hline \multirow{3}{*}{$\mathrm{CO3}$} & $544 C 006$ & $0-3$ & Soil & Environmental & -- & -- & -- & -- & $x$ & -- \\
\hline & 544C007 & $3-6$ & Soil & Environmental & -- & -- & -- & -- & $x$ & -- \\
\hline & $544 C 008$ & $6-12$ & Soil & Environmental & -- & -- & -- & -- & $x$ & -- \\
\hline \multirow{3}{*}{ C04 } & $544 C 009$ & $0-3$ & Soil & Environmental & -- & -- & -- & -- & $\mathrm{x}$ & -- \\
\hline & $544 C 010$ & $3-6$ & Soil & Environmental & -- & -- & -- & -- & $x$ & -- \\
\hline & 544C011 & $6-12$ & Soil & Environmental & -- & -- & -- & -- & $x$ & -- \\
\hline
\end{tabular}


Table B.6-1

\section{Samples Collected at CAS 19-25-01, Oil Spill}

(Page 2 of 2)

\begin{tabular}{|c|c|c|c|c|c|c|c|c|c|c|}
\hline $\begin{array}{l}\text { Sample } \\
\text { Location }\end{array}$ & $\begin{array}{l}\text { Sample } \\
\text { Number }\end{array}$ & $\begin{array}{l}\text { Depth } \\
\text { (in. bgs) }\end{array}$ & Matrix & Purpose & 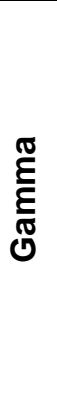 & 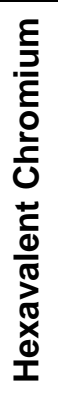 & $\begin{array}{l}\frac{n}{\pi} \\
\frac{\pi}{\mathbb{d}} \\
\Sigma\end{array}$ & 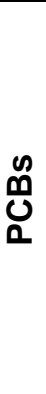 & $\begin{array}{l}\text { U } \\
\text { in }\end{array}$ & $\begin{array}{l}\text { Uू } \\
\text { O̊ }\end{array}$ \\
\hline \multirow{3}{*}{$\mathrm{C} 05$} & $544 C 012$ & $0-3$ & Soil & Environmental & $\overline{--}$ & $\overline{--}$ & $\overline{--}$ & -- & $\bar{x}$ & -- \\
\hline & $544 C 013$ & $3-6$ & Soil & Environmental & -- & -- & -- & -- & $x$ & -- \\
\hline & $544 C 014$ & $6-12$ & Soil & Environmental & -- & -- & -- & -- & $x$ & -- \\
\hline \multirow{3}{*}{$\mathrm{C} 06$} & $544 C 015$ & $0-3$ & Soil & Environmental & -- & -- & -- & -- & $X$ & -- \\
\hline & $544 C 016$ & $3-6$ & Soil & Environmental & -- & -- & -- & -- & $x$ & -- \\
\hline & $544 C 017$ & $6-12$ & Soil & Environmental & -- & -- & -- & -- & $x$ & -- \\
\hline N/A & $544 C 301$ & $\mathrm{~N} / \mathrm{A}$ & Water & Trip Blank & -- & -- & -- & -- & -- & $x$ \\
\hline
\end{tabular}

$X=$ Required

$--=$ Not required

\section{B.6.1.1 Field Screening}

Investigation samples were field screened for alpha and beta/gamma radiation. The FSRs were compared to FSLs to guide subsequent sampling decisions where appropriate. All soil samples were below background radiological FSLs for alpha and beta/gamma.

\section{B.6.1.2 Visual Inspections}

No spills, staining, disturbances of soil, or other indications of potential contamination were identified during the inspection of the area with the reported oil spill, and site conditions were unchanged from previous field visits. The area was covered with pea gravel and vegetation, and the oil spills were not readily apparent. A shovel was used to pothole around the CAS marker. Stained soil was evident beneath the pea gravel to a depth of 3 in. bgs. From 3 to 6 in. bgs, there was no visible staining. 


\section{B.6.1.3 Sample Collection}

Decision I environmental sampling included the collection of biased surface soil samples at two locations within the oil spill area. Samples were collected using hand-sampling methods (scoops and trowels).

Seventeen Decision I soil samples (including one FD) were collected from six locations (C01 through C06) within the oil spill area (Figure B.6-1). Based on the visual inspection, six locations within the area of the spill were selected for sampling. The surface soil samples were collected from the stained soil that extended to a depth of 3 in. bgs. The subsurface sample was collected from the unstained interval that extended from 3 to 6 in. bgs and 6 to12 in. bgs. No additional biased sample locations were identified.

\section{B.6.1.4 Deviations}

The SAFER Plan stated that the surface interval would be 0 to 6 in. bgs, and the shallow subsurface interval would be 6 to 12 in. bgs. Because the staining of the soil at location C01 extended only to a depth of 3 in. bgs, the surface interval was reduced to 0 to 3 in. bgs and the shallow subsurface interval to 3 to 6 in. bgs. Shallow subsurface soil samples were also collected from 6 to12 in. bgs.

\section{B.6.2 Investigation Results}

The following sections provide analytical results from the samples collected to complete investigation activities as outlined in the SAFER Plan (NNSA/NSO, 2010). Investigation samples were analyzed for the SAFER Plan-specified COPCs, which included VOCs, SVOCs, RCRA metals and hexavalent chromium, and gamma-emitting radionuclides; PCBs are added parameters because these contaminants are a common concern at the NNSS. The analytical parameters and laboratory methods used to analyze the investigation samples are listed in Table B.2-2. Table B.6-1 lists the sample-specific analytical suite for CAS 19-25-01. Because no wastes were generated, no waste characterization samples were collected at this CAS.

Analytical results from the soil samples with concentrations exceeding MDCs are summarized in the following sections. An evaluation was conducted on all contaminants detected above MDCs by comparing individual concentration or activity results against the FALs. Establishment of the FALs is 


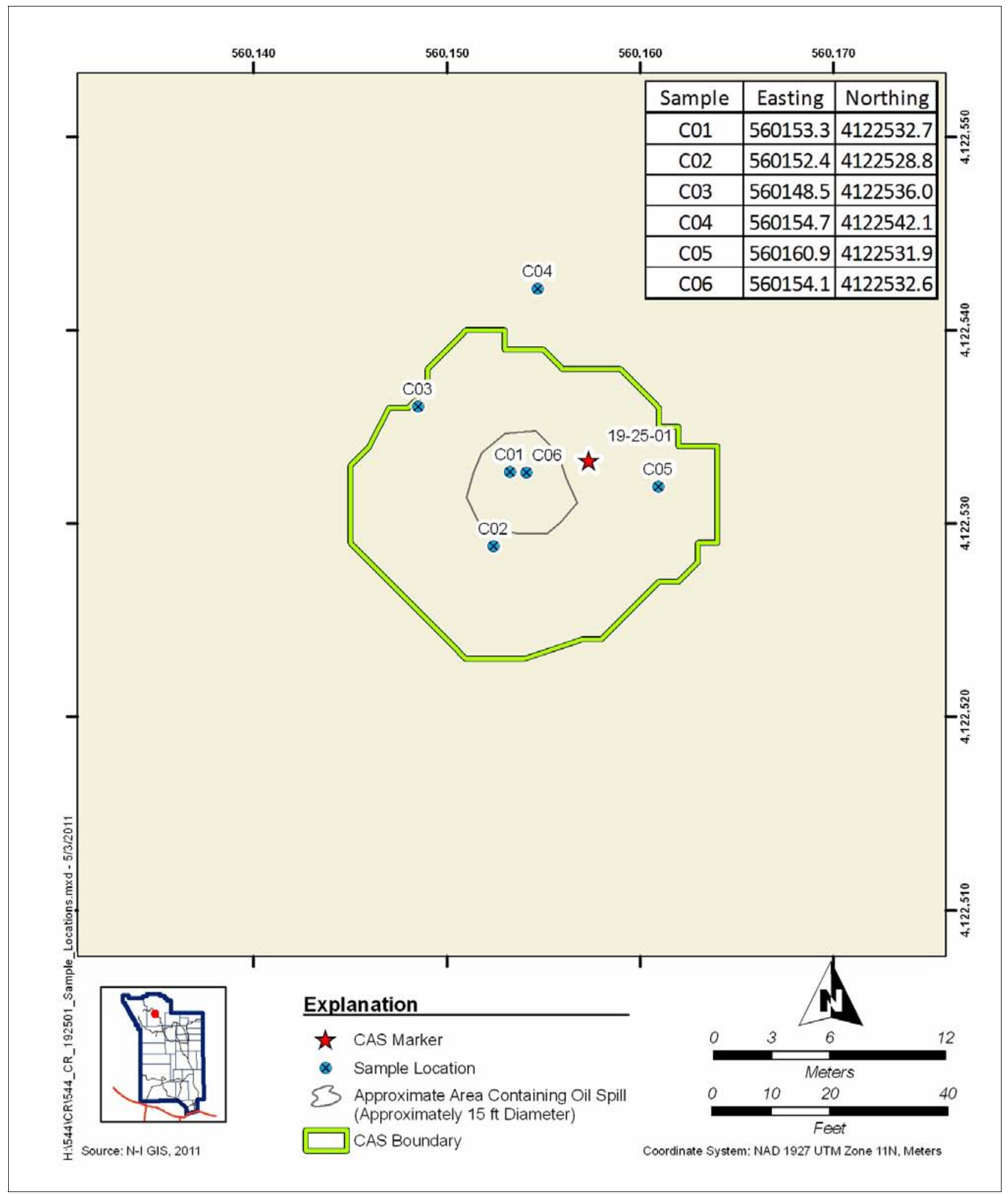

Figure B.6-1

Sample Locations at CAS 19-25-01, Oil Spill 
presented in Appendix D. The FALs were established as the corresponding PAL concentrations or activities if the contaminant concentrations were below their respective PALs.

\section{B.6.2.1 Volatile Organic Compounds}

The only VOC detected at a concentration exceeding the MDC was p-isopropyltoluene at a concentration of $0.00129 \mathrm{mg} / \mathrm{kg}$ at a depth of 0 to 3 in. bgs (Table B.6-2). This concentration is well below the PAL of 11,000 mg/kg. Therefore, the FAL was established at the corresponding PAL.

Table B.6-2

Sample Results of VOCs Detected above MDCs at CAS 19-25-01, Oil Spill

\begin{tabular}{||c|c|c|c||}
\hline \multirow{2}{*}{$\begin{array}{c}\text { Sample } \\
\text { Location }\end{array}$} & $\begin{array}{c}\text { Sample } \\
\text { Number }\end{array}$ & $\begin{array}{c}\text { Depth } \\
\text { (in. bgs) }\end{array}$ & COPC (mg/kg) \\
\cline { 4 - 4 } & & p-isopropyltoluene \\
\hline \multicolumn{3}{|c|}{ FAL } & $\mathbf{1 1 , 0 0 0}$ \\
\hline \hline $\mathrm{C} 02$ & $544 \mathrm{C} 004$ & $0-3$ & 0.00129 \\
\hline
\end{tabular}

\section{B.6.2.2 Semivolatile Organic Compounds}

Analytical results for SVOCs in soil samples collected at this CAS that were detected above MDCs are presented in Table B.6-3. No other SVOCs, including the hazardous constituents of TPH-diesel-range organics (DRO), were detected at concentrations exceeding the respective PALs. The FALs were established at the PAL concentrations. 
Table B.6-3

\section{Sample Results for SVOCs Detected above MDCs at CAS 19-25-01, Oil Spill}

\begin{tabular}{|c|c|c|c|}
\hline \multirow{2}{*}{$\begin{array}{c}\text { Sample } \\
\text { Location }\end{array}$} & \multirow{2}{*}{$\begin{array}{c}\text { Sample } \\
\text { Number }\end{array}$} & $\begin{array}{c}\text { Depth } \\
\text { (in. bgs) }\end{array}$ & Bis(2-ethylhexyl)phthalate \\
\cline { 4 - 4 } & & & $\mathbf{1 2 0}$ \\
\hline \multicolumn{3}{|c|}{ FAL } & $3.85(\mathrm{~J})$ \\
\hline \hline C01 & $544 \mathrm{C} 003$ & $3-6$ & $0.818(\mathrm{~J})$ \\
\hline \multirow{3}{*}{ C06 } & $544 \mathrm{C} 015$ & $0-3$ & $0.123(\mathrm{~J})$ \\
\cline { 2 - 4 } & $544 \mathrm{C} 016$ & $3-6$ & $0.132(\mathrm{~J})$ \\
\cline { 2 - 4 } & $544 \mathrm{C} 017$ & $6-12$ & \\
\hline
\end{tabular}

$\mathrm{J}=$ Estimated value

\section{B.6.2.3 RCRA Metals and Hexavalent Chromium}

Analytical results for RCRA metals and hexavalent chromium in soil samples collected at this CAS that were detected above MDCs are presented in Table B.6-4. No metals were detected at concentrations exceeding their PALs. The FALs were established at the PAL concentrations.

Table B.6-4

Sample Results for Metals Detected above MDCs at CAS 19-25-01, Oil Spill

\begin{tabular}{|c|c|c|c|c|c|c|c|c|c|}
\hline \multirow[b]{2}{*}{$\begin{array}{c}\text { Sample } \\
\text { Location }\end{array}$} & \multirow[b]{2}{*}{$\begin{array}{l}\text { Sample } \\
\text { Number }\end{array}$} & \multirow[b]{2}{*}{$\begin{array}{l}\text { Depth } \\
\text { (in. bgs) }\end{array}$} & \multicolumn{7}{|c|}{ COPCs $(\mathrm{mg} / \mathrm{kg})$} \\
\hline & & & 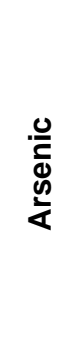 & 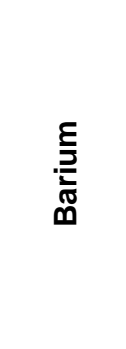 & 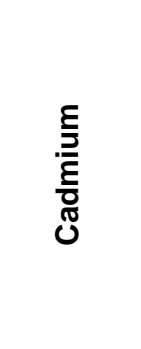 & 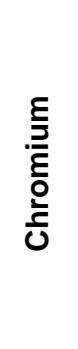 & 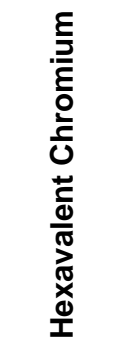 & ฐ్తు & 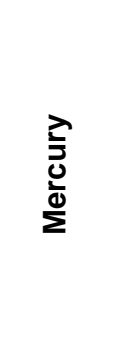 \\
\hline \multicolumn{3}{|c|}{ FALs } & 23 & 190,000 & 800 & N/A & 5.6 & 800 & 34 \\
\hline \multirow{3}{*}{$\mathrm{C} 01$} & $544 \mathrm{C001}$ & $0-3$ & 2.45 & $122(\mathrm{~J}-)$ & 0.671 & 4.71 & $1.89(\mathrm{~J}-)$ & $44.7(\mathrm{~J})$ & 0.0201 \\
\hline & 544C002 & $0-3$ & 2.34 & $87.8(\mathrm{~J}-)$ & 0.588 & 4.84 & $1(\mathrm{~J}-)$ & $25.3(\mathrm{~J})$ & 0.0219 \\
\hline & $544 C 003$ & $3-6$ & 2.34 & $125(\mathrm{~J}-)$ & $0.333(\mathrm{~J})$ & 3.83 & -- & $18.4(\mathrm{~J})$ & 0.0344 \\
\hline \multirow{2}{*}{$\mathrm{CO} 2$} & $544 C 004$ & $0-3$ & 2.74 & $120(\mathrm{~J}-)$ & -- & 8.1 & -- & $12.6(\mathrm{~J})$ & 0.0269 \\
\hline & $544 C 005$ & $3-6$ & 2.83 & $128(\mathrm{~J}-)$ & -- & 5.63 & -- & $22.8(\mathrm{~J})$ & 0.0727 \\
\hline
\end{tabular}

$\mathrm{J}=$ Estimated value

$\mathrm{J}$ - = Result is an estimated quantity, but may be biased low.

$--=$ Not detected above MDCs 


\section{B.6.2.4 Polychlorinated Biphenyls}

Polychlorinated biphenyls above the MDCs or PALs were not detected in soil samples. Therefore, the FALs were established at the corresponding PAL concentrations.

\section{B.6.2.5 Gamma-Emitting Radionuclides}

Analytical results for gamma-emitting radionuclides in soil samples collected at this CAS that were detected above MDCs are presented in Table B.6-5. No gamma-emitting radionuclides were detected at concentrations exceeding the respective PALs. The FALs were established at the PAL concentrations.

Table B.6-5

Sample Results for Gamma-Emitting Radionuclides

Detected above MDCs at CAS 19-25-01, Oil Spill

\begin{tabular}{|c|c|c|c||}
\hline \multirow{2}{*}{$\begin{array}{c}\text { Sample } \\
\text { Location }\end{array}$} & \multirow{2}{*}{$\begin{array}{c}\text { Sample } \\
\text { Number }\end{array}$} & $\begin{array}{c}\text { Depth } \\
\text { (in. bgs) }\end{array}$ & COPC (pCi/g) \\
\cline { 4 - 5 } & & & Ac-228 \\
\hline \hline \multirow{3}{*}{ C01 } & 544 CAL 001 & $0-3$ & $\mathbf{5}$ \\
\cline { 2 - 5 } & 544 C002 & $0-3$ & 2.78 \\
\cline { 2 - 5 } & $544 C 003$ & $3-6$ & 2.95 \\
\hline \multirow{2}{*}{ C02 } & 544 C004 & $0-3$ & 4.53 \\
\cline { 2 - 5 } & $544 C 005$ & $3-6$ & 2.97 \\
\hline
\end{tabular}

\section{B.6.3 Nature and Extent of Contamination}

Based on the analytical results for soil samples collected within CAS 19-25-01, no COCs were identified.

\section{B.6.4 Revised Conceptual Site Model}

The SAFER Plan requirements were met at this CAS, and no revisions were necessary to the CSM. 


\section{B.7.0 CAS 19-99-06, Waste Spill, Investigation Results}

Corrective Action Site 19-99-06 is located east of the U-19j emplacement hole in Area 19 of the NNSS. The environmental concern at this CAS consists of potential environmental releases associated with several large spills of dry, light gray bentonite drilling mud and/or cement grout. Additional detail is provided in the SAFER Plan (NNSA/NSO, 2010).

\section{B.7.1 SAFER Activities}

A total of four characterization samples (including one FD) were collected during investigation activities at CAS 19-99-06. The sample IDs, locations, types, and analyses are listed in Table B.7-1. The specific CAI activities conducted to satisfy the SAFER Plan requirements at this CAS are described in the following sections.

Table B.7-1

Samples Collected at CAS 19-99-06, Waste Spill

\begin{tabular}{|c|c|c|c|c|c|c|c|c|c|c|}
\hline $\begin{array}{l}\text { Sample } \\
\text { Location }\end{array}$ & $\begin{array}{l}\text { Sample } \\
\text { Number }\end{array}$ & $\begin{array}{l}\text { Depth } \\
\text { (in. bgs) }\end{array}$ & Matrix & Purpose & 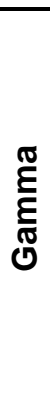 & 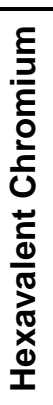 & $\begin{array}{l}\frac{\omega}{\pi} \\
\frac{\pi}{\mathbb{2}}\end{array}$ & 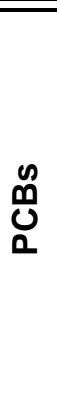 & 帒 & $\begin{array}{l}\text { U } \\
\text { ○ }\end{array}$ \\
\hline \multirow{3}{*}{ D01 } & 544D001 & $4-6$ & Soil & Environmental & $x$ & $\bar{x}$ & $x$ & $\bar{x}$ & $x$ & $\bar{x}$ \\
\hline & 544D002 & $4-6$ & Soil & $\begin{array}{l}\text { Field duplicate } \\
\text { of \#544D001 }\end{array}$ & $x$ & $x$ & $x$ & $x$ & $x$ & $x$ \\
\hline & $544 \mathrm{D} 003$ & $6-12$ & Soil & Environmental & $x$ & $x$ & $x$ & $x$ & $x$ & $x$ \\
\hline D02 & 544D004 & $0-6$ & Soil & Environmental & $x$ & $x$ & $x$ & $x$ & $x$ & $x$ \\
\hline $\mathrm{N} / \mathrm{A}$ & 544D301 & $N / A$ & Water & Trip Blank & -- & -- & -- & -- & -- & $x$ \\
\hline $\mathrm{N} / \mathrm{A}$ & 544D302 & N/A & Water & Field Blank & $x$ & $x$ & $x$ & $x$ & $x$ & $x$ \\
\hline
\end{tabular}

$X=$ Required

-- = Not required 


\section{B.7.1.1 Field Screening}

Investigation samples were field screened for alpha and beta/gamma radiation. The FSRs were compared to FSLs to guide subsequent sampling decisions where appropriate. All soil samples were below background radiological FSLs for alpha and beta/gamma.

\section{B.7.1.2 Visual Inspections}

No other spills or stained soil, disturbances of soil, or other indications of potential contamination were identified during the inspection of the waste spill, and site conditions were unchanged from previous field visits. The waste spill consisted of dried bentonite drilling mud and/or cement grout.

\section{B.7.1.3 Sample Collection}

Decision I environmental sampling included the collection of biased surface soil samples at two locations within the waste spill area. Samples were collected using hand-sampling methods (scoops and trowels).

One sample was collected from 4 to 6 in. bgs near the middle of bentonite drilling mud and/or cement grout, and one sample was collected from below the spill (6 to 12 in. bgs) near the middle of the spill at the native soil interface. A second surface soil sample was collected from the outside edge of the bentonite drilling mud and/or cement grout spill.

Four Decision I soil samples (including one FD) were collected from two locations (D01 and D02) within the waste spill area (Figure B.7-1). The spill consisted of bentonite drilling mud and/or cement grout and was approximately $10 \mathrm{ft}$ in diameter. Two samples were collected near the center of the spill at location D01: one sample was collected at a depth of 4 to 6 in. bgs, and one sample was collected directly beneath the bentonite drilling mud and/or cement grout at a depth of 6 to 12 in. bgs. Another sample was collected at a depth of 0 to 6 in. bgs at the outside edge of the bentonite drilling mud and/or cement grout at location D02 to determine whether contaminants, if present, have migrated laterally. 


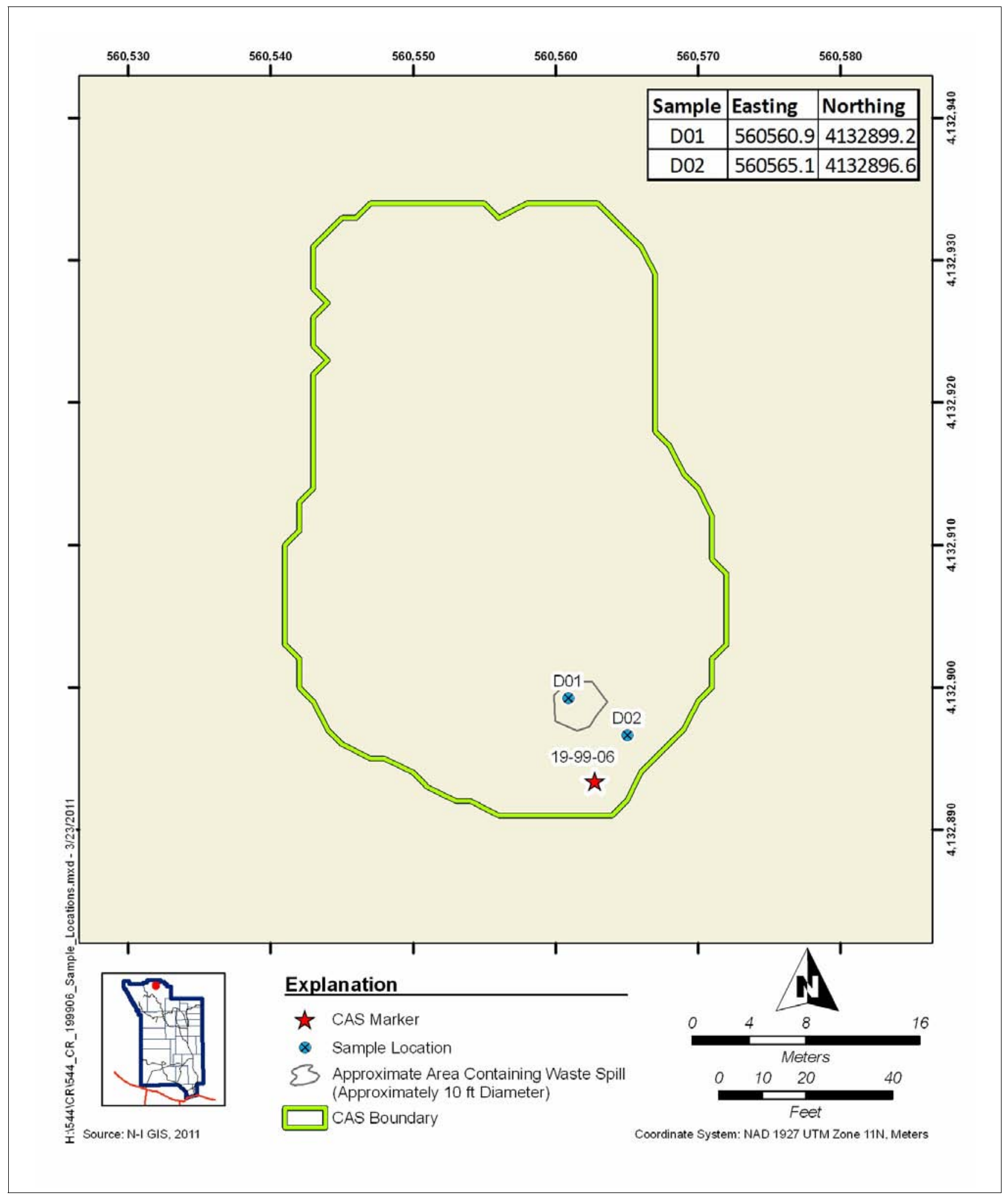

Figure B.7-1

Sample Locations at CAS 19-99-06, Waste Spill 


\section{B.7.1.4 Deviations}

The SAFER Plan stated that the surface interval would be 0 to 6 in. bgs and the shallow subsurface interval would be 6 to 12 in. bgs. Because the bentonite drilling mud/cement grout extended below the surface of the soil, the surface interval was changed to 4 to 6 in. bgs, while the shallow subsurface interval remained at 6 to $12 \mathrm{in.} \mathrm{bgs.}$

\section{B.7.2 Investigation Results}

The following sections provide analytical results from the samples collected to complete investigation activities as outlined in the SAFER Plan (NNSA/NSO, 2010). Investigation samples were analyzed for the SAFER Plan-specified COPCs, which included VOCs, SVOCs, RCRA metals and hexavalent chromium, and gamma-emitting radionuclides; PCBs are added parameters because these contaminants are a common concern at the NNSS. The analytical parameters and laboratory methods used to analyze the investigation samples are listed in Table B.2-2. Table B.7-1 lists the sample-specific analytical suite for CAS 19-99-06. No waste characterization samples were collected.

Analytical results from the soil samples with concentrations exceeding MDCs are summarized in the following sections. An evaluation was conducted on all contaminants detected above MDCs by comparing individual concentrations or activities to the FALs. Establishment of the FALs is presented in Appendix D. The FALs were established as the corresponding PAL concentrations or activities if the contaminant concentrations were below their respective PALs.

\section{B.7.2.1 Volatile Organic Compounds}

Volatile organic compounds above the MDCs or PALs were not detected in soil samples.

\section{B.7.2.2 Semivolatile Organic Compounds}

Semivolatile organic compounds, including the hazardous constituents of TPH-DRO, above the MDCs or PALs were not detected in soil samples. 


\section{B.7.2.3 RCRA Metals and Hexavalent Chromium}

Concentrations of RCRA metals and hexavalent chromium in soil samples detected at concentrations above the MDCs are presented in Table B.7-2. None of the reported metal concentrations exceeded the PALs; therefore, the FALs were established as the PALs.

Table B.7-2

Sample Results for Metals Detected above MDCs at CAS 19-99-06, Waste Spill

\begin{tabular}{|c|c|c|c|c|c|c|c|c|c|}
\hline \multirow[b]{2}{*}{$\begin{array}{l}\text { Sample } \\
\text { Location }\end{array}$} & \multirow[b]{2}{*}{$\begin{array}{l}\text { Sample } \\
\text { Number }\end{array}$} & \multirow[b]{2}{*}{$\begin{array}{l}\text { Depth } \\
\text { (in. bgs) }\end{array}$} & \multicolumn{7}{|c|}{ COPCs $(\mathrm{mg} / \mathrm{kg})$} \\
\hline & & & 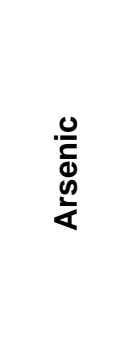 & 衣 & 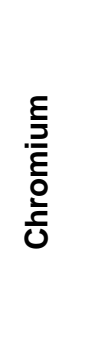 & 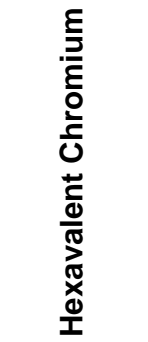 & శ్తు & $\begin{array}{l}\grave{J} \\
\frac{d}{0} \\
\frac{d}{\Sigma}\end{array}$ & $\sum_{\bar{\omega}}^{\bar{\omega}}$ \\
\hline \multicolumn{3}{|c|}{ FALs } & 23 & 190,000 & N/A & 5.6 & 800 & 34 & 5,100 \\
\hline \multirow{3}{*}{ D01 } & $\overline{544 \mathrm{D} 001}$ & $4-6$ & 1.5 & $43.9(\mathrm{~J}-)$ & 4.48 & $0.412(\mathrm{~J}-)$ & $3.85(\mathrm{~J})$ & -- & -- \\
\hline & 544D002 & $4-6$ & 1.1 & $57.2(\mathrm{~J}-)$ & 2.93 & $0.467(\mathrm{~J}-)$ & $3.11(\mathrm{~J})$ & -- & -- \\
\hline & 544D003 & $6-12$ & $0.768(\mathrm{~J})$ & $61.2(\mathrm{~J}-)$ & 1.75 & -- & $6.18(\mathrm{~J})$ & $0.00507(\mathrm{~J})$ & $0.125(\mathrm{~J})$ \\
\hline D02 & $\overline{544 D 004}$ & $0-6$ & 2.07 & $135(\mathrm{~J}-)$ & 5.21 & $\overline{--}$ & $11.9(\mathrm{~J})$ & $0.0102(\mathrm{~J})$ & -- \\
\hline
\end{tabular}

$\mathrm{J}=$ Estimated value

$\mathrm{J}-$ = Result is an estimated quantity, but may be biased low.

-- = Not detected above MDCs

\section{B.7.2.4 Polychlorinated Biphenyls}

Analytical results for PCBs in soil samples collected at this CAS that were detected above MDCs are presented in Table B.7-3. No PCBs were detected at concentrations exceeding their PALs; therefore, FALs were established at the PAL concentrations.

\section{B.7.2.5 Gamma-Emitting Radionuclides}

Analytical results for gamma-emitting radionuclides in soil samples collected at this CAS that were detected above MDCs are presented in Table B.7-4. No gamma-emitting radionuclides were detected at concentrations exceeding their PALs. The FALs were established at the PAL concentrations. 
Table B.7-3

Sample Results for PCBs Detected above MDCs at CAS 19-99-06, Waste Spill

\begin{tabular}{|c|c|c|c|c|}
\hline \multirow{2}{*}{$\begin{array}{c}\text { Sample } \\
\text { Location }\end{array}$} & \multirow{2}{*}{$\begin{array}{c}\text { Sample } \\
\text { Number }\end{array}$} & \multirow{2}{*}{$\begin{array}{c}\text { Depth } \\
\text { (in. bgs) }\end{array}$} & \multicolumn{2}{c|}{ COPCs (mg/kg) } \\
\cline { 4 - 5 } & & & Aroclor 1242 & Aroclor 1254 \\
\hline \multicolumn{3}{|c|}{ FALs } & $\mathbf{0 . 7 4}$ & $\mathbf{0 . 7 4}$ \\
\hline \hline \multirow{2}{*}{ D01 } & $544 \mathrm{D} 001$ & $4-6$ & $0.002(\mathrm{~J})$ & $0.0025(\mathrm{~J})$ \\
\cline { 2 - 5 } & $544 \mathrm{D} 002$ & $4-6$ & -- & $0.0023(\mathrm{~J})$ \\
\hline D02 & $544 \mathrm{D} 004$ & $0-6$ & -- & $0.0023(\mathrm{~J})$ \\
\hline
\end{tabular}

$\mathrm{J}=$ Estimated value

-- = Not detected above MDCs

Table B.7-4

Sample Results for Gamma-Emitting Radionuclides Detected above MDCs at CAS 19-99-06, Waste Spill

\begin{tabular}{|c|c|c|c|}
\hline \multirow{2}{*}{$\begin{array}{c}\text { Sample } \\
\text { Location }\end{array}$} & $\begin{array}{c}\text { Sample } \\
\text { Number }\end{array}$ & $\begin{array}{c}\text { Depth } \\
\text { (in. bgs) }\end{array}$ & COPC (pCi/g) \\
\cline { 4 - 4 } & & & Ac-228 \\
\hline \hline \multirow{3}{*}{ D01 } & FAL & $\mathbf{5}$ \\
\cline { 2 - 4 } & 544D001 & $4-6$ & 3.24 \\
\cline { 2 - 4 } & 544D003 & $6-12$ & 3.41 \\
\hline D02 & 544D004 & $0-6$ & 3.04 \\
\hline
\end{tabular}

\section{B.7.3 Nature and Extent of Contamination}

Based on the analytical results for soil samples collected within CAS 19-99-06, no COCs were identified.

\section{B.7.4 Revised Conceptual Site Model}

The SAFER Plan requirements were met at this CAS, and no revisions were necessary to the CSM. 


\section{B.8.0 CAS 20-25-04, Oil Spills Investigation Results}

Because of safety concerns associated with the potential crater area, personnel could not collect samples from the oil spill in this CAS. Therefore, it is assumed that COCs are present in the soil at this CAS. Closure in place with a UR is the recommended CAA. The UR will prevent unauthorized intrusive activities at this CAS. An annual post-closure inspection will be conducted to certify that postings are in place, intact, and readable. Signage will be placed to designate the restricted area. The restriction of the crater instability will also eliminate any future contact from site workers. Figure B.8-1 shows the location of the oil spill at this CAS. 


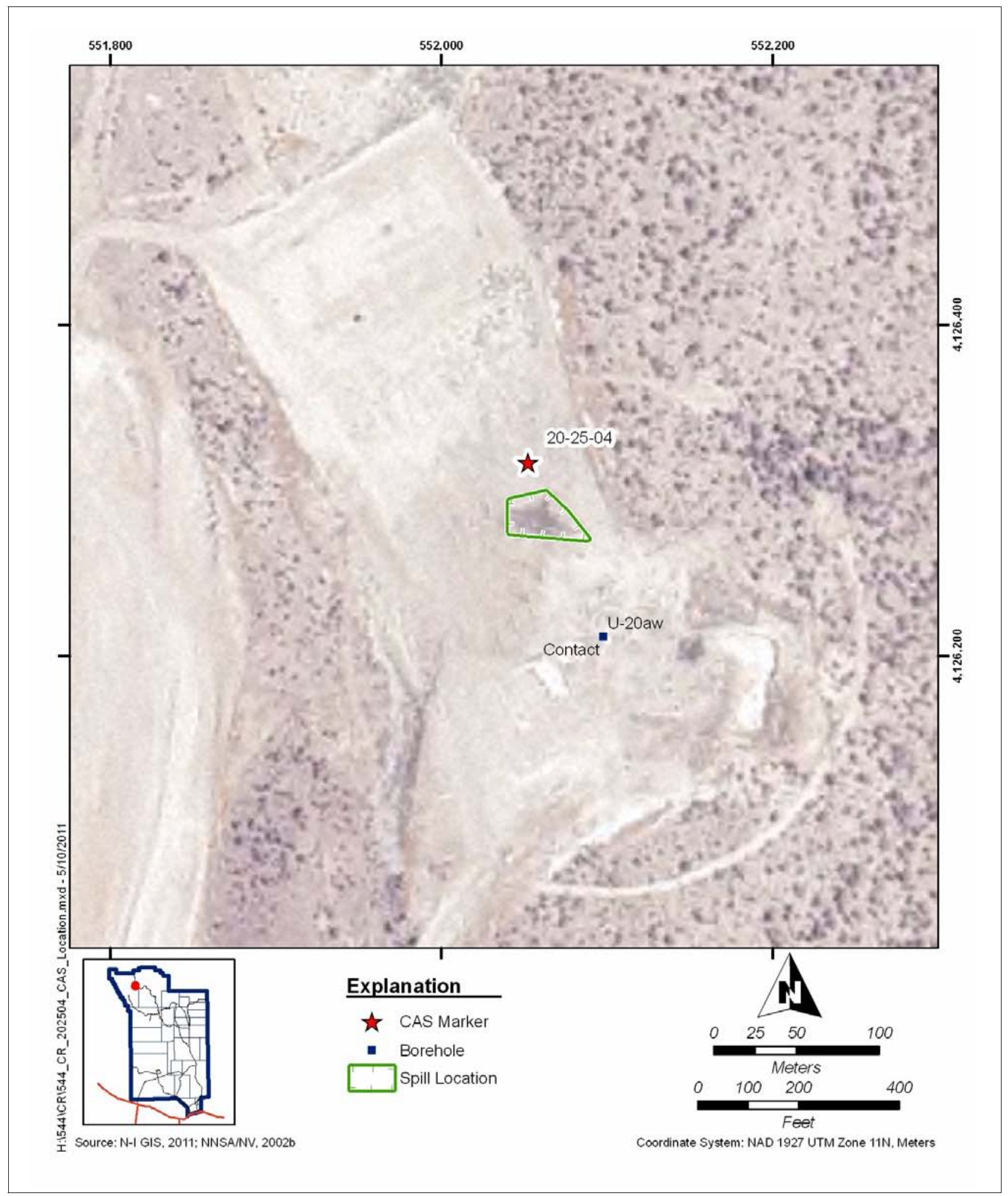

Figure B.8-1

Location of CAS 20-25-04, Oil Spills 


\section{B.9.0 CAS 20-25-05, Oil Spills, Investigation Results}

Corrective Action Site 20-25-05 is located in Area 20 of the NNSS and consists of potential releases of hydrocarbons to the soil from reported numerous oil spills. The CAS is located near U-20be in the area formerly used as the trailer park for the nuclear test. Additional detail is provided in the SAFER Plan (NNSA/NSO, 2010).

\section{B.9.1 SAFER Activities}

A total of five environmental samples (including one FD) were collected during investigation activities at CAS 20-25-05. The sample IDs, locations, types, and analyses are listed in Table B.9-1. The specific CAI activities conducted to satisfy the SAFER Plan requirements at this CAS are described in the following sections.

Table B.9-1

Samples Collected at CAS 20-25-05, Oil Spills

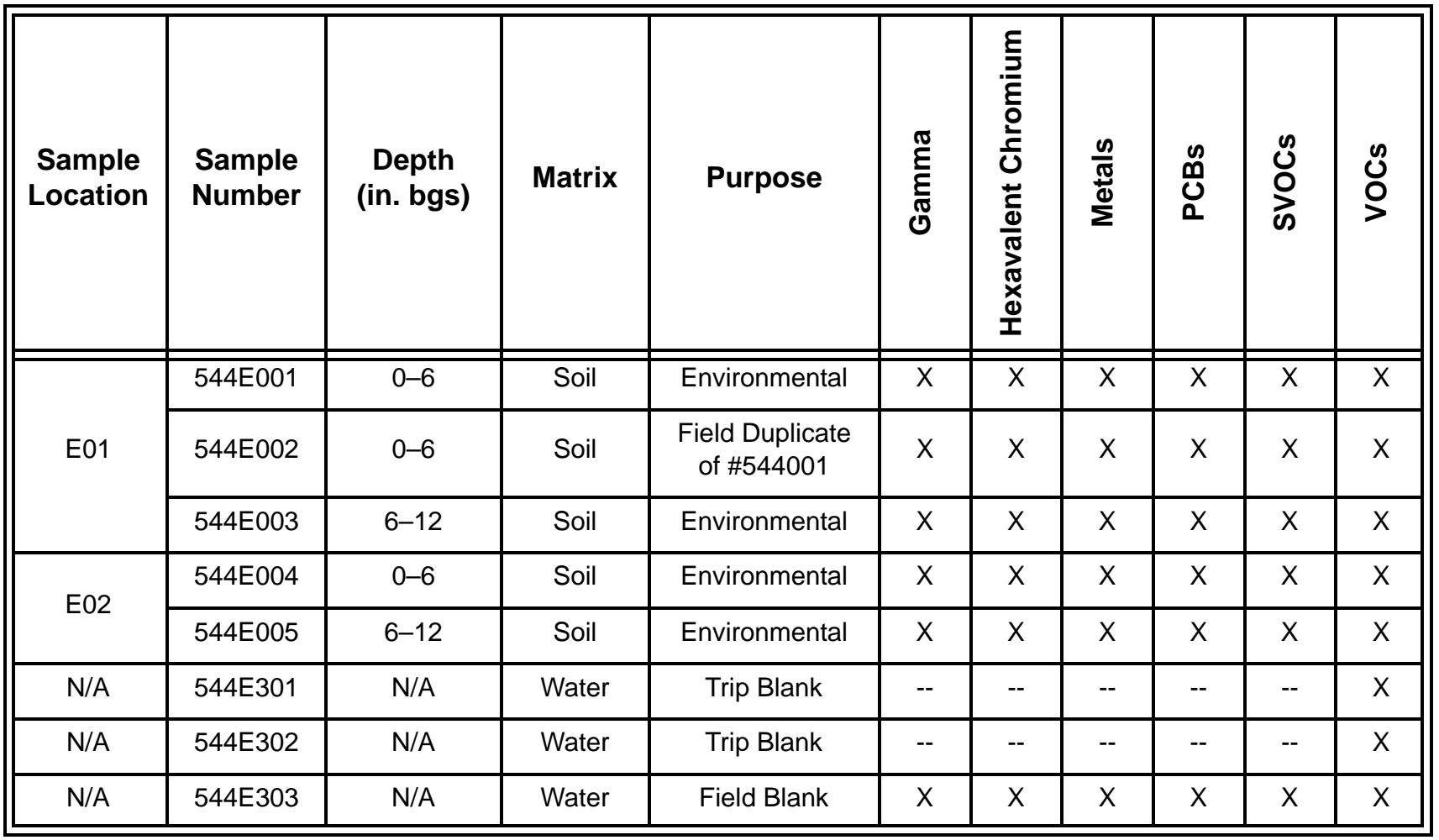

$X=$ Required

$--=$ Not required 


\section{B.9.1.1 Field Screening}

Investigation samples were field screened for alpha and beta/gamma radiation. The FSRs were compared to FSLs to guide subsequent sampling decisions where appropriate. All soil samples were below background radiological FSLs for alpha and beta/gamma.

\section{B.9.1.2 Visual Inspections}

No other spills or stained soil, disturbances of soil, or other indications of potential contamination were identified during the inspection of the area with the reported oil spill, and site conditions were unchanged from previous field visits. A shovel was used to pothole in the vicinity of the CAS marker, but the visibly stained soil was not identified. The area was covered with pea gravel and vegetation, and the oil spill was not readily visible. Although a thorough visual inspection of the area was conducted, no stained soil suggesting the presence of an oil spill was identified. It was decided that weathering over the years had eliminated any visible evidence of the oil spill; therefore, the CAS marker was considered the location of the spill.

\section{B.9.1.3 Sample Collection}

Decision I environmental sampling included the collection of biased surface soil samples at two locations within the area identified as the oil spill. Five Decision I soil samples (including one FD) were collected from two locations (E01 and E02) within the oil spill area (Figure B.9-1). Samples were collected using hand-sampling methods (scoops and trowels) in accordance with the SAFER Plan (NNSA/NSO, 2010).

\section{B.9.1.4 Deviations}

Investigation samples were collected as outlined in the CAU 544 SAFER Plan (NNSA/NSO, 2010) and submitted for laboratory analysis.

\section{B.9.2 Investigation Results}

The following sections provide analytical results from the samples collected to complete investigation activities as outlined in the SAFER Plan (NNSA/NSO, 2010). Investigation samples were analyzed for the COPCs identified in the SAFER Plan and included VOCs, SVOCs, RCRA 


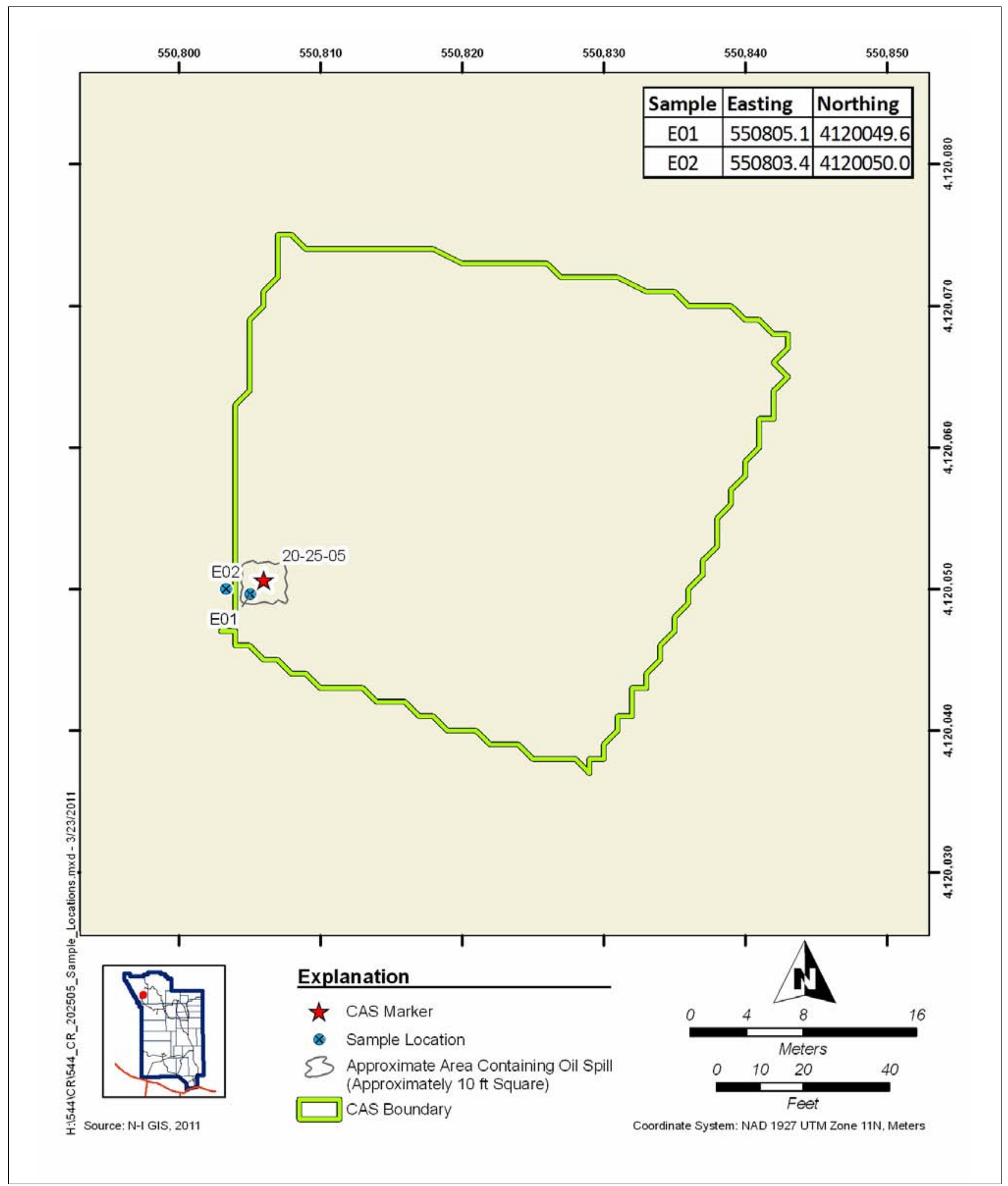

Figure B.9-1

Sample Locations and Analytical Results Exceeding FALs at CAS 20-25-05, Oil Spills 
metals and hexavalent chromium, and gamma-emitting radionuclides; PCBs were added parameters because these contaminants are a common concern at the NNSS. The analytical parameters and laboratory methods used to analyze the investigation samples are listed in Table B.2-2. Table B.9-1 lists the sample-specific analytical suite for CAS 20-25-05. No waste was generated at this CAS; therefore, no waste characterization samples were collected.

Analytical results from the soil samples with concentrations exceeding MDCs are summarized in the following sections. An evaluation was conducted on all contaminants detected above MDCs by comparing individual concentration or activity results against the FALs on a point-by-point basis. Establishment of the FALs is presented in Appendix D. The FALs were established as the corresponding PAL concentrations or activities if the contaminant concentrations were below their respective PALs.

\section{B.9.2.1 Volatile Organic Compounds}

Volatile organic compounds above the MDCs or PALs were not detected in soil samples.

\section{B.9.2.2 Semivolatile Organic Compounds}

Semivolatile organic compounds, including the hazardous constituents of TPH-DRO, above the MDCs or PALs were not detected in soil samples.

\section{B.9.2.3 RCRA Metals and Hexavalent Chromium}

Analytical results for RCRA metals and hexavalent chromium in soil samples collected at this CAS that were detected above MDCs are presented in Table B.9-2. No metals were detected at concentrations exceeding their PALs. The FALs were established at the PAL concentrations.

\section{B.9.2.4 Polychlorinated Biphenyls}

Analytical results for PCBs in soil samples collected at this CAS that were detected above MDCs are presented in Table B.9-3. No PCBs were detected at concentrations exceeding their PALs, and the FALs were established at the PAL concentrations. 
Table B.9-2

Sample Results for Metals Detected above MDCs at CAS 20-25-05, Oil Spills

\begin{tabular}{|c|c|c|c|c|c|c|c|c|c|}
\hline \multirow[b]{2}{*}{$\begin{array}{c}\text { Sample } \\
\text { Location }\end{array}$} & \multirow[b]{2}{*}{$\begin{array}{l}\text { Sample } \\
\text { Number }\end{array}$} & \multirow[b]{2}{*}{$\begin{array}{l}\text { Depth } \\
\text { (in. bgs) }\end{array}$} & \multicolumn{7}{|c|}{ COPCs (mg/kg) } \\
\hline & & & $\begin{array}{l}\frac{0}{\bar{L}} \\
\frac{\omega}{\grave{L}} \\
\end{array}$ & 怂 & 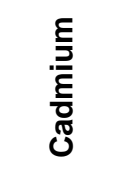 & 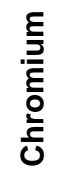 & ఫ్ & 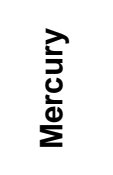 & $\frac{\bar{\Phi}}{\bar{\omega}}$ \\
\hline \multicolumn{3}{|c|}{ FALs } & 23 & 190,000 & 800 & N/A & 800 & 34 & 5,100 \\
\hline \multirow{3}{*}{ E01 } & 544E001 & $0-6$ & 1.2 & $65(\mathrm{~J})$ & $0.264(\mathrm{~J})$ & 2.28 & $6.16(\mathrm{~J})$ & 0.0487 & -- \\
\hline & 544E002 & $0-6$ & 1.21 & $66.5(\mathrm{~J})$ & $0.161(\mathrm{~J})$ & 1.91 & $5.47(\mathrm{~J})$ & 0.036 & -- \\
\hline & 544E003 & $6-12$ & 8.14 & $63.8(\mathrm{~J})$ & $0.147(\mathrm{~J})$ & 3.43 & $19.1(\mathrm{~J})$ & 0.025 & $0.256(\mathrm{~J})$ \\
\hline \multirow{2}{*}{ E02 } & 544E004 & $0-6$ & 2.16 & $78.8(\mathrm{~J})$ & -- & 3.37 & $8.85(\mathrm{~J})$ & 0.0176 & $0.372(\mathrm{~J})$ \\
\hline & 544E005 & $6-12$ & 2.62 & $64.8(\mathrm{~J})$ & $0.158(\mathrm{~J})$ & 3.6 & $9.37(\mathrm{~J})$ & 0.0153 & $0.248(\mathrm{~J})$ \\
\hline
\end{tabular}

$\mathrm{J}=$ Estimated value

$--=$ Not detected above MDCs

Table B.9-3

Sample Results for PCBs Detected above MDCs at CAS 20-25-05, Oil Spills

\begin{tabular}{|c|c|c|c|}
\hline \multirow{2}{*}{$\begin{array}{l}\text { Sample } \\
\text { Location }\end{array}$} & \multirow{2}{*}{$\begin{array}{l}\text { Sample } \\
\text { Number }\end{array}$} & \multirow{2}{*}{$\begin{array}{l}\text { Depth } \\
\text { (in. bgs) }\end{array}$} & COPC (mg/kg) \\
\hline & & & Aroclor 1248 \\
\hline \multicolumn{3}{|c|}{ FAL } & 0.74 \\
\hline E01 & 544E003 & $6-12$ & $0.0021(\mathrm{~J})$ \\
\hline
\end{tabular}

$\mathrm{J}=$ Estimated value

\section{B.9.2.5 Gamma-Emitting Radionuclides}

Analytical results for gamma-emitting radionuclides in soil samples collected at this CAS that were detected above MDCs are presented in Table B.9-4. No gamma-emitting radionuclides were detected at concentrations exceeding their PALs, and the FALs were established at the PAL concentrations.

\section{B.9.3 Nature and Extent of Contamination}

Based on the analytical results for soil samples collected within CAS 20-25-05, no COCs were identified. 
Table B.9-4

Sample Results for Gamma-Emitting Radionuclides

Detected above MDCs at CAS 20-25-05, Oil Spills

\begin{tabular}{|c|c|c|c|}
\hline \multirow{2}{*}{$\begin{array}{c}\text { Sample } \\
\text { Location }\end{array}$} & \multirow{2}{*}{$\begin{array}{c}\text { Sample } \\
\text { Number }\end{array}$} & $\begin{array}{c}\text { Depth } \\
\text { (in. bgs) }\end{array}$ & COPC (pCi/g) \\
\cline { 4 - 4 } & & & $\mathbf{5 c - 2 2 8}$ \\
\hline \hline \multirow{2}{*}{ E01 } & FAL & 2.48 \\
\cline { 2 - 4 } & $544 \mathrm{E} 001$ & $0-6$ & 2.53 \\
\cline { 2 - 4 } & $544 \mathrm{E} 003$ & $6-6$ & 3.16 \\
\hline E02 & $544 \mathrm{E} 005$ & $6-12$ & 3.02 \\
\hline
\end{tabular}

\section{B.9.4 Revised Conceptual Site Model}

The SAFER Plan requirements were met at this CAS, and no revisions were necessary to the CSM. 


\section{B.10.0 LANL and LLNL Pretest and Post-test Mud Pits}

Based on the criteria presented in the RBCSR (NNSA/NSO, 2004) and CAUs 530-535 closure document (NNSA/NSO, 2006a), 13 CASs and 1 mud pit CAS component have been recommended for closure without sampling. The evaluation of these mud pit CASs followed the criteria and processes discussed in the RBCSR, and as such, each of the CASs was identified by the laboratory that conducted the test and whether it was a pretest boring or post-test boring. The CASs, laboratories that conducted the tests, and the categories are presented in Table B.1-1.

The mud pits of CAU 544 fall into three categories: (1) LANL pretest mud pits, (2) LLNL pretest mud pits, and (3) LLNL post-test mud pits. Sections B.1.1.1.1 through B.1.1.1.3 discuss the features at these types of mud pits.

Of the 16 mud pits included in CAU 544, 2 mud pit CASs (02-37-09 and 09-09-46) were sampled during the CAU 544 CAI, and 14 mud pits are recommended for NFA without field investigations. These mud pits meet the criteria in the RBCSR and the approach approved for previous mud pit investigations (CAUs 530-535). The criteria included the following:

- CAS is either a single mud pit or system of mud pits.

- CAS is not located in a radiological or radioactive material posted area.

- There are no biasing factors evident at the mud pits based on visual inspections. 


\section{B.11.0 Waste Management}

Wastes generated during the SAFER field activities include disposable PPE, disposable sampling equipment, and housekeeping waste. Investigation activities did not require waste characterization samples to be collected, and non-IDW waste streams were not generated.

\section{B.11.1 Investigation-Derived Waste}

During the CAU 544 field investigation activities, IDW was generated. The waste streams generated include disposable PPE and disposable sampling equipment. The IDW was segregated to the greatest extent possible, and waste minimization techniques were effectively integrated into the field activities to reduce the amount of waste generated. Controls were in place to minimize the use of hazardous materials and the unnecessary generation of hazardous and/or mixed waste. Decontamination activities were planned and executed in a manner that minimized the volume of rinsate generated to amounts that did not require management.

There were no drums of waste (hazardous or nonhazardous) generated during the field investigation, and the one area at CAS 02-37-09 designated for a hazardous waste accumulation area (HWAA) was not established.

\section{B.11.2 Waste Streams}

During the investigation, IDW generated was segregated into the following waste streams:

- Disposable PPE and sampling equipment

- Decontamination rinsate

Disposable PPE and sampling equipment waste was inspected for gross contamination and radioactivity, managed as industrial IDW, disposed of in a designated industrial waste rolloff bin at Building 23-153, and allocated for NNSS industrial waste landfill disposal. Although decontamination rinsate was generated during the decontamination of the Geoprobe equipment, small volumes evaporated before the rinsate could be transferred for containment or sampled. 


\section{B.12.0 Quality Assurance}

This section contains a summary of QA/QC measures implemented during the sampling and analysis activities conducted in support of the CAU 544 CAI. The following sections discuss the data validation process, QC samples, and nonconformances. A detailed evaluation of the DQIs is presented in Section 4.1.

Laboratory analyses were conducted for samples used in the decision-making process to provide a quantitative measurement of any COPCs present. Rigorous QA/QC was implemented for all laboratory samples, including documentation, verification and validation of analytical results, and affirmation of DQI requirements related to laboratory analysis. Detailed information regarding the QA program is contained in the Industrial Sites QAPP (NNSA/NV, 2002a).

\section{B.12.1 Data Validation}

Data validation was performed in accordance with the Industrial Sites QAPP and approved protocols and procedures. All laboratory data from samples collected and analyzed for CAU 544 were evaluated for data quality in a tiered process described in Sections B.12.1.1 through B.12.1.3. Data were reviewed to ensure that samples were appropriately processed and analyzed, and the results were evaluated using validation criteria. Documentation of the data qualifications resulting from these reviews is retained in project files as a hard copy and electronic media.

One hundred percent of the data analyzed as part of this investigation were subjected to Tier I and Tier II evaluations. A Tier III evaluation was performed on approximately 5 percent of the data analyzed.

\section{B.12.1.1 Tier I Evaluation}

Tier I evaluation for chemical and radiochemical analysis examines, but is not limited to, the following:

- Sample count/type consistent with chain of custody

- Analysis count/type consistent with chain of custody

- Correct sample matrix 
- Significant problems stated in cover letter or case narrative

- Completeness of certificates of analysis

- Completeness of Contract Laboratory Program (CLP) or CLP-like packages

- Completeness of signatures, dates, and times on chain of custody

- Condition-upon-receipt variance form included

- Requested analyses performed on all samples

- Date received/analyzed given for each sample

- Correct concentration units indicated

- Electronic data transfer supplied

- Results reported for field and laboratory QC samples

- Whether or not the deliverable met the overall objectives of the project

\section{B.12.1.2 Tier II Evaluation}

Tier II evaluation for chemical analysis examines, but is not limited to, the following:

- Correct detection limits achieved

- Sample date, preparation date, and analysis date for each sample

- Holding time criteria met

- Quality control batch association for each sample

- Cooler temperature upon receipt

- Sample pH for aqueous samples, as required

- Detection limits properly adjusted for dilution, as required

- Blank contamination evaluated and applied to sample results/qualifiers

- Matrix spike/matrix spike duplicate (MSD) percent recoveries (\%R) and RPDs evaluated and qualifiers applied to laboratory results, as necessary

- Field duplicate RPDs evaluated using professional judgment and qualifiers applied to laboratory results, as necessary

- Laboratory duplicate RPDs evaluated and qualifiers applied to laboratory results, as necessary

- Surrogate \%R evaluated and qualifiers applied to laboratory results, as necessary

- Laboratory control sample \%R evaluated and qualifiers applied to laboratory results, as necessary 
- Initial and continuing calibration evaluated and qualifiers applied to laboratory results, as necessary

- Internal standard evaluation

- Mass spectrometer tuning criteria

- Organic compound quantitation

- Inductively coupled plasma interference check sample evaluation

- Cold vapor atomic absorption QC

- Inductively coupled plasma serial dilution effects

- Recalculation of 10 percent of laboratory results from raw data

Tier II evaluation for radiochemical analysis examines, but is not limited to, the following:

- Correct detection limits achieved

- Blank contamination evaluated and, if significant, qualifiers are applied to sample results

- Certificate of Analysis consistent with data package documentation

- Quality control sample results (duplicates, LCSs, laboratory blanks) evaluated and used to determine laboratory result qualifiers

- Sample results, uncertainty, and MDC evaluated.

- Detector system calibrated with National Institute of Standards and Technology (NIST)-traceable sources

- Calibration sources preparation was documented, demonstrating proper preparation and appropriateness for sample matrix, emission energies, and concentrations.

- Detector system response to daily or weekly background and calibration checks for peak energy, peak centroid, peak full-width half-maximum, and peak efficiency, depending on the detection system

- Tracers NIST-traceable, appropriate for the analysis performed, and recoveries that met QC requirements

- Documentation of all QC sample preparation complete and properly performed 
- Spectra lines, photon emissions, particle energies, peak areas, and background peak areas support the identified radionuclide and its concentration.

\section{B.12.1.3 Tier III Evaluation}

The Tier III review is an independent examination of the Tier II evaluation. A Tier III review of 5 percent of the sample analytical data was performed by Analytical Quality Associates, Albuquerque, New Mexico. Tier II and Tier III results were compared, and where differences were noted, data were reviewed and changes were made accordingly. This review included the following additional evaluations:

- Review

- Case narrative, chain of custody, and sample receipt forms

- Lab qualifiers (applied appropriately)

- Method of analyses performed as dictated by the chain of custody

- Raw data, including chromatograms, instrument printouts, preparation logs, and analytical logs

- Manual integrations to determine whether the response is appropriate

- Data package for completeness

- Determine sample results qualifiers through the evaluation of (but not limited to) the following:

- Tracers and QC sample results (e.g., duplicates, LCSs, blanks, MSs) evaluated and used to determine sample results qualifiers

- Sample preservation, sample preparation/extraction and run logs, sample storage, and holding time

- Instrument and detector tuning

- Initial and continuing calibrations

- Calibration verification (initial, continuing, second source)

- Retention times 
- Second column and/or second detector confirmation

- Mass spectra interpretation

- Interference check samples and serial dilutions

- Post-digestion spikes and method of standard additions

- Breakdown evaluations

- Perform calculation checks of the following:

- At least one analyte per QC sample and its recovery

- At least one analyte per initial calibration curve, continuing calibration verification, and second source recovery

- At least one analyte per sample that contains positive results (hits); radiochemical results only require calculation checks on activity concentrations (not error).

- Verify that target compound detects identified in the raw data are reported on the results form.

- Document any anomalies for the laboratory to clarify or rectify. The contractor should be notified of any anomalies.

\section{B.12.2 Field QC Samples}

Field QC samples consisted of 8 trip blanks, 1 equipment rinsate blank, 3 field blanks, 6 full laboratory quality controls, and 6 FDs collected and submitted for analysis by the laboratory analytical methods shown in Table B.2-2. The QC samples were assigned individual sample numbers and sent to the laboratory "blind." Additional samples were selected by the laboratory to be analyzed as laboratory duplicates.

Review of the field blank analytical data resulted in three acetone and/or chloroform samples being qualified due to possible field blank contamination. Field blanks, source blanks, and equipment rinsates were analyzed for the applicable parameters listed in Table B.2-2, and six FDs were sent as blind samples to the laboratory to be analyzed for the investigation parameters listed in Table B.2-2. For these samples, the duplicate results precision (i.e., RPDs between the environmental sample results and their corresponding FD sample results) were evaluated. 


\section{B.12.2.1 Laboratory QC Samples}

Analysis of method QC blanks was performed on each sample delivery group (SDG) for inorganics. Analysis for surrogate spikes and preparation blanks (PBs) was performed on each SDG for organics only. Initial and continuing calibration and LCSs were performed for each SDG. The results of these analyses were used to qualify associated environmental sample results. Documentation of data qualifications resulting from the application of these guidelines is retained in project files as both hard copy and electronic media.

The laboratory included a PB, LCS, and a laboratory duplicate sample with each batch of field samples analyzed for radionuclides.

\section{B.12.3 Field Nonconformances}

There were no field nonconformances identified for the CAI.

\section{B.12.4 Laboratory Nonconformances}

Laboratory nonconformances are generally due to inconsistencies in the analytical instrumentation operation, sample preparations, extractions, missed holding times, and fluctuations in internal standard and calibration results. Twenty-one nonconformances were issued by the laboratories that may or may not have resulted in qualifying data. These laboratory nonconformances have been accounted for and resolved during the data qualification process. 


\section{B.13.0 Summary}

Organic, inorganics, and radionuclide contaminants detected in environmental samples during the CAI were evaluated against FALs to determine the nature and extent of COCs for CAU 544.

Assessment of the data generated from investigation activities indicates the FALs were not exceeded in any samples from the six CASs sampled. The following summarizes the results for each CAS.

\section{CAS 02-37-08, Cellar \& Mud Pit}

Based on the observations made and the analytical results of the environmental samples collected from the cellar at this CAS, no contamination has been released to the soil at this CAS. Therefore, no further corrective action is required at this CAS. The mud pit met the closure criteria specified in the RBCSR and therefore was not sampled.

\section{CAS 02-37-09, Cellar \& Mud Pit}

Based on the observations made and the analytical results of the environmental samples collected at this CAS, no contamination has been released to the soil at this CAS. Therefore, no further corrective action is required at this CAS.

\section{CAS 09-09-46, U-9itsx20 PS \#1A Mud Pit}

Based on the observations made and the analytical results of the environmental samples collected at this CAS, no contamination has been released to the soil at this CAS. Therefore, no further corrective action is required at this CAS.

\section{CAS 19-25-01, Oil Spill}

Based on the observations made and the analytical results of the environmental samples collected at this CAS, no contamination has been released to soil at this CAS. Therefore, no further corrective action is required at this CAS. 


\section{CAS 19-99-06, Waste Spill}

Based on the observations made and the analytical results of the environmental samples collected at this CAS, no contamination has been released to the soil at this CAS. Therefore, no further corrective action is required at this CAS.

\section{CAS 20-25-04, Oil Spills}

Because of safety concerns associated with the potential crater area, personnel could not collect samples from the oil spills in this CAS. Closure in place with a UR is the recommended CAA. The UR will prevent unauthorized intrusive activities at this CAS. An annual post-closure inspection will be conducted to certify that postings are in place, intact, and readable. Signage will be placed to designate the restricted area. The restriction of the crater instability will also eliminate any future contact from site workers.

\section{CAS 20-25-05, Oil Spills}

Based on the observations made and the analytical results of the environmental samples collected at this CAS, no contamination has been released to the soil at this CAS. Therefore, no further corrective action is required at this CAS.

\section{LANL and LLNL Pretest and Post-test Mud Pits}

Using the RBCSR and the approach approved for previous mud pit investigations (CAUs 530-535 and 177), 13 of the 16 mud pit CASs in CAU 544 are recommended for NFA. In addition, the mud pit component of CAS 02-37-08 met the closure criteria and is also recommended for NFA. 


\section{B.14.0 References}

DOE, see U.S. Department of Energy.

EPA, see U.S. Environmental Protection Agency.

N-I GIS, see Navarro-Intera Geographic Information Systems.

NNES, see Navarro Nevada Environmental Services, LLC.

NNSA/NV, see U.S. Department of Energy, National Nuclear Security Administration Nevada Operations Office.

NNSA/NSO, see U.S. Department of Energy, National Nuclear Security Administration Nevada Site Office.

Navarro-Intera Geographic Information Systems. 2011. ESRI ArcGIS Software.

Navarro Nevada Environmental Services, LLC. 2009. Statement of Work for Analytical Laboratories, Section C. Las Vegas, NV.

PNNL, see Pacific Northwest National Laboratory.

Pacific Northwest National Laboratory. 2007. Visual Sample Plan, Version 5.0 User's Guide, PNNL-16939. Richland, WA.

Pawloski, G.A., Lawrence Livermore National Laboratory. 2003. Memorandum to B. Bangeter (NNSA/NSO) regarding status of surface crater collapse for selected LLNL tests on Pahute Mesa and Yucca Flat, 27 January. Livermore, CA.

U.S. Department of Energy. 1997. The Procedures Manual of the Environmental Measurements Laboratory, HASL-300. 28th Ed., Vol. I. February. New York, NY.

U.S. Department of Energy, National Nuclear Security Administration Nevada Operations Office. 2002a. Industrial Sites Quality Assurance Project Plan, Rev. 3, DOE/NV--372--REV. 3.

Las Vegas, NV.

U.S. Department of Energy, National Nuclear Security Administration Nevada Operations Office. 2002b. Nevada Test Site Orthophoto Site Atlas, DOE/NV/11718--604. Aerial photos acquired Summer 1998. Prepared by Bechtel Nevada. Las Vegas, NV. 
U.S. Department of Energy, National Nuclear Security Administration Nevada Site Office. 2004. Mud Pit Risk-Based Closure Strategy Report, Nevada Test Site, Nevada, DOE/NV--991. Las Vegas, NV.

U.S. Department of Energy, National Nuclear Security Administration Nevada Site Office. 2006a. Closure Report for Corrective Action Units 530, 531, 532, 533, 534, 535: NTS Mud Pits, Nevada Test Site, Nevada, Rev. 0, DOE/NV--1131. Las Vegas, NV.

U.S. Department of Energy, National Nuclear Security Administration Nevada Site Office. 2006b. Industrial Sites Project Establishment of Final Action Levels, Rev. 0, DOE/NV--1107. Las Vegas, NV.

U.S. Department of Energy, National Nuclear Security Administration Nevada Site Office. 2010. Streamlined Approach for Environmental Restoration (SAFER) for Corrective Action Unit 544: Cellars, Mud Pits, and Oil Spills, Nevada Test Site, Nevada, Rev. 0, DOE/NV--1393. Las Vegas, NV.

U.S. Environmental Protection Agency. 1980. Prescribed Procedures for Measurement of Radioactivity in Drinking Water, EPA 600/4-80-032. Cincinnati, OH: Environmental Monitoring and Support Laboratory Office of Research and Development.

U.S. Environmental Protection Agency. 2006. Guidance on Systematic Planning Using the Data Quality Objectives Process, EPA QA/G-4, EPA/240/B-06/001. Washington, DC: Office of Environmental Information.

U.S. Environmental Protection Agency. 2009. SW-846 On-Line, Test Methods for Evaluating Solid Waste, Physical/Chemical Methods. As accessed at http://www.epa.gov/epawaste/hazard/testmethods/sw846/index.htm on 1 March 2011. 


\section{Appendix C}

\section{Use Restrictions}


The following section documents the UR completed for CAU 544 at CAS 20-25-04. Corrective Action Site 20-25-04 could not be sampled because of its location within a potential crater area. Due to safety concerns, personnel were not permitted to enter the crater area. Because sampling was not conducted, it is assumed that COCs are present in the soil at this CAS.

\section{C.1.1 CAS 20-25-04 Use Restrictions}

Attachment C-1 of this appendix provides details of the UR and a figure of the UR boundary. 


\section{Attachment C-1 \\ Use Restriction}

(3 Pages) 


\section{CAU Use Restriction Information}

CAU Number/Description: _ CAU 544 Cellars, Mud Pits and Oil Spills

Applicable CAS Number/Description: $\underline{\text { CAS 20-25-04, Oil Spills }}$

Contact (Federal Sub-Project Director/Sub-Project): Kevin Cabble Industrial Sites - DP

Physical Description:

Surveyed Area (UTM, Zone 11, NAD 27, meters):

Point 1 [SE corner]) $\mathrm{N}=4126131.6 \mathrm{E}=552172.3$

Point 2) $\quad \mathrm{N}=4126109.1 \mathrm{E}=552132.6$

Point 3) $\quad \mathrm{N}=4126106.6 \mathrm{E}=552081.2$

Point 4 [SW corner]) $\mathrm{N}=4126125.1 \mathrm{E}=552030.5$

Point 5) $\quad \mathrm{N}=4126170.4 \mathrm{E}=551995.7$

Point 6) $\quad \mathrm{N}=4126228.0 \mathrm{E}=551985.6$

Point 7) $\quad \mathrm{N}=4126284.8 \mathrm{E}=552007.4$

Point 8 [NW corner]) $\mathrm{N}=4126310.5 \mathrm{E}=552035.6$

Point 9) $\quad \mathrm{N}=4126325.2 \mathrm{E}=552086.9$

Point 10) $\quad \mathrm{N}=4126316.6 \mathrm{E}=552140.2$

Point 11 [NE corner]) $\mathrm{N}=4126275.9 \mathrm{E}=552190.1$

Point 12) $\quad \mathrm{N}=4126198.4 \mathrm{E}=552207.4$

Depth:

$\underline{0 \text { foot to } 1 \text { foot below ground surface }}$

Survey Method (GPS, etc): GPS points collected around crater fencing

\section{Basis for UR:}

Summary Statement: This FFACO UR was implemented as part of a closure in place corrective action to restrict site activities that may expose workers to site contamination. This standard UR is for surface and shallow subsurface disturbances between 0 foot and 1 foot below ground surface. No sampling was conducted due to the location of the CAS within a potential crater area, therefore, contamination is assumed to be present within the surface and shallow subsurface soil. Contamination may consist of the hazardous constituents of total petroleum hydrocarbons (semivolatile organic compounds).

Contaminants Table:

\begin{tabular}{|c|c|c|c|}
\hline \multicolumn{4}{|c|}{ Maximum Concentration of Contaminants for CAU 544 } \\
CAS 20-25-04, Oil Spills \\
\hline \hline Constituent & $\begin{array}{c}\text { Maximum } \\
\text { Concentration }\end{array}$ & Action Level & Units \\
\hline Unknown & Unknown & Unknown & Unknown \\
\hline
\end{tabular}

Note: Effective upon acceptance of closure documents by NDEP. 
Site Controls: Post UR warning signs every 200 feet on the potential crater area fence.

\section{UR Maintenance Requirements:}

Description:

This UR must be entered into the NNSA/NSO Facility Information Management System (FIMS), the FFACO database, and the NNSA/NSO CAU/CAS files.

Inspection/Maintenance Frequency: Annual post-closure visual inspections will be conducted to ensure postings are in place, intact, and legible, and no evidence of subsurface intrusion between 0 foot and 1 foot.

The future use of any land related to this Corrective Action Unit (CAU), as described by the above surveyed location, is restricted from any DOE or Air Force activity that may alter or modify the containment control as approved by the state and identified in the CAU CR or other CAU documentation unless appropriate concurrence is obtained in advance.

Comments: Personnel are restricted from performing work in this location that would require entry into the potential crater area. Permissible activities include short duration activities such as site visits and maintenance of signs, as long as entry into the potential crater area is restricted.

Submitted By: /s/Kevin Cabble Date: $5-9-11$

Note: Effective upon acceptance of closure documents by NDEP. 


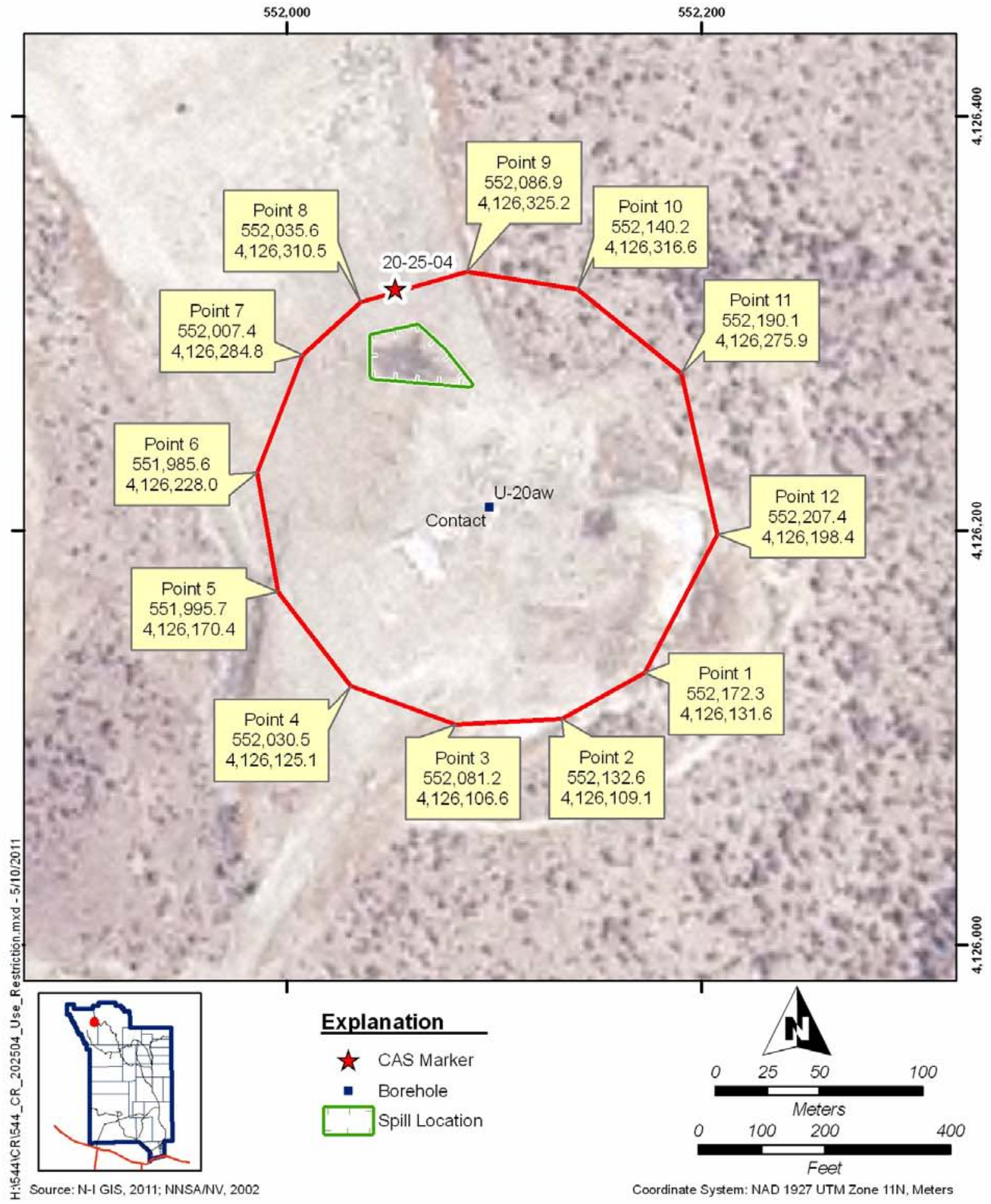

CAU 544, Cellars, Mud Pits, and Oil Spills CAS 20-25-04, Oil Spills, UR Boundary 


\section{Appendix D}

\section{Risk Evaluation}




\section{D.1.0 Risk Assessment}

The risk-based corrective action (RBCA) process used to establish FALs is described in the Industrial Sites Project Establishment of Final Action Levels (NNSA/NSO, 2006b). This process conforms with Nevada Administrative Code (NAC) Section 445A.227, which lists the requirements for sites with soil contamination (NAC, 2008a). For the evaluation of corrective actions, NAC Section 445A.22705 (NAC, 2008b) requires the use of ASTM Method E1739 (ASTM, 1995) to "conduct an evaluation of the site, based on the risk it poses to public health and the environment, to determine the necessary remediation standards (i.e., FALs) or to establish that corrective action is not necessary.”

The presence of a COC would require a corrective action. A corrective action may also be necessary if there is a potential for wastes that are present at a site to release COCs into site environmental media.

The evaluation of the need for corrective action will include the potential for wastes that are present at a site to cause the future contamination of site environmental media if the wastes were to be released.

This section contains documentation of the RBCA process used to establish FALs described in the Industrial Sites Project Establishment of Final Action Levels (NNSA/NSO, 2006b). This process defines three tiers (or levels) to establish FALs used to evaluate DQO decisions:

- $\quad$ Tier 1 -Sample results from source areas (highest concentrations) compared to risk-based screening levels (RBSLs) (i.e., PALs) based on generic (non-site-specific) conditions.

- $\quad$ Tier 2-Sample results from exposure points compared to site-specific target levels (SSTL) calculated using site-specific inputs and Tier 1 formulas.

- Tier 3-Sample results from exposure points compared to SSTLs and points of compliance calculated using chemical fate/transport and probabilistic modeling.

The RBCA decision process stipulated in the Industrial Sites Project Establishment of Final Action Levels (NNSA/NSO, 2006b) is summarized in Figure D.1-1. 


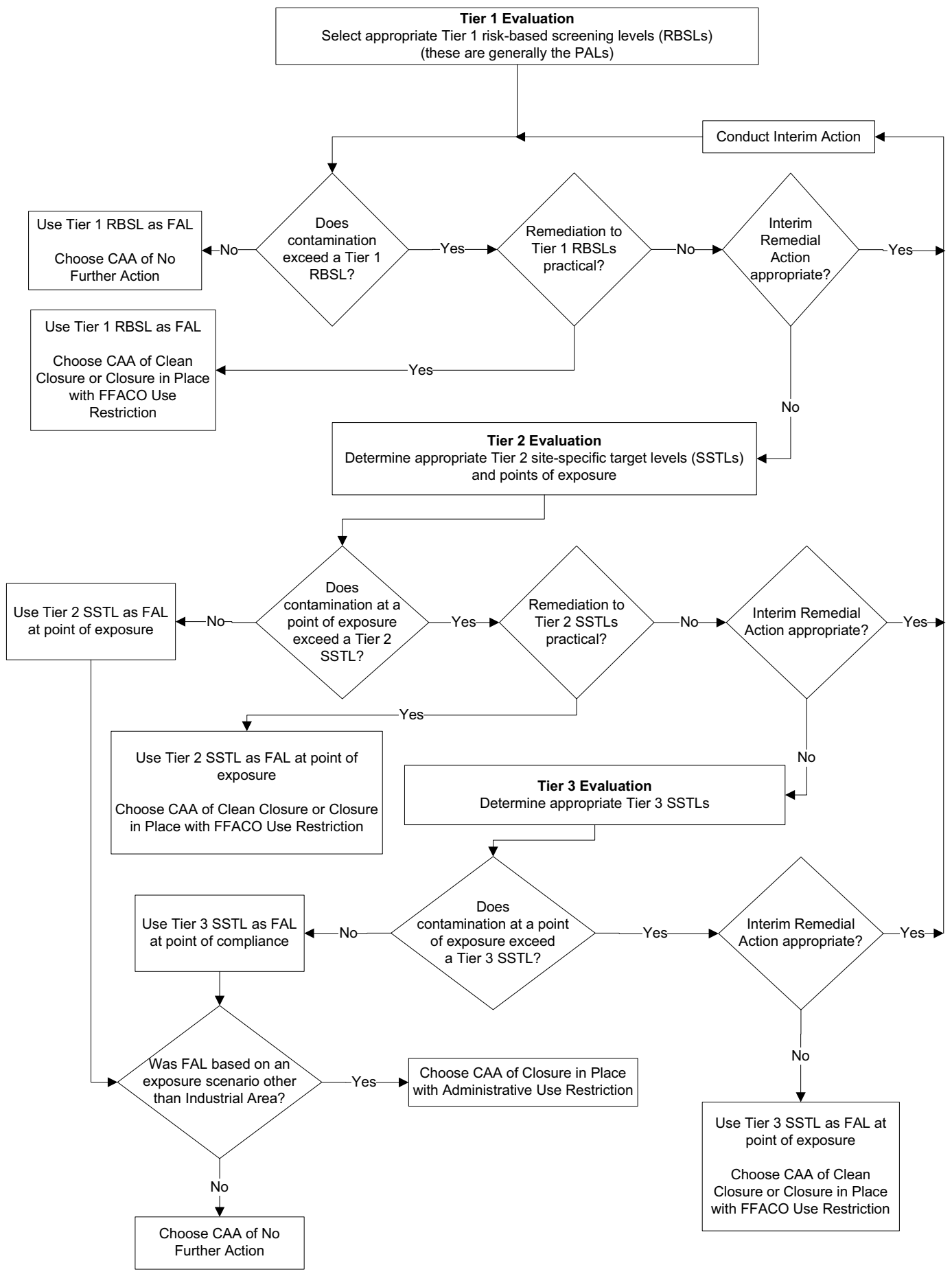

(ASTM, 1995)

Figure D.1-1

Risk-Based Corrective Action Decision Process 


\section{D.1.1 A. Scenario}

Corrective Action Unit 544: Cellars, Mud Pits, and Oil Spills, comprises the following 20 inactive sites within Areas 2, 7, 9, 10, 12, 19, and 20 of the NNSS:

- 02-37-08, Cellar \& Mud Pit

- 02-37-09, Cellar \& Mud Pit

- 07-09-01, Mud Pit

- 09-09-46, U-9itsx20 PS \#1A Mud Pit

- 10-09-01, Mud Pit

- 12-09-03, Mud Pit

- 19-09-01, Mud Pits (2)

- 19-09-03, Mud Pit

- 19-09-04, Mud Pit

- 19-25-01, Oil Spill

- 19-99-06, Waste Spill

- 20-09-01, Mud Pits (2)

- 20-09-02, Mud Pit

- 20-09-03, Mud Pit

- 20-09-04, Mud Pits (2)

- 20-09-06, Mud Pit

- 20-09-07, Mud Pit

- 20-09-10, Mud Pit

- 20-25-04, Oil Spills

- 20-25-05, Oil Spills

Sixteen CASs consist of mud pit CASs and cellar and mud pit CASs. The mud pits and cellars were constructed and used during drilling activities conducted at the NNSS in support of underground nuclear weapons testing. Eleven of the mud pit CASs were constructed as part of pretest drilling activities (four from LANL and seven from LLNL), and five mud pit and cellar and mud pit CASs were constructed as part of the LLNL post-test activities. Of the 16 mud pit and cellar and mud pit CASs, 14 mud pit CASs were recommended for NFA without field investigations. These 14 mud pits met the criteria established in the RBCSR (NNSA/NSO, 2004) and the CAUs 530-535 CR (NNSA/NSO, 2006a). Two mud pits did not meet the RBCSR criteria and therefore were investigated. The criteria established included the following:

- CAS is either a single mud pit or system of mud pits.

- CAS is not located in a radiological or radioactive material posted area.

- There are no biasing factors evident at the mud pits based on visual inspections. 
The remaining four CASs include oil/waste spills. No documentation that identified the date, type, and volume of the spills, or depth of contaminated soil was located for the four oil/waste spills.

However, it is believed that the spills occurred during either the pretest or post-test drilling activities at the related boreholes. The activities at these boreholes occurred between 1979 and 1991 . Three of the oil/waste spills were investigated, but CAS 20-25-04, Oil Spills, was not investigated because it is located within a potential crater area. The crater has been deemed stable in its current configuration by LLNL, but LLNL is less confident in this conclusion than for other craters (Pawloski, 2003). Therefore, for safety concerns, personnel did not enter the crater area.

\section{D.1.2 B. Site Assessment}

The CAI at CASs 02-37-08, 02-37-09, and 09-09-46 involved sampling the mud pits and cellars, whereas the investigation at CASs 19-25-01, 19-99-06, and 20-25-05 involved sampling the oil/waste spills. These CASs were sampled to assess their potential to cause present and future harm to human health and the environment. The cellar and oil/waste spill CASs were visually inspected for biasing factors prior to sampling. The mud pits were sampled using randomly selected locations.

The analytical results support NFA as the closure option for all CAU 544 CASs except for CAS 20-25-04, which was not sampled. All CASs had no COPC concentrations in soil samples that were detected above the respective PALs. No unexpected conditions or other indicators of contamination were encountered during the CAI. The maximum concentrations of contaminants identified at each CAS and their corresponding PALs are presented in Table D.1-1.

Table D.1-1

Maximum Reported Value for Tier 1 Comparison

(Page 1 of 2)

\begin{tabular}{|c|c|c|c|c|c|c|c|}
\hline \multirow[b]{2}{*}{ Parameter } & \multirow[b]{2}{*}{ Unit } & \multicolumn{6}{|c|}{ Maximum Reported Value } \\
\hline & & 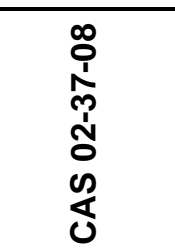 & 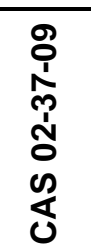 & 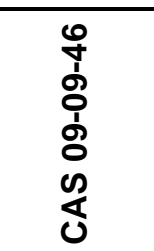 & 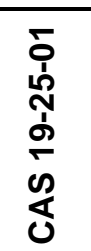 & 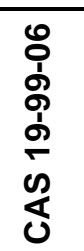 & 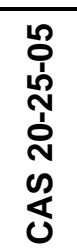 \\
\hline Ac-228 & $\mathrm{pCi} / \mathrm{g}$ & 1.77 & 2.46 & 2.77 & 4.76 & 3.41 & 3.16 \\
\hline $\mathrm{Am}-241$ & $\mathrm{pCi} / \mathrm{g}$ & -- & -- & $0.755(\mathrm{~J})$ & -- & -- & -- \\
\hline Acetone & $\mathrm{mg} / \mathrm{kg}$ & $0.00221(\mathrm{~J})$ & -- & -- & -- & -- & -- \\
\hline
\end{tabular}


Table D.1-1

Maximum Reported Value for Tier 1 Comparison

(Page 2 of 2)

\begin{tabular}{|c|c|c|c|c|c|c|c|}
\hline \multirow[b]{2}{*}{ Parameter } & \multirow[b]{2}{*}{ Unit } & \multicolumn{6}{|c|}{ Maximum Reported Value } \\
\hline & & 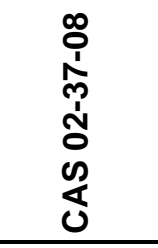 & 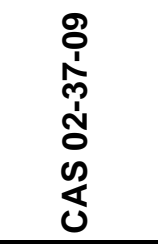 & 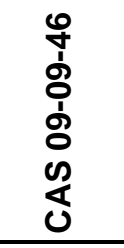 & 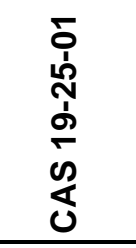 & 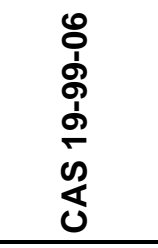 & 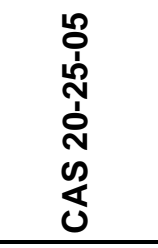 \\
\hline Aroclor 1242 & $\mathrm{mg} / \mathrm{kg}$ & -- & -- & -- & -- & $0.002(\mathrm{~J})$ & -- \\
\hline Aroclor 1248 & $\mathrm{mg} / \mathrm{kg}$ & -- & -- & -- & -- & -- & $0.0021(\mathrm{~J})$ \\
\hline Aroclor 1254 & $\mathrm{mg} / \mathrm{kg}$ & -- & $0.0036(\mathrm{~J})$ & -- & -- & $0.0025(\mathrm{~J})$ & -- \\
\hline Arsenic & $\mathrm{mg} / \mathrm{kg}$ & 3.48 & 2.11 & -- & 2.83 & 2.07 & 8.14 \\
\hline Barium & $\mathrm{mg} / \mathrm{kg}$ & $230(\mathrm{~J})$ & 127 & -- & $128(\mathrm{~J}-)$ & $135(\mathrm{~J}-)$ & $78.8(\mathrm{~J})$ \\
\hline Bis(2-ethylhexyl)phthalate & $\mathrm{mg} / \mathrm{kg}$ & -- & -- & -- & $3.85(\mathrm{~J})$ & -- & -- \\
\hline Benzo(b)fluoranthene & $\mathrm{mg} / \mathrm{kg}$ & $0.0193(\mathrm{~J})$ & -- & -- & -- & -- & -- \\
\hline Cadmium & $\mathrm{mg} / \mathrm{kg}$ & $0.117(\mathrm{~J})$ & $0.112(\mathrm{~J})$ & -- & 0.671 & -- & $0.264(\mathrm{~J})$ \\
\hline Chromium & $\mathrm{mg} / \mathrm{kg}$ & 6.63 & 7.01 & -- & 8.1 & 5.21 & 3.6 \\
\hline Hexavalent Chromium & $\mathrm{mg} / \mathrm{kg}$ & -- & -- & -- & $1.89(\mathrm{~J}-)$ & $0.467(\mathrm{~J}-)$ & -- \\
\hline Cs-137 & $\mathrm{pCi} / \mathrm{g}$ & 0.278 & 0.328 & 0.115 & -- & -- & -- \\
\hline Lead & $\mathrm{mg} / \mathrm{kg}$ & $12.7(\mathrm{~J})$ & 10.2 & -- & $44.7(\mathrm{~J})$ & $11.9(\mathrm{~J})$ & $19.1(\mathrm{~J})$ \\
\hline Mercury & $\mathrm{mg} / \mathrm{kg}$ & 0.028 & $0.0119(\mathrm{~J})$ & -- & 0.0727 & $0.0102(\mathrm{~J})$ & 0.0487 \\
\hline p-isopropyltoluene & $\mathrm{mg} / \mathrm{kg}$ & -- & -- & -- & 0.00129 & -- & -- \\
\hline Pu-239/240 & $\mathrm{pCi} / \mathrm{g}$ & -- & -- & 0.335 & -- & -- & -- \\
\hline Silver & $\mathrm{mg} / \mathrm{kg}$ & -- & -- & -- & -- & $0.125(\mathrm{~J})$ & $0.372(\mathrm{~J})$ \\
\hline Th-234 & $\mathrm{pCi} / \mathrm{g}$ & -- & $4.49(\mathrm{~J})$ & $2.71(\mathrm{~J})$ & -- & -- & -- \\
\hline U-234 & $\mathrm{pCi} / \mathrm{g}$ & 0.9 & 1.62 & 1.56 & -- & -- & -- \\
\hline U-235 & $\mathrm{pCi} / \mathrm{g}$ & 0.0584 & $0.151(\mathrm{~J})$ & 0.127 & -- & -- & -- \\
\hline U-238 & $\mathrm{pCi} / \mathrm{g}$ & 0.994 & 1.35 & 1.65 & -- & -- & -- \\
\hline
\end{tabular}

$\mathrm{J}=$ Estimated value

$\mathrm{J}-=$ Result is an estimated quantity, but may be biased low.

-- = Not detected above PALs 


\section{D.1.3 C. Site Classification and Initial Response Action}

The four major site classifications listed in Table 3 of the ASTM Standard are (1) immediate threat to human health, safety, and the environment; (2) short-term (0 to 2 years) threat to human health, safety, and the environment; (3) long-term (greater than 2 years) threat to human health, safety, or the environment; and (4) no demonstrated long-term threats. Based on the CAI, none of the CASs present an immediate threat to human health, safety, and the environment; therefore, no interim response actions are necessary at these sites. All 20 CASs are determined to be Classification 4 sites as defined by ASTM Method E1739 (ASTM, 1995) and pose no demonstrated near- or long-term threats.

\section{D.1.4 D. Development of Tier 1 Lookup Table of RBSLs}

Tier 1 RBSLs have been defined as the PALs established during the DQO process. The PALs are a tabulation of chemical-specific (but not site-specific) screening levels based on the type of media (soil) and potential exposure scenarios (industrial). These are very conservative estimates of risk, are preliminary in nature, and are used as action levels for site screening purposes. Although the PALs are not intended to be used as FALs, a FAL may be defined as the Tier 1 action level (i.e., PAL) value if individual contaminant analytical results are below the corresponding Tier 1 action level value. The FAL may also be established as the Tier 1 action level value if individual contaminant analytical results exceed the corresponding Tier 1 action level value and implementing a corrective action based on the FAL is practical. The PALs are defined as the following:

- $\quad$ The EPA Region 9 Risk-Based Regional Screening Levels (RSLs) for Industrial Soils (EPA, 2010).

- Background concentrations for RCRA metals will be evaluated when natural background exceeds the PAL, as is often the case with arsenic. Background is considered the mean plus two times the standard deviation of the mean based on data published in Mineral and Energy Resource Assessment of the Nellis Air Force Range (NBMG, 1998; Moore, 1999).

- For COPCs without established RSLs, a protocol similar to EPA Region 9 will be used to establish an action level; otherwise, an established RSL from another EPA region may be chosen.

- The PALs for radioactive contaminants are based on the screening limits recommended in National Council on Radiation Protection and Measurements (NCRP) Report No. 129 for 
construction, commercial, and industrial land use scenarios (NCRP, 1999) scaled to the 25-millirem-per-year-dose constraint (Appenzeller-Wing, 2004) and the generic guidelines for residual concentrations of radionuclides in DOE Order 5400.5 (DOE, 1993).

The PALs were developed based on an industrial scenario. Because the CAU 544 CASs in Areas 2, 7, 9, 10, 12, 19, and 20 are not assigned work stations and are considered to be in remote or occasional use areas, the use of PALs based on an industrial scenario is conservative. The Tier 1 lookup table is defined as the PAL concentrations or activities defined in the SAFER Plan (NNSA/NSO, 2010).

\section{D.1.5 E. Exposure Pathway Evaluation}

The DQOs stated that site workers would only be exposed to COCs through oral ingestion, inhalation, or dermal contact (absorption) due to exposure to potentially contaminated media (i.e., soil) at the CASs. The lack of COCs identified, elapsed time since the suspected release, and depth to groundwater supports the selection and evaluation of only surface and shallow subsurface contacts as the complete exposure pathways. Groundwater is not considered a significant exposure pathway.

\section{D.1.6 F. Comparison of Site Conditions with Tier 1 RBSLS}

All analytical results from CAU 544 samples were less than corresponding Tier 1 action levels (i.e., PALs).

\section{D.1.7 G. Evaluation of Tier 1 Results}

For all contaminants at all CASs, the FALs were established as the Tier 1 RBSLs. It was determined that no further corrective action is required for these contaminants at these CASs.

\section{D.1.8 H. Tier 1 Remedial Action Evaluation}

Because there were no contaminants identified at any of the CASs, no remedial action evaluation was required at these CASs. 


\section{D.1.9 I. Tier 2 and 3 Evaluation}

As all contaminant FALs were established as Tier 1 action levels at all CASs, a Tier 2 or Tier 3 evaluation was not considered necessary. 


\section{D.2.0 Recommendations}

As all of the site contaminant concentrations in soils from the analysis of CAU 544 samples were less than the corresponding FALs at all locations, it was determined that contamination at these locations does not pose an unacceptable risk to human health or the environment, and therefore, does not warrant corrective actions.

Corrective Action Site 20-25-04 is located within a potential crater area. Because of safety concerns associated with the potential crater area, personnel could not collect samples from the oil spill in this CAS. Therefore, it is assumed that COCs are present in the soil at the site. The CAA to be implemented is closure in place with a UR. The UR will prevent unauthorized intrusive activities at this oil spill CAS. 


\section{D.3.0 References}

ASTM, see ASTM International.

ASTM International. 1995 (reapproved 2010). Standard Guide for Risk-Based Corrective Action Applied at Petroleum Release Sites, ASTM E1739 - 95(2010)e1. West Conshohocken, PA.

Appenzeller-Wing, J., U.S. Department of Energy, National Nuclear Security Administration Nevada Site Office. 2004. Letter to T.A. Maize (NDEP) titled "Submittal of Proposed Radiological Preliminary Action Levels (PALs) for the Industrial Sites Project,” 15 January. Las Vegas, NV.

DOE, see U.S. Department of Energy.

EPA, see U.S. Environmental Protection Agency.

Moore, J., Science Applications International Corporation. 1999. Memorandum to M. Todd (SAIC) titled "Background Concentrations for NTS and TTR Soil Samples," 3 February. Las Vegas, NV.

NAC, see Nevada Administrative Code.

NBMG, see Nevada Bureau of Mines and Geology.

NCRP, see National Council on Radiation Protection and Measurements.

NNSA/NSO, see U.S. Department of Energy, National Nuclear Security Administration Nevada Site Office.

National Council on Radiation Protection and Measurements. 1999. Recommended Screening Limits for Contaminated Surface Soil and Review of Factors Relevant to Site-Specific Studies, NCRP Report No. 129. Bethesda, MD.

Nevada Administrative Code. 2008a. NAC 445A.227, “Contamination of Soil: Order by Director for Corrective Action; Factors To Be Considered in Determining Whether Corrective Action Required.” Carson City, NV. As accessed at http://www.leg.state.nv.us/nac on 3 March 2011.

Nevada Administrative Code. 2008b. NAC 445A.22705, "Contamination of Soil: Evaluation of Site by Owner or Operator; Review of Evaluation by Division.” Carson City, NV. As accessed at http://www.leg.state.nv.us/nac on 3 March 2011.

Nevada Bureau of Mines and Geology. 1998. Mineral and Energy Resource Assessment of the Nellis Air Force Range, Open-File Report 98-1. Reno, NV. 
Pawloski, G.A., Lawrence Livermore National Laboratory. 2003. Memorandum to B. Bangeter (NNSA/NSO) regarding status of surface crater collapse for selected LLNL tests on Pahute Mesa and Yucca Flat, 27 January. Livermore, CA.

U.S. Department of Energy. 1993. Radiation Protection of the Public and the Environment, DOE Order 5400.5, Change 2. Washington, DC.

U.S. Department of Energy, National Nuclear Security Administration Nevada Site Office. 2004. Mud Pit Risk-Based Closure Strategy Report, Nevada Test Site, Nevada, DOE/NV--991. Las Vegas, NV.

U.S. Department of Energy, National Nuclear Security Administration Nevada Site Office. 2006a. Closure Report for Corrective Action Units 530, 531, 532, 535, 534, 535: NTS Mud Pits, Nevada Test Site, Nevada, Rev. 0, DOE/NV--1131. Las Vegas, NV.

U.S. Department of Energy, National Nuclear Security Administration Nevada Site Office. 2006b. Industrial Sites Project Establishment of Final Action Levels, Rev. 0, DOE/NV--1107. Las Vegas, NV.

U.S. Department of Energy, National Nuclear Security Administration Nevada Site Office. 2010. Streamlined Approach for Environmental Restoration (SAFER) for Corrective Action Unit 544: Cellars, Mud Pits, and Oil Spills, Nevada Test Site, Nevada, Rev. 0, DOE/NV--1393. Las Vegas, NV.

U.S. Environmental Protection Agency. 2010. Regions 3, 6, and 9: Regional Screening Levels for Chemical Contaminants at Superfund Sites. As accessed at http://www.epa.gov/reg3hwmd/risk/human/rb-concentration_table/Generic_Tables/pdf/master_s l_table_run_NOVEMBER2010.pdf on 14 February 142011. 


\section{Appendix E}

\section{Nevada Division of Environmental Protection Comments}

(2 Pages) 
April 12, 2011

Robert F. Boehlecke

Federal Project Director

Environmental Restoration Project

National Nuclear Security Administration

Nevada Site Office

P. O. Box 98518

Las Vegas, NV 89193-8518

RE: Review of Draft Closure Report for Corrective Action Unit (CAU) 544: Cellars, Mud Pits, and Oil Spills, Nevada National Security Site, Nevada Federal Facility Agreement and Consent Order

Dear Mr. Boehlecke:

The Nevada Division of Environmental Protection, Bureau of Federal Facilities (NDEP) staff has received and reviewed the draft Closure Report for Corrective Action Unit (CAU) 544: Cellars, Mud Pits, and Oil Spills at the Nevada National Security Site, Nevada. NDEP's review of this document did not indicate any deficiencies.

If you have any questions regarding this matter contact Ted Zaferatos at (702) 486-2850, ext. 234, Jeff MacDougall at (702) 486.2850, ext. 233, or me at (702) 486-2850, ext. 231.

Sincerely

\section{/s/ T.H. Murphy}

T. H.Murphy
Chref
Bureau of Federa/Facilities 
Robert F. Boehlecke, Federal Project Director

Page 2

April 12, 2011

$\mathrm{JJM} / \mathrm{TZ}$

cc:

N.Y. Carson, N-1, Las Vegas, NV

M.J. Krauss, N-1, Las Vegas, NV

T. A. Thiele, NSTec, Las Vegas, NV

J. T. Fraher, DTRA/CXTS, Kirtland AFB, NM

T.D. Taylor, $\mathrm{N}-1$, Las Vegas, NV

E. F. Di Sanza, WMP, NNSA/NSO, Las Vegas, NV

K. J. Cabble, ERP, NNSA/NSO, Las Vegas, NV

FFACO Group, PSG, NNSA/NSO, Las Vegas, NV 


\section{Library Distribution List}

\section{$\underline{\text { Copies }}$}

U.S. Department of Energy

National Nuclear Security Administration

Nevada Site Office

Technical Library

P.O. Box 98518, M/S 505

Las Vegas, NV 89193-8518

U.S. Department of Energy

Office of Scientific and Technical Information

P.O. Box 62

Oak Ridge, TN 37831-0062

Southern Nevada Public Reading Facility

c/o Nuclear Testing Archive

P.O. Box 98521, M/S 400

Las Vegas, NV 89193-8521

Manager, Northern Nevada FFACO

Public Reading Facility

c/o Nevada State Library \& Archives

100 N Stewart Street

Carson City, NV 89701-4285
1 (Uncontrolled, electronic copy)

1 (Uncontrolled, electronic copy)

2 (Uncontrolled, electronic copies)

1 (Uncontrolled, electronic copy) 